\title{
Autonomous Vehicle Navigation and Communication by Radio Frequency Identity Tags
}

by

\section{Osama Javaid}

A thesis submitted to the Faculty of Graduate and Postdoctoral Affairs in partial fulfillment of the requirements for the degree of

\author{
Master of Applied Science \\ in
}

Electrical and Computer (Systems) Specialization in Data Science

Carleton University

Ottawa, Ontario

(C)Osama Javaid, 2021 


\section{Contents}

1 Introduction $\quad 1$

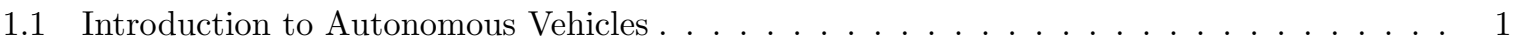

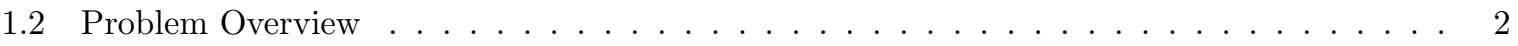

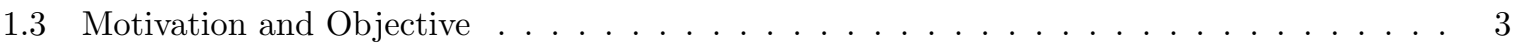



1.5 Accepted Research Paper $\ldots \ldots \ldots \ldots \ldots \ldots$

$\begin{array}{lll}2 & \text { Related Work } & 7\end{array}$

3 RFID Overview $\quad 12$

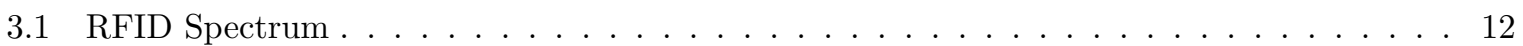

3.2 Passive Tags and Operation . . . . . . . . . . . . . . . . . . . 13

3.3 Battery-Assisted Passive (BAP) and Active Tags and Operation . . . . . . . . . . . 14

3.4 List of Passive and BAP Tags Used in Experiments . . . . . . . . . . . . . . . . 15

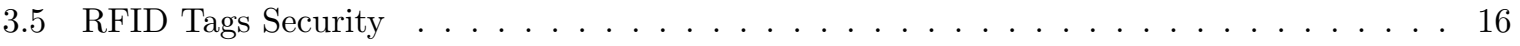

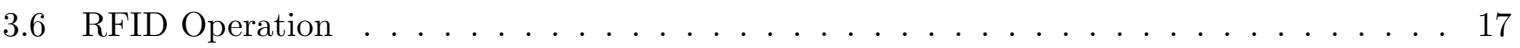

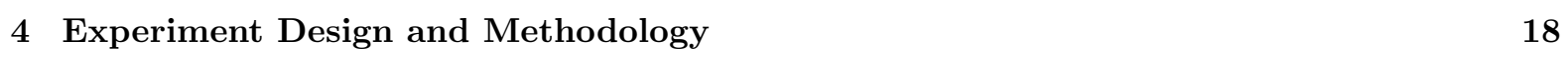

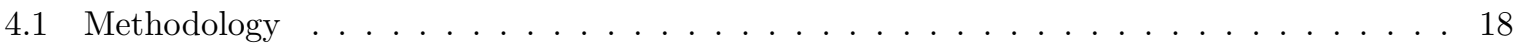

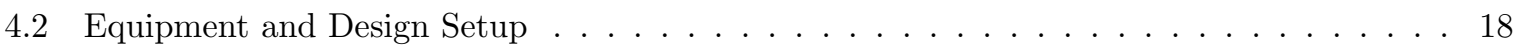


4.3 Propagation Mediums . . . . . . . . . . . . . . . . . . . . . . 19

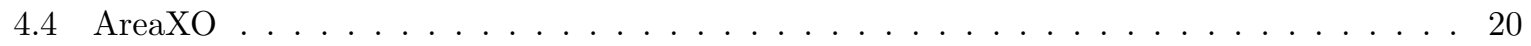

4.5 Passive Reader, Antenna and Antenna Cable . . . . . . . . . . . . . . . . 20

$4.5 .1 \quad$ Reader . . . . . . . . . . . . . . . . . . . . . . 20

4.5 .2 Antenna and Cable . . . . . . . . . . . . . . . . 21

4.6 Power Mapper . . . . . . . . . . . . . . . . . . . . . . . 24

4.7 Passive Reader Software . . . . . . . . . . . . . . . . . . . . . . . . 24

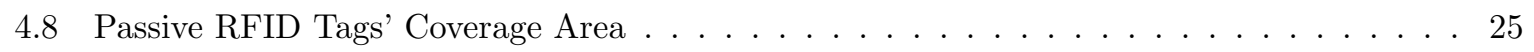

5 Results With Passive and BAP Tags (Single Antenna) 28

5.1 Free-Air vs. Snow Results . . . . . . . . . . . . . . . . . . . 28

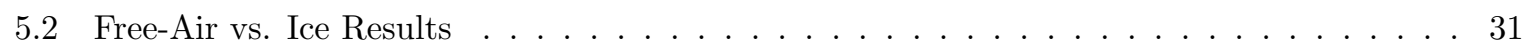

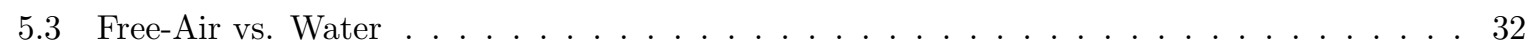

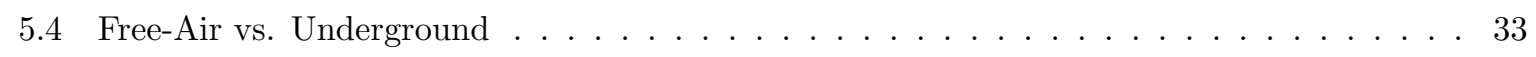

5.4.1 Results (Tables) of Single Passive Antenna . . . . . . . . . . . . . . . . . 34

6 Results With Passive and BAP Tags (Dual Antenna) 44

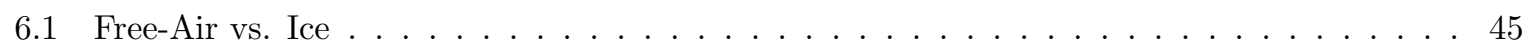

6.2 Free-Air vs. Water and Salted Water Results . . . . . . . . . . . . . . . 45

6.3 Free-Air vs. Underground Results . . . . . . . . . . . . . . . . . . . 47

6.3.1 Results (Tables) of Dual Passive Antenna . . . . . . . . . . . . . . . . . 48 
7 Summary of Passive RFID Tag Results

8 Results With Active Tags

8.1 Results in Free-Air vs. Ice . . . . . . . . . . . . . . . . . . . . 60

8.2 Results in Free-Air vs. Water and Salted Water . . . . . . . . . . . . . . . 61

8.3 Results in Free-Air vs. Embedded Underground . . . . . . . . . . . . . . . . . . 62

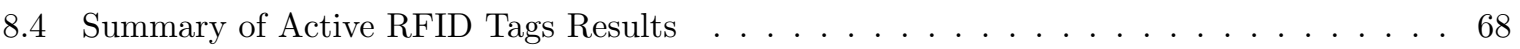

9 Conclusion and Future Work $\quad 70$

$\begin{array}{ll}\text { References } & 72\end{array}$ 


\section{List of Figures}

1 Shows typical sensors on an AV include cameras, LIDAR, RADAR, Ultrasonics, GPS and so on. Despite these sensors there are still limitations as discussed. [3] . . . . . . . . . 2

2 The image shows a few example of camera occlusions caused by weather conditions where the traffic sign and the road is covered with snow and hence occluded. . . . . . . . 3

3 The image shows a few example of recent AV crashes. Uber crash 2018 (left) and Tesla crash 2018 (right). Source: National Transportation Safety Board (NTSB). . . . . . . . . 4

4 Electromagnetic Spectrum is divided based on the various frequencies of its spectrum. The one of interest to this research is UHF $[21] \ldots \ldots \ldots \ldots$. . . . . . . . . . . 12

$5 \quad$ Inlays and Hard tags are typically the two types of Passive Tags available in the market. This research was conducted using both Inlays and Hard tags [10] . . . . . . . . . . . . 13

6 Figure shows how the ICs of Active, Passive and BAP tags are powered. Passive tags are powered by the signal of the reader while BAP and Active tags have batteries to power

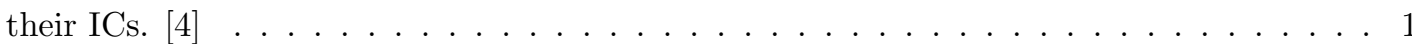

7 Image and details of the tags used in the experiments. It includes Passive Tags, BAP

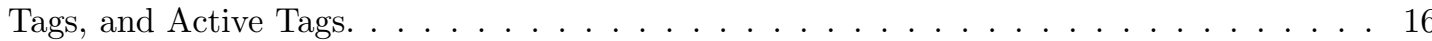

8 Shows an example of a typical RFID Reader and Tag Operation [21] . . . . . . . . . . . 17

9 Typical Passive RFID setup showing an antenna mounted onto the vehicle, a coax cable connecting the reader the antenna, and computer connected to the reader through a USB

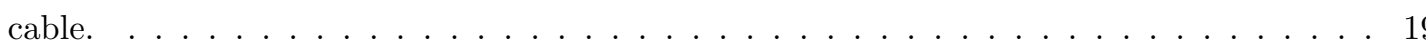

10 Nine kms long test track, AreaXO, where the AV experiments were conducted in this

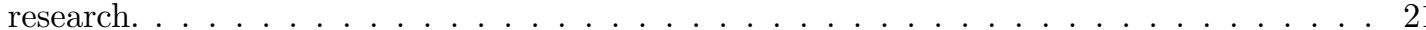


11 Image of a ThingMagic M6e reader used for experiments [24]. . . . . . . . . . . . . . . 22

12 Antenna with Linear polarization beams power on one axis while antenna with circular polarization beams power on both horizontal and vertical axes [10] . . . . . . . . . . . . 22

13 Antenna performance at $902 \mathrm{MHz}$ at different angles in Azimuth and Elevation. There was a significant power drop after 45 degree angle in Azimuth and Elevation. [25]. . . . . 23

14 Vulcan RFID Passive Power Mapper used in the experiments [26]. . . . . . . . . . . . . 24

15 Shows URA software interface and the various parameter-tuning options it presents. . . . 25

16 The figure shows the coverage area with a dual-antenna configuration with a $6 \mathrm{~dB}$ atten-



17 The figure shows the coverage area with a dual-antenna configuration with a $15 \mathrm{~dB}$ at-



18 Tag Read Count and RSSI in Free-Air for single-antenna Passive tags. . . . . . . . . . . . 28

19 Readings taken in Free-Air and 6.5 inches of Snow with a downward-oriented single-antenna. 29

20 Front Facing-Antenna (left) and Backward-facing Antenna (right). . . . . . . . . . . . . . 30

21 Shows antenna setup (left) and tags in about 2.5 inches of ice (middle and right). . . . . . 31

22 Shows $2.5 \mathrm{cms}$ of Water poured into a plastic container and placed over tags. . . . . . . . 32

23 Shows tags placed over unpaved path (left) and 4 inches of underground earth (middle) covered with 0.5 inch of soil (right). . . . . . . . . . . . . . . . . . . 33

24 Dual-Antenna Configuration. . . . . . . . . . . . . . . . . . . . . . . . . 44

25 Setup shows 2 inches of Ice placed on tags in a dual-antenna configuration. . . . . . . . . 45

26 Setup shows 1 inch of Water placed on tags in a dual-antenna configuration. . . . . . . . . 46 
274 grams of Salt was added in $2.5 \mathrm{cms}$ of Water to measure its effect in dual-antenna

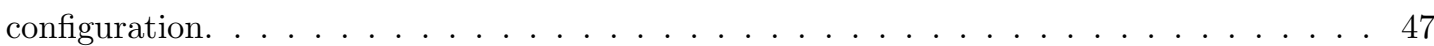

28 Active RFID setup shows Active tags placed on the ground and cellphone as reader in the vehicle. . . . . . . . . . . . . . . . . . . . . . . . . 59

29 Active RFID Tags' Tag Read Count and RSSI (dBm) over various speeds in free air. . . . 60

30 Shows Active tags in free-Air on the left and 2 inches of Ice on the right. . . . . . . . . . 61

31 Shows tags with $2.5 \mathrm{cms}$ of Water on left and $2.5 \mathrm{cms}$ of Salted Water on the right with 4 grams of Salt. . . . . . . . . . . . . . . . . . . . . . . . . 62

32 Shows setup for Active tags embedded in 4-inch Underground Soil. . . . . . . . . . . . . . 63 


\section{List of Tables}

1 Specifications of Passive Equipment Setup Used in This Paper . . . . . . . . . . . . . 19

2 RSSI in Free-Air and 6.5 inches of snow at various car speeds with downward-facing single

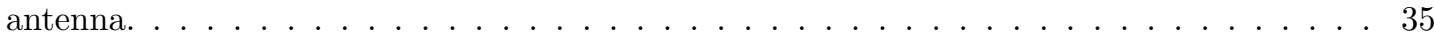

3 Tag Read Count readings in air and 6.5 inches of snow at various car speeds with downward-facing single antenna . . . . . . . . . . . . . . . . . . 36

4 Tag Read Time in snow versus without snow in downward-facing single antenna $\ldots$. . . 36

5 Power (RSSI) in Free-Air vs. 4 inches of Snow at various car speeds with backward-facing

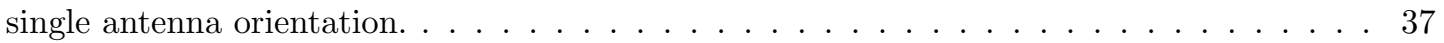

6 Tag Read Count in Ambient Air and 4 inches of Snow at various car speeds with backward-

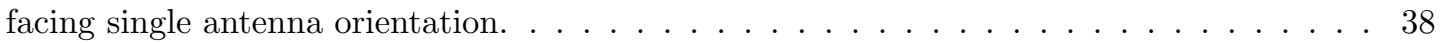

7 Tag Read Time in Ambient Air vs. 4 inches Snow in backward-facing single antenna

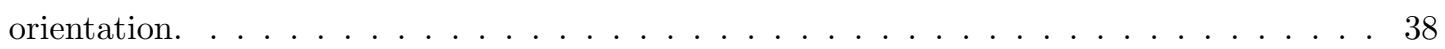

8 Comparison of RSSI in Ambient Air vs. 2.5 inches of Ice in single-front-antenna orienta-

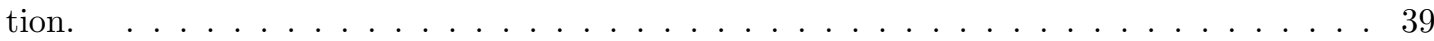

9 Tag Read Count in Ambient Air vs. 2.5 inches of Ice in single-front-antenna orientation. . 39

10 Tag Read Time in Ambient Air vs. 2.5 inches Ice in single-front-antenna orientation. . . . 40

11 Comparison of RSSI in Ambient Air vs. $2.5 \mathrm{cms}$ of Water in single-front-antenna orientation. 40

12 Tag Read Count in Ambient Air vs. $2.5 \mathrm{cms}$ of Water in single-front-antenna orientation. 41

13 Tag Read Time in Ambient Air vs. $2.5 \mathrm{cms}$ of Water in single-front-antenna configuration. 41 
14 Comparison of RSSI in Ambient Air vs. 4 inches of Underground covered with 0.5 inch of soil in single-front-antenna orientation. . . . . . . . . . . . . . . . . . . . 42

15 Tag Read Count in Ambient Air vs. 4 inches of underground covered with 0.5 inch of soil

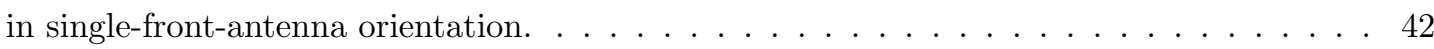

16 Tag Read Time in Ambient Air vs. Underground in single-front-antenna configuration. . . 43

17 Comparison of RSSI (dBm) with in Ambient Air vs. 2 inches of Ice in front-facing dual-



18 Tag Read Count in Ambient Air vs. 2 inches of Ice in front-facing dual-antenna configu-

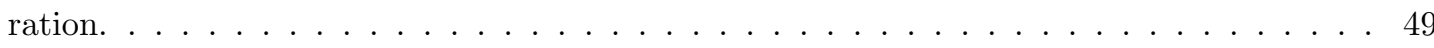

19 Tag Read Time in Ambient Air vs. 2 inches of Ice in dual antenna configuration. . . . . . 49

20 Comparison of RSSI (dBm) in Free Air vs. $2.5 \mathrm{cms}$ Water in front-facing dual-antenna



21 Tag Read Count in Ambient Air vs. $2.5 \mathrm{cms}$ Water in front-facing dual-antenna configu-

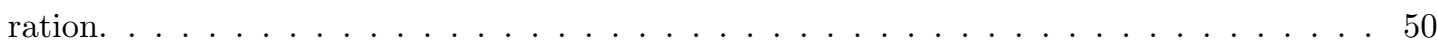

22 Tag Read Time in Ambient Air vs. $2.5 \mathrm{cms}$ of Water in front-facing dual antenna config-



23 Comparison of RSSI (dBm) in Ambient Air vs. $2.5 \mathrm{cms}$ of Water having 4 grams of salt

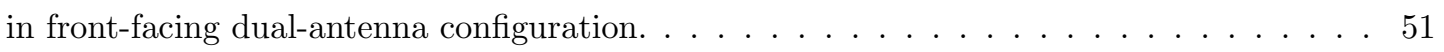

24 Tag Read Rate in Ambient Air vs. $2.5 \mathrm{cms}$ of Water having 4 grams of salt in front-facing

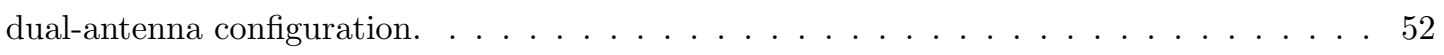

25 Tag Read Time in Ambient Air vs. $2.5 \mathrm{cms}$ of Water with 4 grams of salt in front-facing

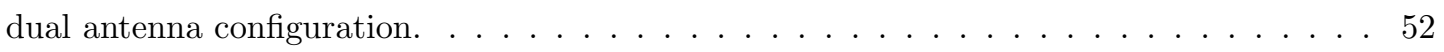


26 Comparison of RSSI in Ambient Air vs. 4 inches of underground covered with 0.5 inch of

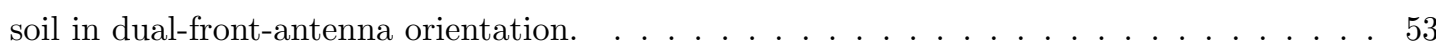

27 Tag Read Count in Ambient Air vs. 4 inches of underground covered with 0.5 inch of soil

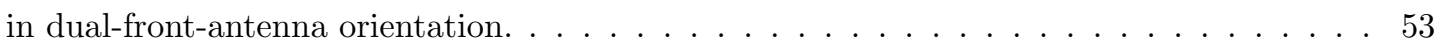

28 Tag Read Time in Ambient Air vs. 4 inches of underground covered with 0.5 inch of soil in dual-front-antenna orientation. . . . . . . . . . . . . . . . . 54

29 Shows summary of Passive RFID Tags results in various propagation mediums with Single

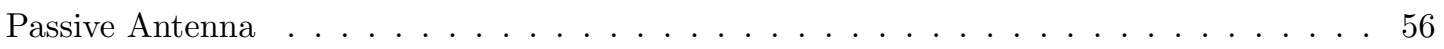

30 Shows summary of Passive RFID Tags results in various propagation mediums with Dual Passive Antenna . . . . . . . . . . . . . . . . . . . . . . 57

31 Comparison of RSSI (dBm) and Tag Read Count in Free-Air and 2 inches of Ice using Active Tags. . . . . . . . . . . . . . . . . . . . . . . . 64

32 Comparison of RSSI (dBm) and Tag Read Count in Free-Air and $2.5 \mathrm{cms}$ of Water using Active Tags. . . . . . . . . . . . . . . . . . . . . . . . 65

33 Comparison of RSSI (dBm) and Tag Read Count in Free-Air and $2.5 \mathrm{cms}$ of Water with

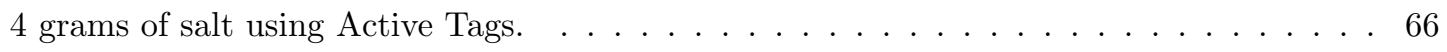

34 Comparison of RSSI (dBm) and Tag Read Count in Free-Air and 4 inch of Underground with 0.5 inch of soil (rendering effective depth at 3.5 inch) using Active Tags. . . . . . . 67

35 Shows summary of Active RFID Tags results in various propagation mediums. . . . . . . 69 


\section{Abstract}

This thesis finds the feasibility of using Radio-Frequency Identity tags for current Autonomous Vehicle (AV) limitations such as camera occlusions, traffic-sign tempering, and spotty GPS signals interrupting localization. Experiments were conducted with an AV on a test track up to $90 \mathrm{~km} / \mathrm{h}$ with Active and Passive Tags in various propagation mediums such as Ice and Snow. Higher speeds could not be tried due to track constraints. One study however was able to read the Passive tags up to $200 \mathrm{~km} / \mathrm{h}$. The study finds how to increase the coverage area and read range of the tags. The Active tags performed better than their Passive counterparts, however at the expense of high cost and battery replacement. Mass production and Piezoelectric technology may be able to help with it, respectively. The study found that the technology in its current form is suitable for controlled environments only. However, if more Passive antennas and readers are experimented with, and more equipment is developed while keeping AV use-case in mind, it can show promise against the current AV limitations. 


\section{Dedication}

This thesis is dedicated to all from whom I have learned and sought inspiration in my life. This is particularly dedicated to my dad for being the greatest mentor in my life and for keeping the flame of engineering and problem-solving alive in a kid who had a tough-love relationship with math. It is also dedicated to my late younger cousin, Hamza Hassaan Ahmed, who always brought joy in our lives and with whom I passionately discussed cars and technology, including my research on Autonomous Vehicles. 


\section{Acknowledgement}

I would like to begin by expressing my primary gratitude and thanks to my advisor, Professor Richard

Fei $\mathrm{Yu}$, for being very welcoming and giving me the liberty to choose a topic of my choice, within the Autonomous Vehicle realm, for my thesis. This thesis research was primarily conducted during unprecedented COVID-19 times, which meant unforeseen challenges to lab and track access where the research was conducted. Chip shortage was another factor that plagued the supply of equipment required

for the experiments. I appreciate Yu's patience and help throughout the research, particularly, in arranging the lab and track access, and for arranging the funding during such unprecedented times.

I would also like to express my utmost gratitude to Professor Jun Steed Huang who was the project co-coordinator on this research. Professor Huang accompanied me during most of my experiments - in the worst of $-30^{\circ} \mathrm{C}$ snowstorms in Ottawa in Winter to its heatwave of $+35^{\circ} \mathrm{C}$ in Summer. Throughout the research, Professor Huang was extremely accessible including evenings and weekends. He shared many research papers, reviewed my work, held many whiteboard-sketches meetings, and answered my intelligent and not-so-intelligent questions. Upon asking how does he manage to be so patient and clear in his teaching towards his students, he mentioned that his mom, who was a teacher herself, taught him that there are no bad students, only bad teachers - a lesson that will stay with me as I teach and mentor other people in my academic and professional career.

My family also deserves special recognition for putting up with me during these four years since I did my Master part-time along with a full-time job. Thank you for bearing with my low-energy and I have a "Masters to do" excuse even at times when it had nothing to do with it. Thanks to my mom and sister for boosting my morale throughout the journey and being a great emotional support and amazing friends. My friends also deserve a special shout-out for putting up with me when I brought my laptop and pretended to study during gatherings. Saving the best for last, I am eternally grateful to my dad for his unconditional love and support; for being my greatest teacher since primary school; compiling notes for me and my sister for ease of learning; making chai for us in the early morning during exam days; and accompanying us during our exam times. Thank you for encouraging me in all of my pursuits 
and inspiring me to follow my dreams.

This research is partially funded through the Natural Sciences and Engineering Research Council of Canada (NSERC) and the Government of Canada's National Crime Prevention Strategy. 


\section{Introduction}

\subsection{Introduction to Autonomous Vehicles}

Over a billion automobiles are driven on earth today. Since their invention in the late 19th century, these automobiles have greatly benefitted humanity by allowing fast access to destinations, connecting people, making transportation of goods accessible, and helping build economies. Today, after over a hundred years, the automobile industry is facing a paradigm shift: Autonomous Vehicles (AV) - the stuff of science fiction since the first roads were paved - are coming to our roadways and will radically change everything. This is because AVs envision a world where people and goods are transported safely and efficiently as vehicles drive on their own, from one place to another, with a smooth cadence. Imagine getting into your car, speaking a location into your vehicle's interface, then letting it painlessly drive you to work while you read a book, surf the web, or take a nap. You would no longer have to waste your time sitting in the traffic or finding a parking spot; but could rather value hundreds of hours saved as your car snakes its way through the road congestion, free of distractions, drunkenness, and other human foibles., This future can certainly be envisioned by the widespread adoption of AVs[1], [2].

Embracing AVs will also make driver error a thing of the past; hence, dramatically decreasing collision deaths. At present, automobile accidents account for about 1.3 million deaths per year and many more serious injuries. It is also the leading death cause among younger people aged 15-30 years old. AVs will reduce road accidents and related injuries and deaths by $90 \%$. The adoption of AVs holds incredible promise for inclusivity as it makes transportation more accessible to the elderly who cannot drive and people who suffer from various illnesses and disabilities. However, as AVs require expensive sensors to come to fruition, the cost estimates make it appear that consumers would not be buying a mass-product autonomous car for more than a decade; but the existence of ride-sharing companies has presented the possibility of amortizing that capital cost over many drivers. The initial adoption and feasibility of self-driving would, therefore, be for Autonomous Ride Sharing (ARS). As the technology matures and becomes less expensive, it will be later expanded to individual consumers as well[1], [2]. 




Figure 1: Shows typical sensors on an AV include cameras, LIDAR, RADAR, Ultrasonics, GPS and so on. Despite these sensors there are still limitations as discussed. [3]

Currently, there are many sensors as seen in figure 1 that are employed for Autonomous Vehicle Navigation (AVN) and need to work together to make AVs possible. These sensors include but are not limited to Radio Detection and Ranging (RADAR), Light Detection and Ranging (LIDAR), cameras, Ultrasonics, and Global Positioning System (GPS).

\subsection{Problem Overview}

Despite having numerous sensors for AV navigation, there are technological limitations associated with them. They include but are not limited to:

Camera Limitations: Cameras fail during occlusions caused by various situations, for example:

- In snowstorms when the traffic signs and road demarcations get covered with snow. This is seen in figure 2;

- In extreme light variations such as entering tunnels due to abrupt extreme pixel intensity changes;

- Additionally, road signs can be tempered with providing incorrect information to the vehicle. This 




Figure 2: The image shows a few example of camera occlusions caused by weather conditions where the traffic sign and the road is covered with snow and hence occluded.

can lead to fatal consequences.

GPS (Localization) Limitations: All AVs need GPS to know their position whereabouts. It is known as localization in technical terms. The GPS signal comes from the satellite orbiting around the earth. However, this signal can be spotty, for example in tunnels. Knowing the position coordinates is a necessity for AVs.

Realtime Track Changes Limitations: The current leading approach for AVs relies on HD mapping which is precise down to centimeters. This poses a challenge when real-time changes such as construction zones cannot be updated immediately.

\subsection{Motivation and Objective}

AVs despite having a multitude of sensors for navigation have technological limitations associated with them. Recent Tesla and Uber crashes, seen in figure 3, indicate that further contingency is required to enhance public safety.

To provide such, the original work in this paper explores a Radio-Frequency Identity (RFID) based technology for AV navigation and communication using Active and Passive RF tags. The research 


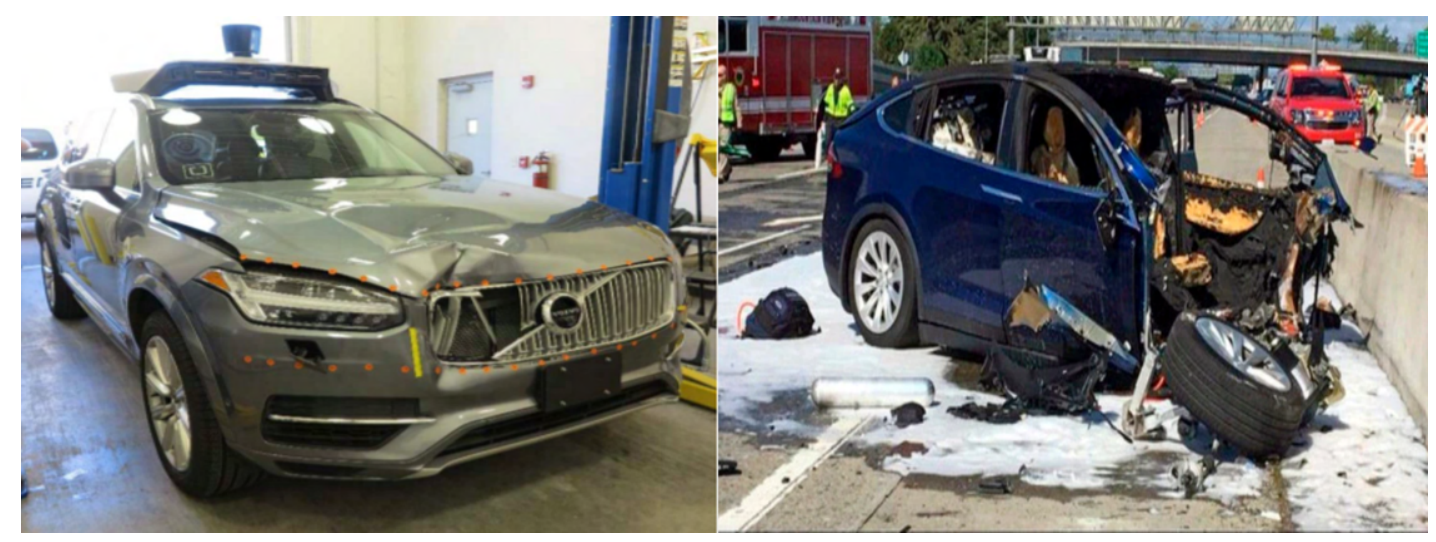

Figure 3: The image shows a few example of recent AV crashes. Uber crash 2018 (left) and Tesla crash 2018 (right). Source: National Transportation Safety Board (NTSB).

is experimental in nature, and experiments are conducted in real-life scenarios, that is, with an AV on a test track under various propagation mediums such as Ice, Snow, and Water. In the end, its performance is evaluated to determine whether this technology is feasible and has the potential to provide contingency and enhance public safety.

The reason why RFID tags-based technology was chosen as a research topic is that it augments the existing technology and is not meant to replace them. Additionally, there is a lot of work being carried out in other technologies, such as cameras and LIDAR, and the space is crowded. The RF technology is mature as it has also been around for a while now with its use-cases dating back to World War 2 Identification Friend or Foe (IFF) systems [4]. Above all, it can help with the above-mentioned AV limitations:

- Camera Occlusions: It can help with road and traffic-signs occlusion problems as neither it is affected by occlusions and nor does it require line of sight. Sign-tempering and Security: It can help with the road sign tempering problem since tags can be password protected and not easily manipulated.

- GPS Localization: GPS signal comes from the orbiting satellite and its signal can be blocked or delayed by the external environment such as tall buildings, tunnels, trees, and so forth. For 
dynamic applications as is the case for AVs, the GPS works with a device known as Inertial Measurement Unit (IMU). It has an accelerometer and gyroscopes that can measure angular rate, force, and acceleration [5]. This means while GPS provides the absolute reference to an AV about its latitude and longitude coordinates, an IMU provides a relative position and movement from an absolute position within a centimeter-level prevision. Therefore, the times when the GPS signal is blocked or delayed, the IMU takes over and guides the AV where it is headed from the last known absolute position provided by GPS [6].

The technical term for providing the relative position and movement from a known or absolute position is known as Dead Reckoning. Dead Reckoning however induces error if used for a prolonged period due to the bias of the sensor readings of an IMU which accumulates with time [7]. In the absence of the GPS signal, IMU provides the position and movement information to the car and gets reset as soon as the GPS signal is reliably available again. However, in its absence, such as in a long tunnel or where the GPS signal is spotty, RFID can provide that absolute reference and reset that error [6].

- Realtime Changes: RFID Tags are a container of information, and their information can be updated. It can also be linked to a database system. If the AVs are to be communicated about the real-time path changes, it can be done by updating the information stored in the tags.

Furthermore, Passive RFID technology in particular is cheap and can be deployed without worrying about the number of tags required for its use case. The thesis paper however trials Active technology as well to not only compare its performance against Passive tags but to provide a comprehensive RFID tags picture.

\subsection{Thesis Contribution}

The research was conducted with the intent to present the significance and limitations of RFID Tags based technology for AV navigation and communication to the automobile industry so that they can 
make informed decisions about incorporating it along with existing sensors for current AV limitations. In specific:

- Collected RFID Tags experimental data under real-life AV conditions with the latest available technology procured from vendors located all over the world.

- Conducted experiments under various propagation mediums such as Ice, Snow, and Water to evaluate RFID Tag performance, such as speed and propagation medium impact on Received Signal Strength Indicator (RSSI), Tag Read Count, and Time Per Tag read. The thesis has a special focus on Canadian weather as the experiments were conducted over a vast temperature range of $-30^{\circ} \mathrm{C}$ to $+35^{\circ} \mathrm{C}$.

- Presented how to increase the Coverage Area (Read Range) of RFID Tags and the best antenna orientation for the RFID Tags.

\subsection{Accepted Research Paper}

The following paper has been accepted:

Osama Javaid, F. Richard Yu, Jun Steed Huang, "Autonomous Vehicle Navigation by Passive Radio Frequency (RFID) Tags" in 11th ACM International Symposium on Design and Analysis of Intelligent Vehicular Networks and Applications (DIVANET'21), Nov. 2021, Alcante, Spain. 


\section{Related Work}

RFID tags technology for AVs is relatively a still-developing technology although the early works started during WW2 to differentiate between enemy versus ally planes [4]. AV Navigation and Communications using RFID tags, in particular, is a nascent field lacking concrete results. The majority of the published literature is related to simulations than experimental work. This section presents previous related work around RFID tags pertinent to this thesis research. The research employs moving-reader-based systems where the reader placed in the vehicle reads tags placed on the road. The other way is to place a tag in the moving vehicle and have it read by fixed reader antennas, as done in the tolling applications. The former solution is preferred as it is less expensive and complex than the latter [8].

Equivalent Isotropic Radiated Power (EIRP) determines the signal power of the reader in the direction of the tag. It is limited by FCC regulations to $36 \mathrm{dBm}[9]$. Therefore, the total system power was mostly capped at around $36 \mathrm{dBm}$ for a Passive setup. For unknown and uncontrollable tag orientation, the circularly polarized antenna is preferred as it gets rid of the tag's sensitivity to polarization. This however comes at a $3 \mathrm{~dB}$ power loss as it splits the RF energy over both the axes [9], $[10]$.

On the reader side, the limitations are EIRP levels, that is, the maximum allowable signal

power towards the tag which happens to be $4 \mathrm{~W}$ EIRP in North America [9]. The other is the reader's sensitivity, which is the minimum (tag) signal it can detect or hear. It is typically defined with respect to signal-to-noise ratio or error probability at the receiver. In summary, for UHF systems, the RFID system is limited by tag characteristics, reader characteristics, and environmental propagation. Typically, between the reader and the tag, the tag limitations prevail as reader sensitivity is usually higher [9]. That said, reader sensitivity is recently getting increased attention. However, many reader suppliers or system integrators do not know how to measure it [11]. There is also no standard way of measuring reader sensitivity and vendors may inflate their claims [12].

For navigation, AVs need to know their current location and surrounding at all times. Local- 
ization is the first requirement for an AV to navigate through a known and unknown environment [8]. GPS is the primary sensor to get geographical coordinates of the current location and for navigation for AVs [13]. Localization can be provided by the combination of GPS, lasers, and odometry fusion. When combined, GPS-RFID fusion leads to more accurate location information for navigation [14].

Proprioception is the internal tracking of the movement and position of an object. For AVs, it is provided by a proprioceptor known as an Inertial Measurement Unit (IMU). The information sensing that takes place outside the body is known as exteroception. In humans, it is provided by the nose, eyes, and ears while in AVs it is provided by exteroceptors such as RADAR, LIDAR, and Camera - that track and detect the external objects. AVs are fitted with Global Positioning System (GPS) and work hand-in-hand with an IMU. This is because, firstly, GPS provides localization to about 15 feet which is insufficient for AV purposes requiring a few centimeter-level precision to know whereabouts and prevent accident [1]. Secondly, GPS signal comes from the orbiting satellite and its signal can be blocked or delayed by the external environment such as tall buildings, tunnels, trees, and so forth. While GPS provides the absolute reference to an AV about its latitude and longitude coordinates, an IMU provides a relative position and movement from an absolute position within a centimeter-level prevision. So, in the case when the GPS signal is blocked or delayed, the IMU takes over and can guide the AV where it is headed from the last known absolute position provided by GPS - and thus both need to work together $[6]$.

The technical term for providing the relative position and movement from a known or absolute position is known as Dead Reckoning. Dead Reckoning however induces error over time due to the approximations. In the absence of the GPS signal, IMU provides the position and movement information to the car and gets reset as soon as the GPS signal is reliably available again. However, in its absence, such as in a long tunnel or where the GPS signal is spotty, RFID can provide that absolute reference and reset that error [6].

GPS is the primary sensor to get geographical coordinates of the current location and for navigation for AVs. However, an AV may lose GPS signals in a tunnel or due to high rises for a brief 
moment which could potentially be dangerous. RFID can help in obtaining information about the local environment. The two key issues are the read range and time to read the tag. It takes about $18 \mathrm{~ms}$ for the reader to read 128 bits from the tag [13]. In the experiments conducted in this paper, in free-air, the average time per reading was about $15 \mathrm{~ms}$, which increased in other mediums.

Motroni et al. in [8] presented 3 methods for localization for indoor vehicles: a). using only the RFID technology; b). fusing RFID technology with proprioceptive sensors, and lastly fusing RFID sensors with exteroceptive sensors. Although AV localization is application-dependent based on the cost and complexity, it concluded that UHF-RFID fused with proprioceptive sensors seems to be the relevant and investigated solution.

Sachindra et. al in In [3] enlist RFID as one of the technologies that can improve AV navigation. It can particularly be used during bad weather conditions and provide useful information stored in the tags. It provides information on how the tags can be embedded in the pavement and a schema can be used to determine the location from it.

Daly et al. in [15] improve on the concrete-embeddable RFID Tag for way-point identification which is a technology that a predetermined position coordinates and is connected to the database. This can be used for AV Navigation. Read range and signal coverage are significantly reduced when embedded in the concrete. After improving the tag design, the team was able to achieve over one-meter height reading from the concrete surface as the tags were embedded in it. This was achieved by a hand-held reader in both dry and water conditions.

The communication range of the RFID system is primarily limited by the power threshold of the passive tag, which is the minimum power to turn on the tag, as the sensitivity of the reader is typically high. $-10 \mathrm{dBm}$ marks typical power threshold for passive tags [16]. If the tag is placed on the asphalt (having permittivity $=6$ ) and the vehicle speed is $200 \mathrm{~km} / \mathrm{h}$, the time window for the reader to interrogate with the passive tag is $126 \mathrm{msec}[16]$.

Nash et. al in their journal paper [17] investigated the effect of tag and reader location and 
vehicle speed on Tag Read Count. It found the higher the vehicle speed, the lower the detection rate or Tag Read Count. The closer is the reader to the tag, the higher is the detection rate and the signal strength. Additionally, it expected having multiple tags nearby would lead to interference due to the shadowing effect, however, it did not affect the detection rate. All these findings are in line with this paper's research.

Nitikin and Rao in [9] investigated performance limitations of Passive UHF RFID Systems. The reader transmits the modulated RF signal to the tag having an antenna and an IC. The IC harnesses the power of the reader to power itself. It sends the modulated signal back to the reader known as a backscattered signal. Modulation is carried out by varying its input impedance. Amplitude Shift Keying (ASK) modulation is typically used in RFID where the chip impedance switches between the two states of being matched to its antenna and the other highly mismatched. it receives the power in this state. The most important characteristic of RFID system performance is the tag's read range. This is the range where it can communicate with the tag. Within the tag, chip sensitivity is the most important tag limitation. It is the minimum power required to turn on the chip, also known as the Power threshold. The other tag limitations include antenna gain, antenna polarization, impedance match, impedance polarization, path loss which depends on the propagation environment.

Wang et. al in [18] proposes an RFID-based method to enhance self-localization to improve safety in AVs. Currently, the most two used localization methods are GPS and LIDAR-based. GPS suffers from signal loss and LIDAR relies on the pattern match of an area in the immediate surrounding and compares it with the predefined HD Map, which may have reliability problems [1]. Known locations of roadside infrastructure such as road signs, traffic lights will be stored in the vehicle's infotainment system and compared against reads of three or more tags on the infrastructure and read by the reader in the vehicle as it moves along. The tags are surveyed by the high precision method and thus have a high precision location.

One of the issues with Active or BAP tags is that it runs out of battery and changing that is not feasible in case of AVs if it is embedded within the infrastructure. This is where the Piezoelectric power 
supply that converts the mechanical energy into electrical energy can help. Chu et. al in [19] presented a design of semi-active or BAP tags with Piezoelectric Power Supply (PPS) and called it is PPS-RFID system. If tags can be fitted with this technology and their battery can be charged without needing to replace it, this may be a paradigm shift for RFID systems since Active or BAP tags perform much better than purely passive tags. Takeuchi et. al in [20] also demonstrated a piezoelectric power generator for Active tags. Its current utility was in children's monitoring system but sees future application in automobiles and robotics. 


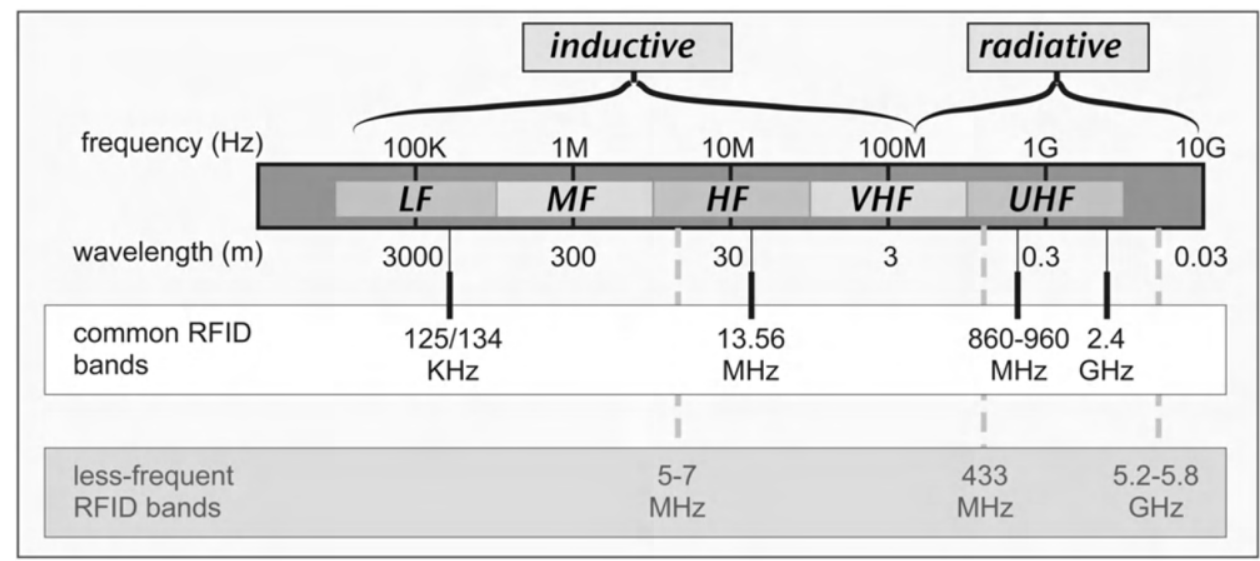

Figure 4: Electromagnetic Spectrum is divided based on the various frequencies of its spectrum. The one of interest to this research is UHF [21].

\section{RFID Overview}

\subsection{RFID Spectrum}

An electromagnetic spectrum is comprised of various frequencies of waves. Therefore, based on their frequency they are classified into frequency bands, such as Low Frequency, High Frequency, and Ultra High Frequency. This is seen in figure 4. Lower the frequency, lower the throughput or data carrying capacity and penetration power. From Low Frequency to Very High Frequency (VHF), the band stays inductive. This means that the communication takes place upon close contact. Widely used $13.56 \mathrm{MHz}$ Near Field Communication (NFC) frequency is also inductive. VHF is also where the cut-over happens and the communication becomes radiating, meaning close contact is no longer required. The UHF Passive RFID operates between 860-960 MHz while Active at $433 \mathrm{MHz}$ and $2.4 \mathrm{GHz}$. Higher frequencies have more data carrying capacity than the lower ones but are also more sensitive to liquid and metal, especially the Passive UHF as wave reflect off or absorb into non-friendly RF materials, respectively [10], $[21]$. 


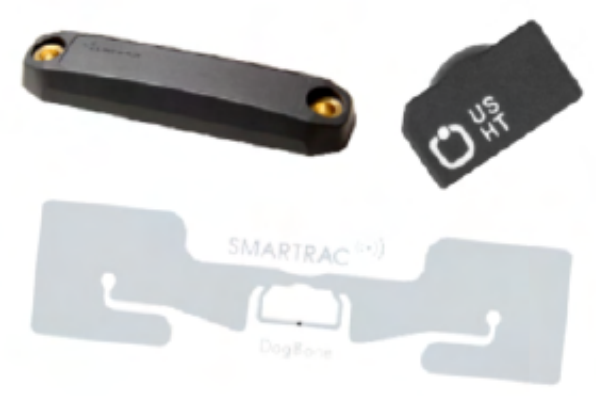

Figure 5: Inlays and Hard tags are typically the two types of Passive Tags available in the market. This research was conducted using both Inlays and Hard tags [10].

\subsection{Passive Tags and Operation}

Tags typically fall into two categories: Inlays and Hard Tags seen in figure 5. Labels and Inlays are paper-like while hard tags have a rugged casing around it, typically for outdoor applications. Without delving into the tag circuit design, it has two main components: an antenna and an Integrated Chip (IC). Antenna receives the RF energy, uses that to energize the IC of the tag, and then also sends the modulated signal back to the reader, known as the backscattered signal. IC on the other hand processes and modulates the information and stores it. There are a few IC manufacturers in the world [10].

The most common antenna used for the Passive tags is dipole antenna as it is two wires and convenient to produce. Different types of memory that reside on a tag are: 1) Electronic Product Code (EPC), which can be unique or random. It provides limited 96 to 496 bits of user-editable memory; 2) Tag Identity (TID) Memory, which is a unique number set by the manufacturer and cannot be changed; 3). Reserved Memory Bank, this is where the access and lock passwords reside. If the user locks this memory, then a password is required to view or change it; 4) User Memory Bank, provides 32 bits to 64 kbits space for custom user-information but this memory bank is typically available on the higher end tags. [10]. 


\subsection{Battery-Assisted Passive (BAP) and Active Tags and Operation}

Read range of a Passive RFID setup depends on three things: 1). Tag Sensitivity - This is the power required to activate the $\mathrm{IC}$ of the tag and is known as the forward link or downlink. Its threshold value is typically $-10 \mathrm{dBm}[16] ; 2)$. The power of the backscattered signal to the reader is known as the return link or uplink; 3). Reader's Sensitivity - This is the minimum signal power that can be picked up or "heard" by a reader. Despite the claims, measuring reader's sensitivity is tricky and there is no standard way of measuring it. Reader sensitivity is typically much higher than the tag's sensitivity and the range is typically dependant on tag's chip threshold [12], [21]. The communication range of the Passive RFID system is primarily limited by the power threshold of the passive tag, which is the minimum power to turn on the tag, as the sensitivity of the reader is typically high. $-10 \mathrm{dBm}$ marks typical power threshold for passive tag $[16]$.

A Passive tag harnesses reader's RF signal to activate its IC and backscatter the signal (information) to the reader. In case of a BAP tag, the IC is activated by the battery, however the energy required to transmit the backscattered signal still comes from the reader. The experiments are conducted with both Passive and BAP tags to evaluate the difference in performance. BAP is the middle of the road solution between Passive and Active tags where the battery only powers the IC and it does not have an active transmitter.

In case of Active tags, such as in Bluetooth tags, the battery not only powers the IC, but it also has an active transmitter used to transmit the signal to the reader. It was extremely difficult to find BAP tags in the market as Passive and Active tags dominated the RFID ecosystem. Passive tags were most used due to their cheap cost. For difficult RF transmission scenarios (requiring large read range, buildings etc.) or where the tags were tracking a costly equipment, Active tags were used. BAP tags were hard to find as they provided marginal benefits at substantially high cost. Additionally, just as Active tags, it inherits the problem of running out of battery and requiring replacing it. Another major issue with the BAP tags are activating their Battery-Assisted (BA) mode. The tags may come in the BA mode or fully Passive. Since the industry has not widely adapted BAP tags, there are few 


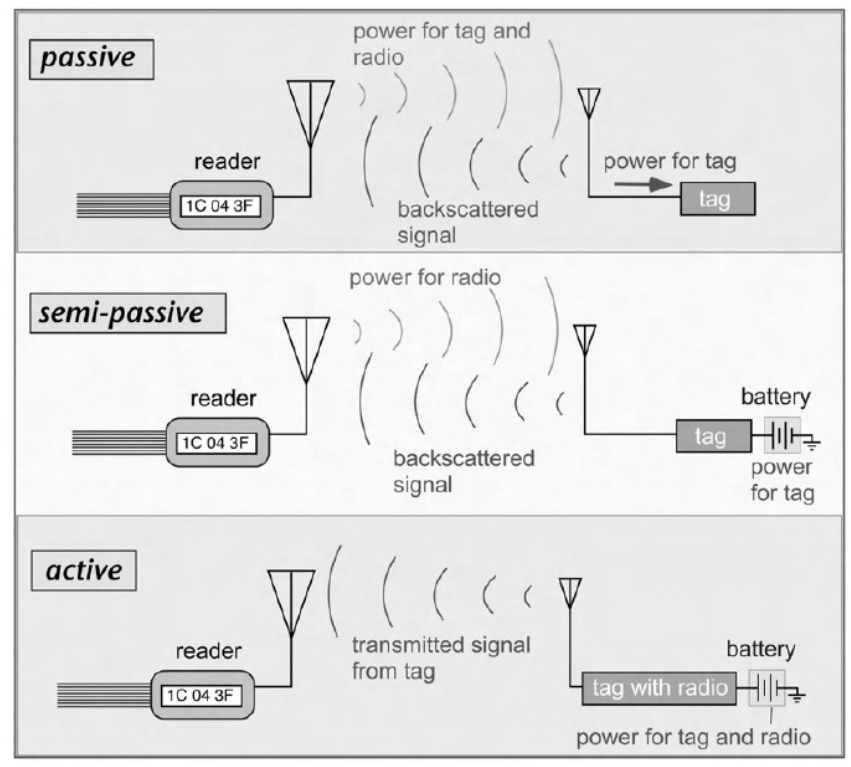

Figure 6: Figure shows how the ICs of Active, Passive and BAP tags are powered. Passive tags are powered by the signal of the reader while BAP and Active tags have batteries to power their ICs. [4]

and far companies providing them. Software that activates the BA mode is typically Custom of The Shelf (COTS) by companies. This means there is no standardization and companies typically provide with Software Development Kits (SDK) rather than ready-to-use software. For example, for Confidex Survivor B tag, a lot of time and energy was spent in activating its BA mode. After trying multiple times using reader's URA software, support was reached out. Support reached back with Java and C\# SDKs. Considerable time was subsequently spent in configuring the code and activating the tags in their BA mode. The other HCL tag came in with a BA mode activated.

\subsection{List of Passive and BAP Tags Used in Experiments}

Readers cannot differentiate the tags with the similar EPC [10]. Therefore, for identification purposes, tags were either numbered or a combination of a number and characters was used. The list below shows an inconsistent tag numbering. This is because initially kit tags of inlay type were numbered in sequence but the best out of them were selected for experimentation. The development kit inlay tags are cheap (a few cents). The tags with characters are procured separately and are expensive (in 10s of dollars). 


\begin{tabular}{|c|c|c|c|c|c|}
\hline Tag ID & \begin{tabular}{|l|} 
Name (If \\
Applicable)
\end{tabular} & \begin{tabular}{|l|} 
Tag \\
(Inlay/Hard)
\end{tabular} & \begin{tabular}{|l|} 
Passive/BAP \\
\end{tabular} & Integrated Chip & Image \\
\hline 9 & Kit Tag & Inlay & Passive & NA & \\
\hline 16 & Kit Tag & Inlay & Passive & NA & 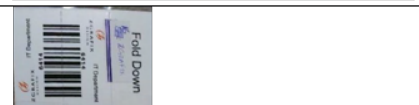 \\
\hline 18 & Kit Tag & Inlay & Passive & NA & 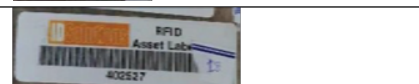 \\
\hline 24 & Kit Tag & Inlay & Passive & NA &  \\
\hline ConP & $\begin{array}{l}\text { Confidex Survivor } \\
\text { B }\end{array}$ & Hard & Passive & EM4325 & \\
\hline ExoP & Omni Exo 3000 & Hard & Passive & Impinj Monza 4 QT & \\
\hline BAP1 & $\begin{array}{l}\text { Confidex Survivor } \\
\text { B }\end{array}$ & Hard & BAP & EM4325 & \\
\hline BAP2 & $\begin{array}{l}\text { Confidex Survivor } \\
\text { B }\end{array}$ & Hard & BAP & EM4325 & \\
\hline $\mathrm{HCL}$ & H92SP-Mo8k-Fe & Hard & BAP & Impinj Monza X-8K &  \\
\hline $\begin{array}{l}\text { BLE 5, BLE } 6 \\
\text { and BLE } 7\end{array}$ & $\begin{array}{l}\text { Confidex Viking } \\
\text { Classic }\end{array}$ & Hard & Active & nRF52832 & \\
\hline
\end{tabular}

Figure 7: Image and details of the tags used in the experiments. It includes Passive Tags, BAP Tags, and Active Tags.

After trying various different tags, the selected tags in the end used in the experiments in the upcoming chapters can be seen in figure 7 .

\subsection{RFID Tags Security}

Tags provide security against tempering as they can be made password protected so information cannot be changed easily [10]. Additionally, for some of the Active used in this experiment, one of the vendors used a lock key mechanism to change the information of the tags. Firstly, tags were only activated upon close contact at NFC frequency. The reader was only able to change the configuration of the tags if it 




Figure 8: Shows an example of a typical RFID Reader and Tag Operation [21].

had the secure encrypted files for security. Any reader without this file would not be able make changes to the tag configuration. 3M company, that makes Post-IT sticky notes, is also working on traffic sign stickers transparent to the naked eye but readable by AVs [1]. This idea will further add to the tags related security.

\subsection{RFID Operation}

The RFID system is comprised of a tag(s), reader, and a host computer that is connected to the reader and interprets or reads the information it receives back from the tag. Both reader and tags have their own antennas. A reader has a minimum of one antenna, but used for both transmission and reception. Readers can have multiple antennas. For example, the reader used in this experiment could handle up to four antennas.

Tag has an IC which stores information and modulates the information. Passive RFID tags typically modulate the information changing their impedance. The typical modulation type is Frequency Shift Keying (FSK) [21]. The reader to tag signal is known as downlink while from tag to the reader is known as the uplink. This is shown in figure 8. 


\section{Experiment Design and Methodology}

\subsection{Methodology}

This thesis is focused on RFID experimental data collected by an AV than simulations, so that the parameters such as read range, tag read count, tag read time, reader's coverage area, and vehicle speed can be determined. The readings were collected under various propagation mediums of air, water, ice, and snow to find the impact of external factors on an RFID system.

A typical setup is shown in figure 9. A front-facing reader's antenna is connected to the reader by a coax cable and mounted onto the vehicle for transmission and reception of the UHF RF signal. The reader is inside the car powered by an inverter. A computer is connected to the reader through a USB cable to collect the readings. Reader software, URA, runs on the computer where various parameters such as signal power can be adjusted. Tags are placed on the roads or embedded in it. As the vehicle drives over the tags, data is collected. Each run was conducted at a specific speed, for example, 10 $\mathrm{km} / \mathrm{h}$, then $20 \mathrm{~km} / \mathrm{h}$ and so on. Average of readings were taken in the end and compared in various propagation mediums for analysis. Information such as RSSI, Phase, Time of Read, Protocol and so forth. Data was exported into .csv files and analyzed.

This set up is different than the common existing RFID system such as tolling station where the reader is static and tags are moving. In this approach however the reader is dynamic and moving while the tags are static.

\subsection{Equipment and Design Setup}

A typical Passive RFID setup is shown in figure 9. A reader's antenna is connected to the reader by a coax cable and mounted onto the vehicle for transmission and reception of the UHF RF signal. The reader is inside the car powered by an inverter (to convert DC to AC for reader's plug). A computer is connected to the reader through a USB cable to collect the readings. A custom software, provided by 

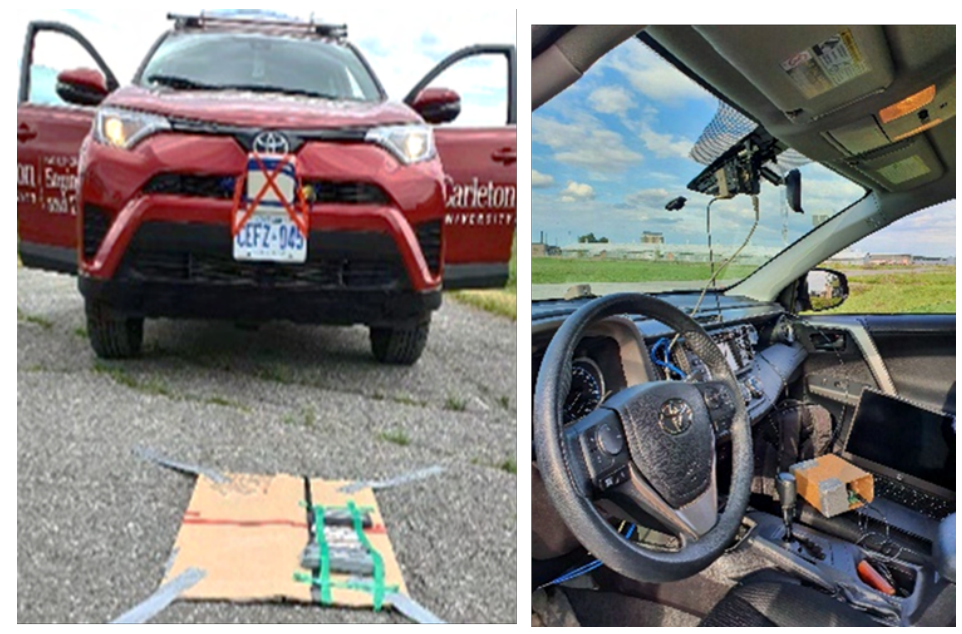

Figure 9: Typical Passive RFID setup showing an antenna mounted onto the vehicle, a coax cable connecting the reader the antenna, and computer connected to the reader through a USB cable.

Table 1: Specifications of Passive Equipment Setup Used in This Paper

\begin{tabular}{l|c|r}
\hline Equipment & Vendor & Specification \\
\hline Passive Reader & ThingMagic M6e & $30 \mathrm{dBm}$ \\
\hline Antenna & MT242025/TRH/A & $7.5 \mathrm{dBic}$ RCHP; $865-956 \mathrm{MHz}$ \\
\hline Antenna Cable & Vulcan RFID ${ }^{\mathrm{TM}} 12 \mathrm{ft}$ Antenna Cable & $195 \mathrm{Rating} ; 1.4 \mathrm{~dB}$ loss \\
\hline Reader Software & Universal Reader Assistant Custom Software by Jadak & Read Continuously; Max. Read Distance \\
\hline \hline System Power Output & $30 \mathrm{dBm}$ (reader output) $-1.4 \mathrm{~dB}$ (cable loss) $+7.5 \mathrm{dBic}$ (antenna gain) $=36.1 \mathrm{dBm}$ \\
\hline
\end{tabular}

the reader or tag vendor, is run on the computer where various parameters such as transmission power and modes of reading can be adjusted. Tags are placed on the roads or embedded in it. As the vehicle drives, signal data is collected having information such as RSSI, Phase, Time of Read, Protocol and so forth. Data was exported into .csv files and analyzed in the later chapters. Specifications of Passive equipment setup can be seen in Table 1.

\subsection{Propagation Mediums}

Experiments were conducted in the following propagation mediums: 
- Free Air.

- Water.

- Salted Water.

- Snow.

- Ice.

- Underground.

\subsection{AreaXO}

The test track where the experiments were conducted is a 9-kilometers long test track known as AreaXO [22]. It is located in the West end of Ottawa and operated in collaboration with private and public partnerships and is supported by governments at different levels (municipality, provincial and national). Its mandate is to provide test bed to upcoming technologies and promote them. It has a particular emphasis on Autonomous Driving. The track can be seen in figure 10.

\subsection{Passive Reader, Antenna and Antenna Cable}

ThingMagic's M6e RFID Reader Module Development kit was procured for experiments. The development kits are designed for testing purposes, as it comes with a complete package of a reader, antenna, cables and various (inlay) tag samples of various kinds. This was well suited for this research. Kit

readers are also cheaper than their solo-counterparts, however one potential downside is that they are not enclosed in casing. This was overcome by making a makeshift casing [23].

\subsubsection{Reader}

ThingMagic M6e is a multiprotocol reader compatible up to 4 antennas. It is suitable for Original Equipment Manufacture (OEM) applications. Its transmission power is up to $+31.5 \mathrm{dBm}(1.4 \mathrm{~W})$. 


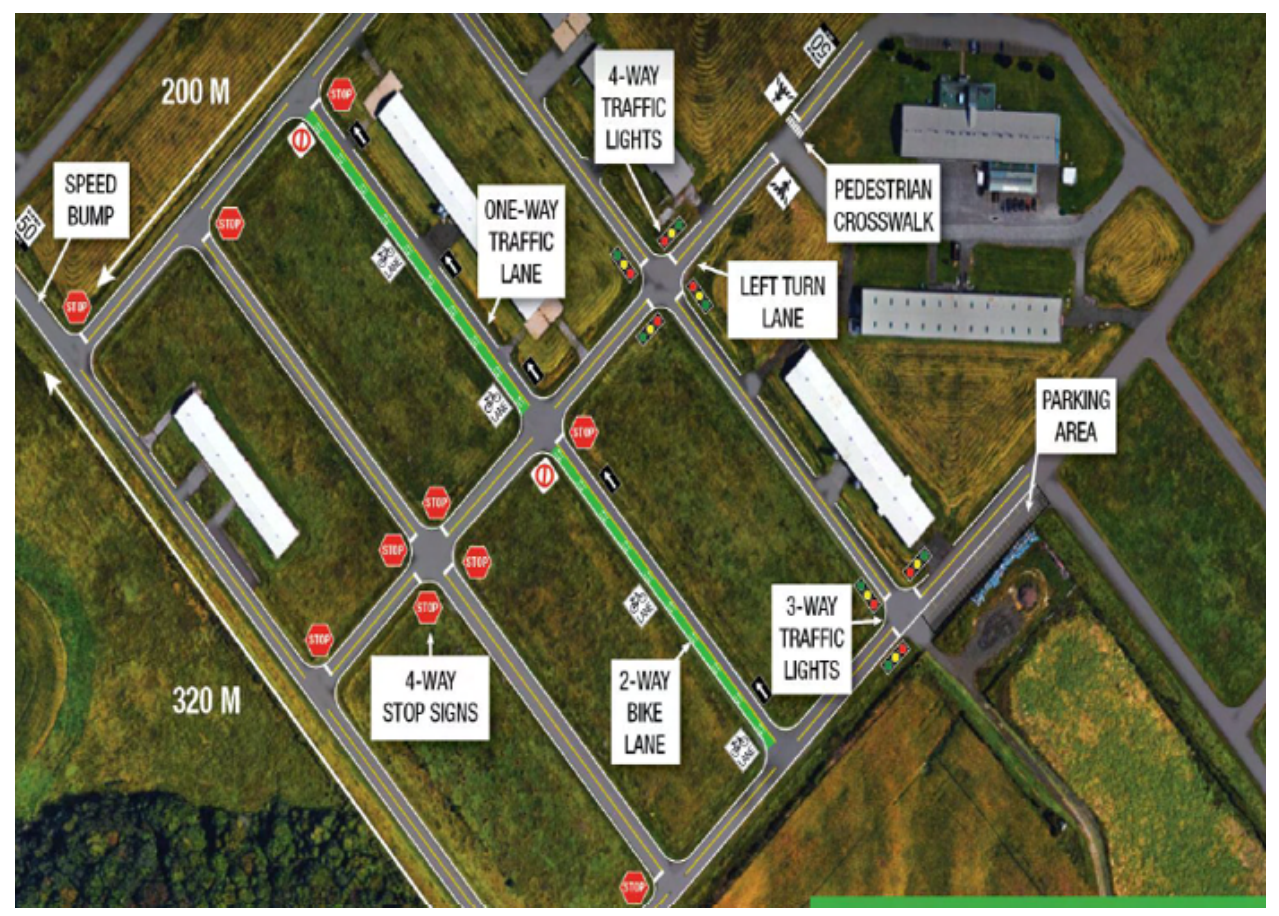

Figure 10: Nine kms long test track, AreaXO, where the AV experiments were conducted in this research.

The reader supports both USB and Serial interfaces. The protocols supported and used in the research includes EPCGlobal Gen2 (ISO 18000-6C). The input voltage power required is 5V DC [24]. Its image can be seen in figure 11 .

\subsubsection{Antenna and Cable}

Experiments were performed with the antenna, MT-242025 [25], (865 - 956) MHz, 7.5dBic, that came with the development kit. This reader came with a $7.5 \mathrm{dBi}$ (where i represents isotopic antenna) gain and with circular polarization. Antennas are of linear or circular type. If the RF wave oscillates in a single direction, it is termed as linear polarization - or if it is in a rotating pattern, it is circular polarization [10]. Linear and Circular polarization can be seen in figure 12. A circular polarized antenna is preferred if the orientation, height, and location of the tag (antenna) is unknown. This is better suited for $\mathrm{AV}$ application where the tags are in different location and orientation, and the environment is very dynamic. Circular antenna however has $3 \mathrm{~dB}$ less power than the linear as it beams the power on both the horizontal and vertical axes. Antenna polarization can be seen in figure 12 . 




Figure 11: Image of a ThingMagic M6e reader used for experiments [24].
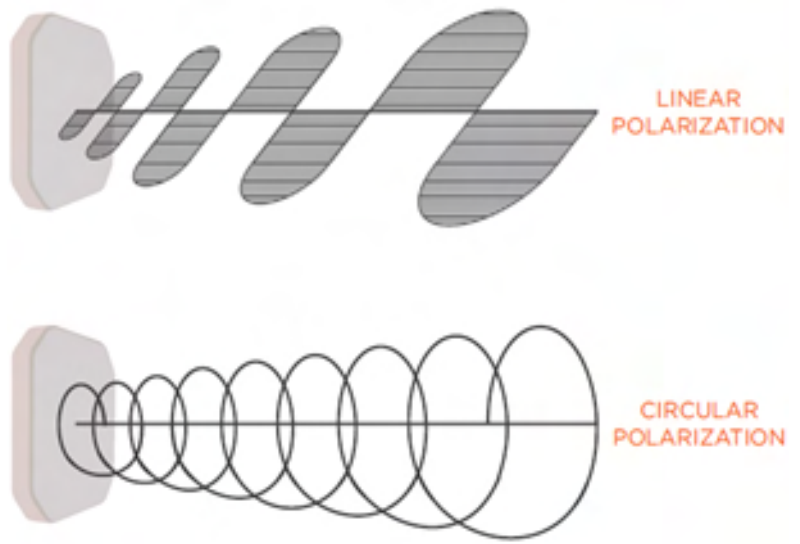

Figure 12: Antenna with Linear polarization beams power on one axis while antenna with circular polarization beams power on both horizontal and vertical axes [10]. 


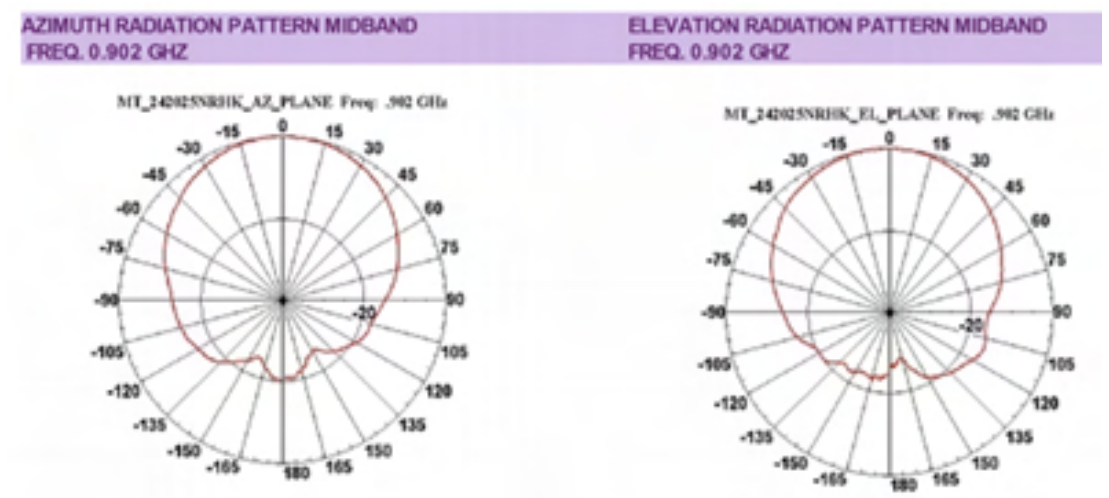

Figure 13: Antenna performance at $902 \mathrm{MHz}$ at different angles in Azimuth and Elevation. There was a significant power drop after 45 degree angle in Azimuth and Elevation. [25].

The antenna is Right Hand Circularly Polarized (RHCP). Left or Right-hand direction only matters if there are more than two RFID systems with two readers in the vicinity - where the similar direction would lead to destructive interference and null zones [10]. The radiation pattern shows that antenna performance is dependent on angles of azimuth (longitude) and elevation (height). The RF power is maximum at the center of the antenna, at 0 degree angle in the azimuth and elevation. The power attenuates away from the center. In both the planes, the power substantially degraded after \pm 45-degree angle. Antenna performance at various angles in Azimuth and Elevation can be seen in figure 13.

The cable that came with the kit was 6 feet long, RP-TNC to RP-TNC type. Since cables conduct RF energy and no cable has perfect insulation, therefore longer the cable, more it loses the energy, and hence the energy loss. As the antenna(s) was mounted to the front of the vehicle, longer 12 feet cable(s) were needed. Cables come with various insulation rating, ranging from 195 to 600 . Higher the insulation rating, less is the RF power loss. Since both 6- and 12-feet cables came with 195 rating, their loss was about $0.75 \mathrm{~dB}$ and $1.4 \mathrm{~dB}$, respectively. 


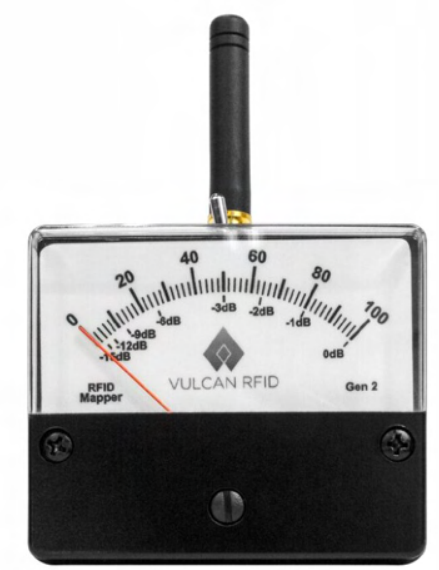

Figure 14: Vulcan RFID Passive Power Mapper used in the experiments [26].

\subsection{Power Mapper}

Initial experiments were relied upon the RSSI values in $\mathrm{dBm}$ from the reader. Soon it was realized that the RF power varied quite a bit with slight changes in elevation, azimuth, and tag orientation. To find a more concrete way to map the RF field and understand how much power was received by the tags, a Vulcan RFID's Passive power mapper was used. It is a small pocket-sized device that operates by harnessing the power of the RF waves transmitted by the reader. It can show the variation in the RF field such as, polarization effects, nulls and interference caused by multi-path. Its working frequency range is from 850 - $950 \mathrm{MHz}$. It requires 1 micro-Watt power from the reader's signal to operate. Power Mapper is shown in figure 14.

\subsection{Passive Reader Software}

As mentioned earlier, as the RFID market is evolving, therefore the reader software is not standardized. Each company offers its own custom solution, with a few companies offering ready-to-go solution. Most 


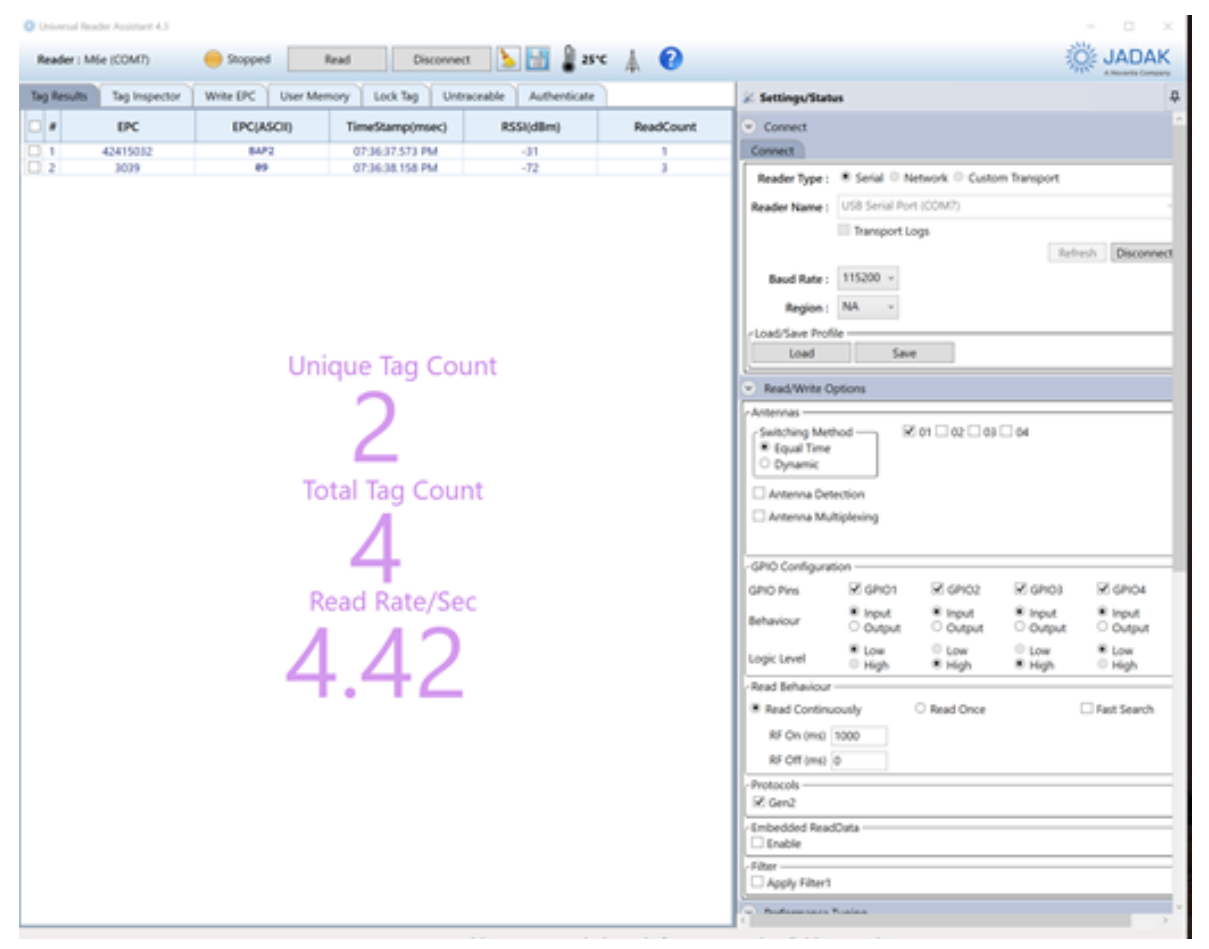

Figure 15: Shows URA software interface and the various parameter-tuning options it presents.

of the software offered are in the form of SDKs. Fortunately, ThingMagic's M6e reader came with a developed, GUI based, Universal Reader Assistant (URA) software. The software captures various attributes of the tags such as EPC, RSSI, Time, Antenna \# (that read the tag), ReadCount. It also granted to password protect the tags, edit the names, write into tag memory. Additionally, it provided the settings to change Read/Write transmission power, select different switching modes between antennas, Gen2 protocol performance tuning. Software also allowed to save the data into .csv files that were later used to capture data and analyze it after experiments. URA software can be seen in figure 15 .

\subsection{Passive RFID Tags' Coverage Area}

Since results with Single Passive antenna were not impressive, as shown in the later chapters, DualPassive Antenna setup was later tried which was much more promising than the single one. This was because of its increased coverage area. And therefore, coverage area was calculated with Dual-Passive Antenna configuration. The fist area was calculated at $-6 \mathrm{~dB}$ drop which meant reduction of read range 


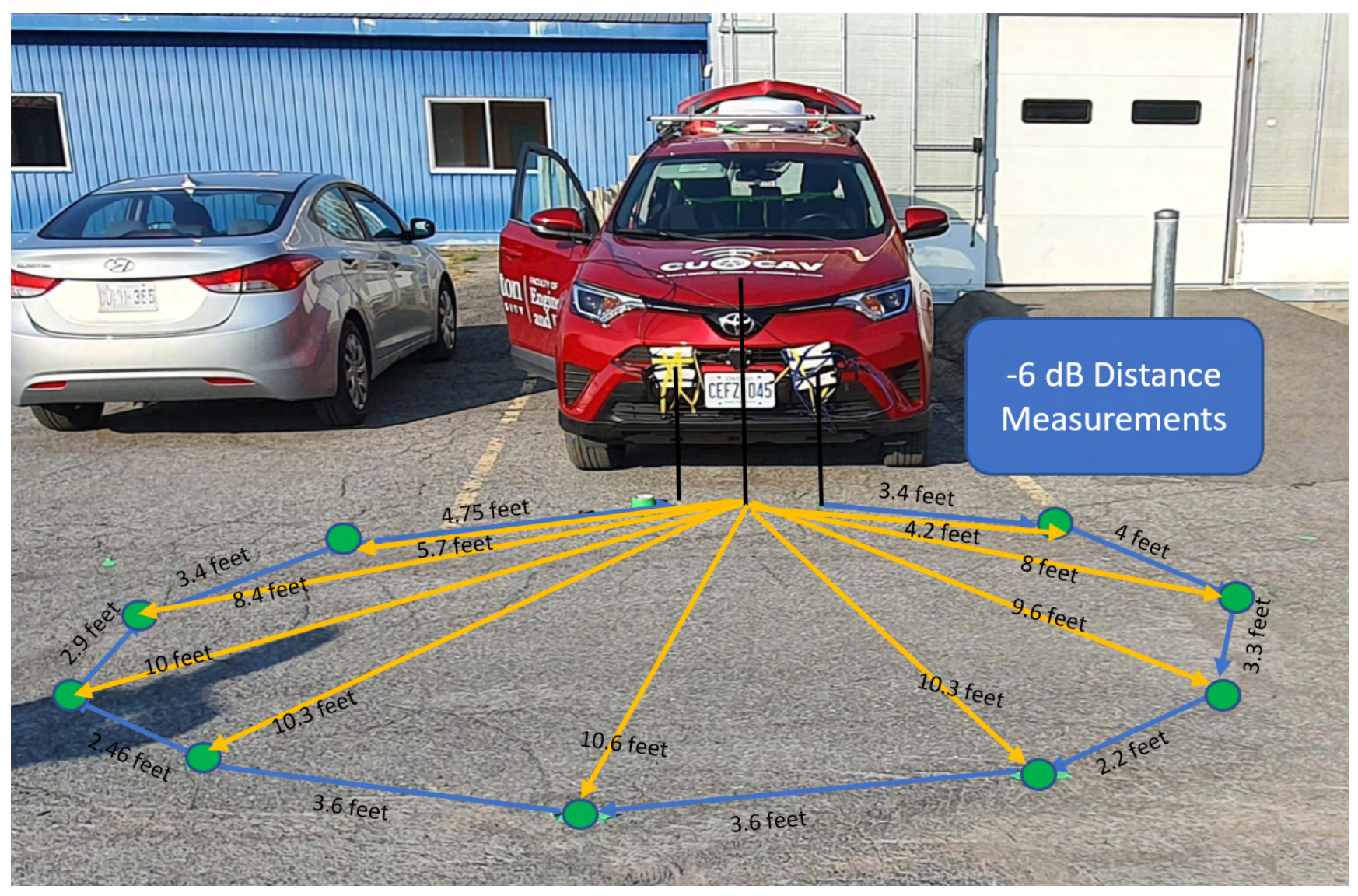

Figure 16: The figure shows the coverage area with a dual-antenna configuration with a $6 \mathrm{~dB}$ attenuation

by $50 \%$ from the antenna. The second coverage area was calculated at $-15 \mathrm{~dB}$ drop which meant less than $25 \%$ read range from the baseline reading of antenna. The readings were calculated with the help of Power Mapper that only takes 1 micro-watt to operate. It operates from the power received from the antenna signals.

The setup was configured such that $30 \mathrm{dBm}$ was the power being delivered by each antenna. This meant that the first coverage area was calculated at $24 \mathrm{dBm}$ power with $6 \mathrm{~dB}$ loss - seen in figure 16. Similarly, the second coverage area was calculated at $15 \mathrm{dBm}$ at $15 \mathrm{~dB}$ loss - seen in figure 17 . The Passive tags need about $-10 \mathrm{dBm}$ of power to power their Integrated Chip (IC). The coverage area calculated therefore was sufficient to power the tags. As expected, the area was lobe shaped with maximum distance in the middle and tapering off in the Azimuth and Elevation. This is how the beam of directional antenna looks like. 




Figure 17: The figure shows the coverage area with a dual-antenna configuration with a $15 \mathrm{~dB}$ attenuation 


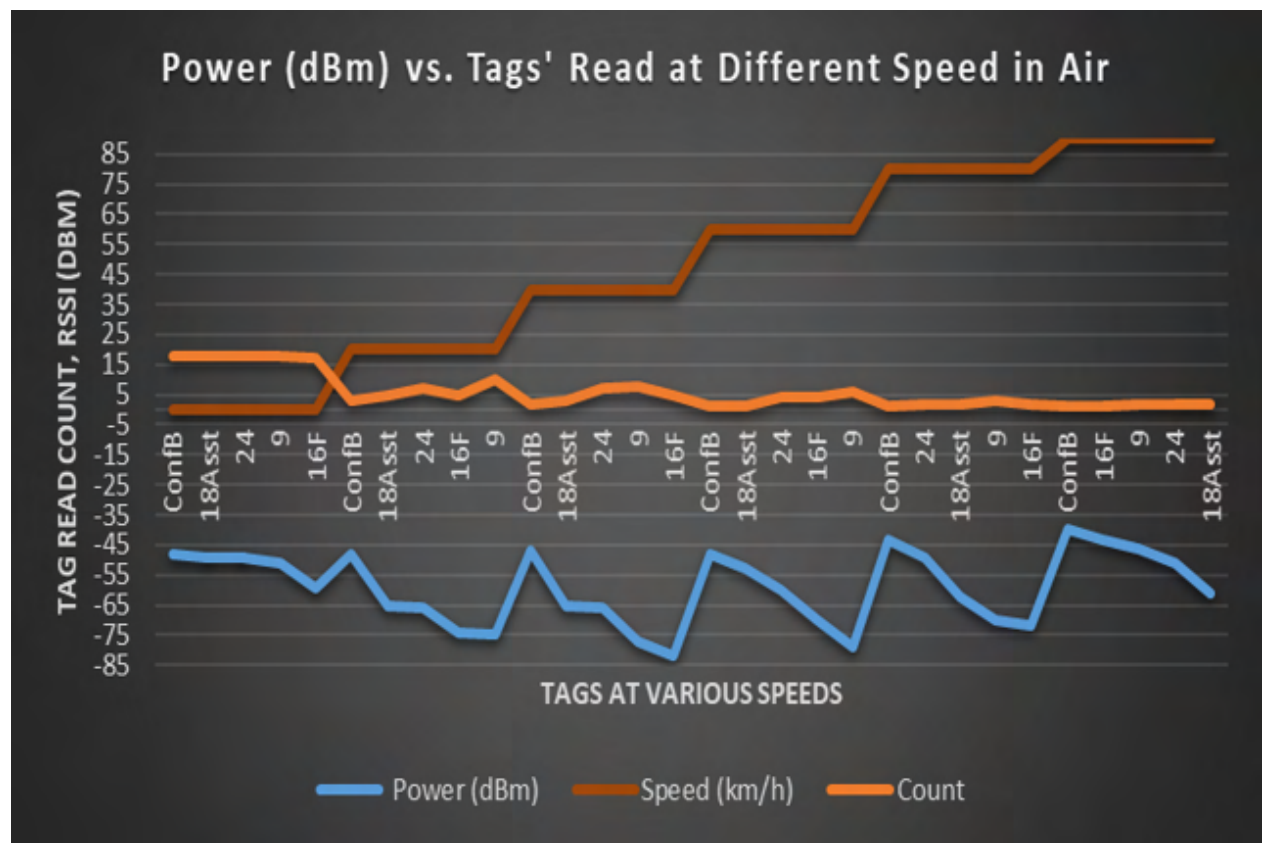

Figure 18: Tag Read Count and RSSI in Free-Air for single-antenna Passive tags.

\section{Results With Passive and BAP Tags (Single Antenna)}

Initially, the experiments were conducted with a single passive antenna. Results showed, as seen in figure 18, with the increase in speed the Tag Read Count decreased. The RSSI fluctuated among tags depending upon their position and type. Typically, more expensive tags yielded better results. As a trend line however the RSSI did not decrease with the increase in speed, contrary to expectations. This is explained later in the chapter. Experiments were conducted in various propagation mediums and their results are compared against Free-Air.

\subsection{Free-Air vs. Snow Results}

The first experiment was carried out by a downward facing antenna, seen in figure 19. Tags were placed on the road in free air and 6.5 inches of snow. The results are captured in Tables 2, 3 , and 4, and demonstrated:

- AV sped up to $60 \mathrm{~km} / \mathrm{h}$ and all tags were read up to that speed. Surprisingly increase in speed 



Figure 19: Readings taken in Free-Air and 6.5 inches of Snow with a downward-oriented single-antenna.

did not decrease the RSSI. In fact, it increased for some readings. This observation was noted and probed in later experiments.

- With the increase in speed, the Tag Read Count (that is, \# of tags read) went down, seen in Table 3.

- The average RSSI (dBm) value taken over six readings for tags significantly decreased by $1.5 \mathrm{dBm}$ to $12.5 \mathrm{dBm}$ in the presence of 6.5 inches of snow. There was one exception where it increased. This could be due to reader's measurement error.

- The expensive hard tag, Survivor B, outperformed cheap inlay tags by a margin.

- Without snow, a total of 105 tags were read in 855 msec making the time per tag read at $8.1 \mathrm{msec}$. In snow, a total of 165 tags were read in 1575 msec making the time per tag read at 9.5 msec (17 $\%$ higher). Time to read a tag increases with the increase in stored information [10]. Only tag names were stored in the tags taking up to 60 bits (20 characters). Tags stored in Hex characters with each consuming 4 bits [10]. This is shown in Table 4 .

When the experiment was repeated with the antenna facing-forward and facing-backward, seen in figure 20, again, with the increase in speed, the RSSI did not go up but in fact increased. There was no conclusive difference on RSSI value between front-facing and downward-facing antenna. However, for 

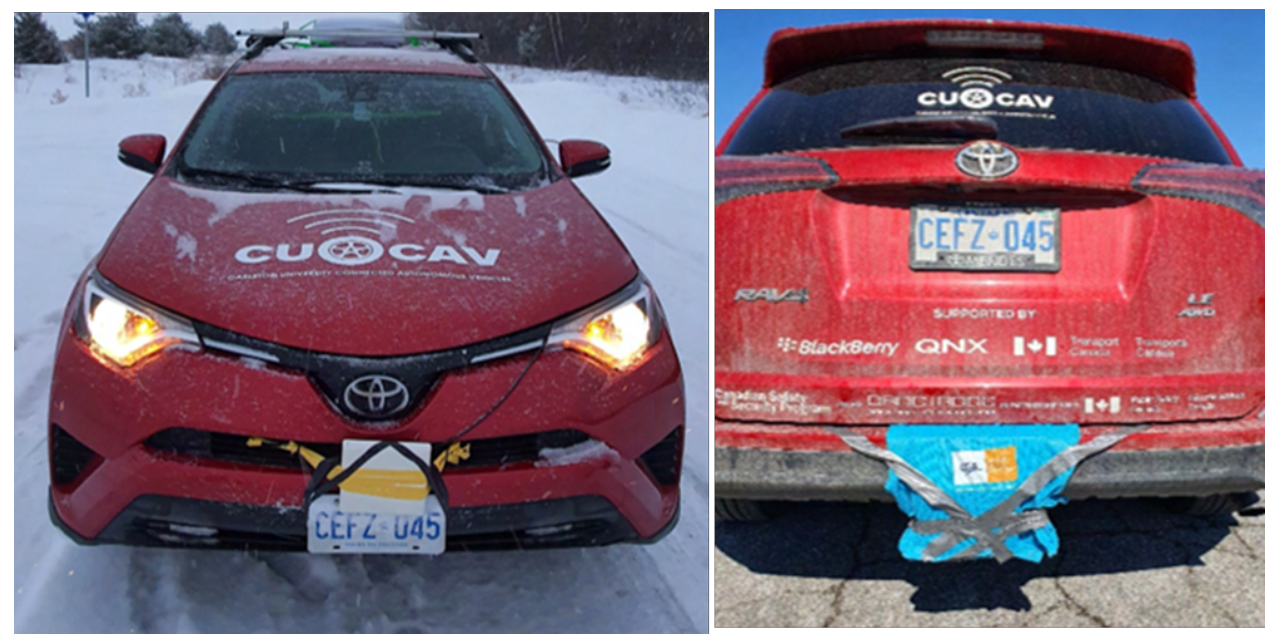

Figure 20: Front Facing-Antenna (left) and Backward-facing Antenna (right).

the tag read count, the former yielded about $50 \%$ more tag reads. This is likely due to the reason that tags are exposed to the RF energy much earlier and longer in comparison to the latter where the beam is more confined, and tags are only read as the AV goes over the tags.

To rule out the Doppler effect causing the increase in RSSI with the increase in speed, the antenna was mounted facing backward, opposite to the direction of vehicle's travel. Readings were taken at speeds up to $90 \mathrm{~km} / \mathrm{h}$. The snow however, this time was spring snow, loose and more water-filled. Readings for the backward-facing antenna are captured in Tables 5, 6 and 7. Results demonstrated:

- Contrary to the downward-facing antenna, the Tag Read Count switched as more tags were read in ambient air than in snow. Time per tag read was comparable for ambient air and snow - in mid-14 milliseconds - up from 8 to 9.5 msec.

- Comparing tables 2 and 5 , for the tags that were in common in the two configurations, the RSSI difference for ambient air and in snow was about the same, indicating that the composition of snow did not affect the readings.

- Readings were taken up to $90 \mathrm{~km} / \mathrm{h}$. Speeds higher than that could not be tried due to speed constraint of the track. Even at this high-speed, tags were successfully read. A study in Germany was able to read Passive RFID tags up to $200 \mathrm{~km} / \mathrm{h}[27]$. 


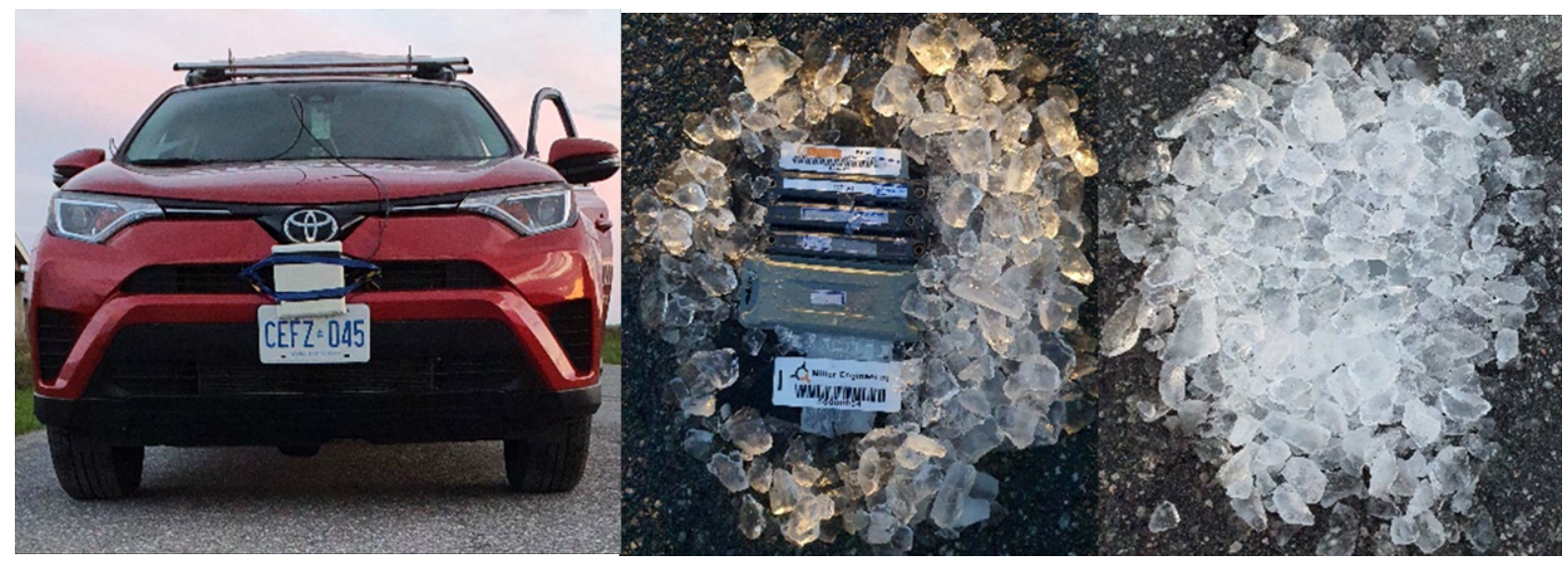

Figure 21: Shows antenna setup (left) and tags in about 2.5 inches of ice (middle and right).

- Despite mounting antenna opposite to the direction of the travel, RSSI increased with the increase in speed. This was particularly conspicuous without snow. This ruled out the Doppler Effect. This was now believed to be happening due to the reader design or dynamic effect such as Automatic Gain Control (AGC). Vendors typically do not disclose the details on such information as it is their "secret sauce". However, When the company that made the reader used in this experiment was reached out, their whitepaper showed that a fast-moving reader with respect to tag typically yields higher RSSI than a slow moving one. Additionally, the phase of the signal returned from the tag relative to the transmitted signal leads to an increased or decreased sensitivity at the reader. And if tag and reader move relative to each other, it will result in covering a range of phase variations including the favored ones.

\subsection{Free-Air vs. Ice Results}

To compare the results between Air and Ice, front-facing antenna was used as seen in the figure 21. The figure shows how the tags were placed on the asphalt road and covered with 2.5 inches of Ice. Results captured in tables 8,9 and 10 are as follows:

- Ice really diminished the signal power, so much so that tags were not being read. Therefore, for trial purposes reader's power was increased to $31.5 \mathrm{dBm}$ with overall power at up from $36.1 \mathrm{dBm}$ 


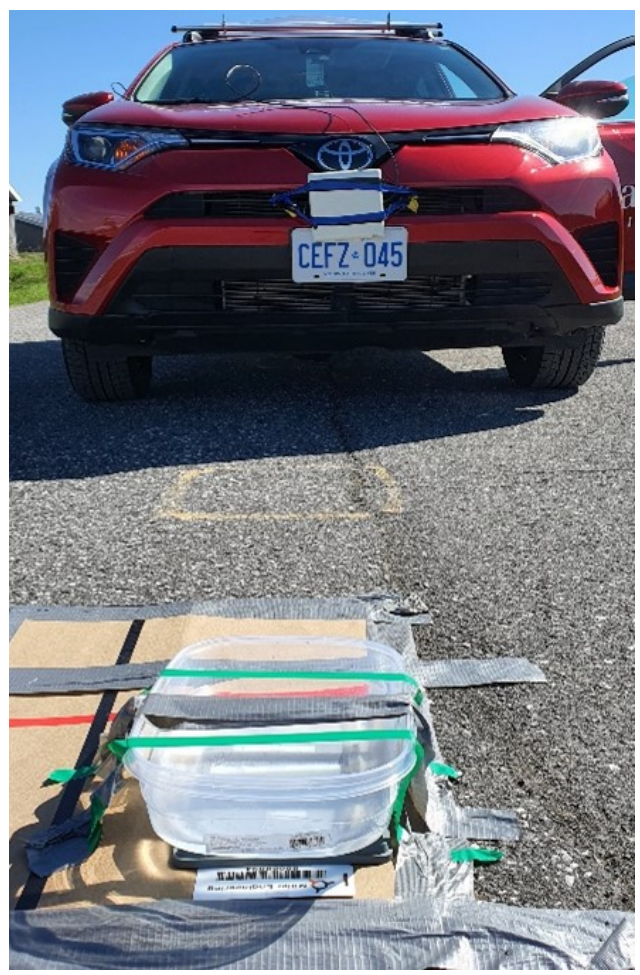

Figure 22: Shows $2.5 \mathrm{cms}$ of Water poured into a plastic container and placed over tags.

to $37.6 \mathrm{dBm}$. Despite this increase in $41 \%$ power, half the tags were not read.

- Therefore, Ice diminished the signal power more than Snow did.

- Tag Read Count was also immeasurable since most of the tags were unread.

- Time per tag read in Ice was 34.4 milliseconds (msec) in comparison to $25.7 \mathrm{msec}$ of Free Air. This means that it took $33 \%$ or one-third more time to read a tag in Ice. Recall that read time in Snow vs. Air were comparable.

\subsection{Free-Air vs. Water}

To study the impact of water on tags' read count and signal power, about 2.5 centimeters of water was poured into the plastic container placed over the tags. Since the container was not a conductor, it was expected not to have an impact on the signal power or Tag Read Count. Later experiment conducted showed that the plastic container indeed did not have a quantifiable impact on the signal power or Tag 




Figure 23: Shows tags placed over unpaved path (left) and 4 inches of underground earth (middle) covered with 0.5 inch of soil (right).

Read Count. The setup is shown in figure 22. Results captured in tables 11, 12 and 13 are as follows:

- Just as Ice, $2.5 \mathrm{cms}$ of Water really diminished the signal power. 6 out of 7 tags were unread in Water even when the experiments were conducted with higher $37.6 \mathrm{dBm}$. Therefore, tag RSSI could not really be compared.

- Water diminished the signal power the same as Ice if not more.

- Tag Read Count was also immeasurable since most of the tags were unread.

- Time (msec) per tag read in Water was $16 \mathrm{msec}$ while in Air was $25.7 \mathrm{msec}$, which is $60 \%$ less than Air. Since most of the tags were unread in Water and a very few data points collected, it could have skewed the reading.

\subsection{Free-Air vs. Underground}

If AVs are to use RFID technology, one important consideration to find is how RFID fares when tags are embedded underground as one of the likely cases is that they will be buried under the asphalt 
road. Therefore, to study the impact on the signal power and Tag Read Count on tags when embedded underground, the tags were placed underground in a 4-inch-deep unpaved earth and covered with half an inch of soil. The setup is shown in figure 23. Results are captured in tables 14,15 and 16 . Results demonstrated:

- In Air, all the tags were read. Placing tags underground diminished the signal power such that 5 out of 7 tags were unread even when the experiments were conducted with higher $37.6 \mathrm{dBm}$.

- Tag Read Count comparison between Air and Embedded-Underground tags were not possible since most of the latter tags were unread. In Air, the average of all the tags over various speeds was about 5 .

- Time (msec) per tag read in Air was about 15 msec while that of Embedded Underground was 71 msec or astounding 3.75 times more. This however could be a bit skewed owing to fewer reads of the latter tags.

- Results with Single Passive Tag Antenna were not impressive.

\subsubsection{Results (Tables) of Single Passive Antenna}


Table 2: RSSI in Free-Air and 6.5 inches of snow at various car speeds with downward-facing single antenna.

\begin{tabular}{|c|c|c|c|c|c|c|c|c|c|c|}
\hline Tag \# & \multicolumn{2}{|l|}{ Conf. B } & \multicolumn{2}{|c|}{16} & \multicolumn{2}{|c|}{18} & \multicolumn{2}{|c|}{19} & \multicolumn{2}{|c|}{24} \\
\hline $\begin{array}{l}\text { Speed } \\
(\mathrm{km} / \mathrm{h})\end{array}$ & $\begin{array}{l}\text { Power } \\
(\mathrm{dBm})\end{array}$ & $\begin{array}{l}\text { Power } \\
\text { in Snow } \\
(\mathrm{dBm})\end{array}$ & $\begin{array}{l}\text { Power } \\
(\mathrm{dBm})\end{array}$ & $\begin{array}{l}\text { Power } \\
\text { in Snow } \\
(\mathrm{dBm})\end{array}$ & $\begin{array}{l}\text { Power } \\
(\mathrm{dBm})\end{array}$ & $\begin{array}{l}\text { Power } \\
\text { in Snow } \\
(\mathrm{dBm})\end{array}$ & $\begin{array}{l}\text { Power } \\
(\mathrm{dBm})\end{array}$ & $\begin{array}{l}\text { Power } \\
\text { in Snow } \\
(\mathrm{dBm})\end{array}$ & $\begin{array}{l}\text { Power } \\
(\mathrm{dBm})\end{array}$ & $\begin{array}{l}\text { Power } \\
\text { in Snow } \\
(\mathrm{dBm})\end{array}$ \\
\hline 0 & -45 & -53 & -43 & -64 & -51 & -77 & -52 & -62 & -48 & -78 \\
\hline 5 & -61 & -49 & -63 & -72 & -67 & -75 & -56 & -63 & -69 & -80 \\
\hline 10 & -34 & -46 & -51 & -55 & -69 & -76 & -70 & -62 & -66 & -74 \\
\hline 20 & -51 & -46 & -49 & -60 & -65 & -74 & -70 & -47 & -66 & -78 \\
\hline 40 & -36 & -40 & -63 & -48 & -66 & -74 & -52 & -43 & -62 & -68 \\
\hline 60 & -45 & -47 & -51 & -55 & -66 & -67 & -69 & -55 & -66 & -74 \\
\hline $\begin{array}{l}\text { Avg. of } \\
\text { Readings } \\
(\mathrm{dBm})\end{array}$ & -45.3 & -46.8 & -53.3 & -59 & -64 & -73.8 & -61.5 & -55.3 & -62.8 & -75.3 \\
\hline
\end{tabular}


Table 3: Tag Read Count readings in air and 6.5 inches of snow at various car speeds with downwardfacing single antenna

\begin{tabular}{|c|c|c|c|c|c|c|c|c|c|c|}
\hline Tag ID & \multicolumn{2}{|c|}{ Conf. B } & \multicolumn{2}{|c|}{16} & \multicolumn{2}{|c|}{18} & \multicolumn{2}{|c|}{19} & \multicolumn{2}{|c|}{24} \\
\hline Speed & Num & Num & Num & Num & Num & Num & Num & Num & Num & Num \\
\hline$(\mathrm{km} / \mathrm{h})$ & Reads & Reads in & Reads & Reads in & Reads & Reads in & Reads & Reads in & Reads & Reads in \\
\hline & & Snow & & Snow & & Snow & & Snow & & Snow \\
\hline 5 & 11 & 8 & 10 & 18 & 10 & 28 & 10 & 19 & 13 & 28 \\
\hline 10 & 3 & 2 & 3 & 5 & 5 & 8 & 4 & 7 & 5 & 8 \\
\hline 20 & 3 & 2 & 2 & 3 & 4 & 4 & 3 & 3 & 4 & 5 \\
\hline 40 & 2 & 1 & 2 & 2 & 2 & 3 & 2 & 2 & 1 & 3 \\
\hline 60 & 1 & 1 & 1 & 1 & 1 & 1 & 1 & 1 & 2 & 2 \\
\hline Avg. of & 4 & 2.8 & 3.6 & 5.8 & 4.4 & 8.8 & 4 & 6.4 & 5 & 9.2 \\
\hline Readings & & & & & & & & & & \\
\hline
\end{tabular}

Table 4: Tag Read Time in snow versus without snow in downward-facing single antenna

\begin{tabular}{|l|c|c|}
\hline & No Snow & Snow \\
\hline Total & 855 & 1575 \\
Read Time & & \\
(msec) & & \\
\hline Total Num & 105 & 165 \\
Reads & & \\
\hline Time(msec) & 8.1 & 9.5 \\
per Read & & \\
\hline
\end{tabular}


Table 5: Power (RSSI) in Free-Air vs. 4 inches of Snow at various car speeds with backward-facing single antenna orientation.

\begin{tabular}{|c|c|c|c|c|c|c|c|c|c|c|}
\hline Tag ID & \multicolumn{2}{|l|}{ Conf. B } & \multicolumn{2}{|c|}{9} & \multicolumn{2}{|c|}{16} & \multicolumn{2}{|c|}{18} & \multicolumn{2}{|c|}{24} \\
\hline $\begin{array}{l}\text { Speed } \\
(\mathrm{km} / \mathrm{h})\end{array}$ & $\begin{array}{l}\text { Power } \\
(\mathrm{dBm})\end{array}$ & $\begin{array}{l}\text { Power } \\
\text { in Snow } \\
(\mathrm{dBm})\end{array}$ & $\begin{array}{l}\text { Power } \\
(\mathrm{dBm})\end{array}$ & $\begin{array}{l}\text { Power } \\
\text { in Snow } \\
(\mathrm{dBm})\end{array}$ & $\begin{array}{l}\text { Power } \\
(\mathrm{dBm})\end{array}$ & $\begin{array}{l}\text { Power } \\
\text { in Snow } \\
(\mathrm{dBm})\end{array}$ & $\begin{array}{l}\text { Power } \\
(\mathrm{dBm})\end{array}$ & $\begin{array}{l}\text { Power } \\
\text { in Snow } \\
(\mathrm{dBm})\end{array}$ & $\begin{array}{l}\text { Power } \\
(\mathrm{dBm})\end{array}$ & $\begin{array}{l}\text { Power } \\
\text { in Snow } \\
(\mathrm{dBm})\end{array}$ \\
\hline 0 & -48 & -49 & -51 & -68 & -59 & -66 & -49 & -73 & -49 & -68 \\
\hline 20 & -48 & -55 & -75 & -74 & -74 & -75 & -65 & -75 & -66 & -72 \\
\hline 40 & -47 & -48 & -77 & -74 & -82 & -80 & -65 & -67 & -66 & -70 \\
\hline 60 & -48 & No Read & -79 & -74 & -70 & -80 & -53 & -63 & -60 & -70 \\
\hline 80 & -43 & No Read & -70 & -79 & -72 & -72 & -62 & -70 & -49 & -64 \\
\hline 90 & -40 & No Read & -46 & -76 & -43 & -60 & -61 & -67 & -51 & -74 \\
\hline $\begin{array}{l}\text { Av. of } \\
\text { Readings } \\
(\mathrm{dBm})\end{array}$ & -45.7 & NA & -66.3 & -74.2 & -66.7 & -72.2 & -59.2 & -69.2 & -56.8 & -69.7 \\
\hline
\end{tabular}


Table 6: Tag Read Count in Ambient Air and 4 inches of Snow at various car speeds with backward-facing single antenna orientation.

\begin{tabular}{|c|c|c|c|c|c|c|c|c|c|c|}
\hline Tag ID & \multicolumn{2}{|c|}{ Conf. B } & \multicolumn{2}{|c|}{9} & \multicolumn{2}{|c|}{16} & \multicolumn{2}{|c|}{18} & \multicolumn{2}{|c|}{24} \\
\hline $\begin{array}{l}\text { Speed } \\
(\mathrm{km} / \mathrm{h})\end{array}$ & $\begin{array}{l}\text { Num } \\
\text { Reads }\end{array}$ & $\begin{array}{l}\text { Num } \\
\text { Reads in } \\
\text { Snow }\end{array}$ & $\begin{array}{l}\text { Num } \\
\text { Reads }\end{array}$ & $\begin{array}{l}\text { Num } \\
\text { Reads in } \\
\text { Snow }\end{array}$ & $\begin{array}{l}\text { Num } \\
\text { Reads }\end{array}$ & $\begin{array}{l}\text { Num } \\
\text { Reads in } \\
\text { Snow }\end{array}$ & $\begin{array}{l}\text { Num } \\
\text { Reads }\end{array}$ & $\begin{array}{l}\text { Num } \\
\text { Reads in } \\
\text { Snow }\end{array}$ & $\begin{array}{l}\text { Num } \\
\text { Reads }\end{array}$ & $\begin{array}{l}\text { Num } \\
\text { Reads in } \\
\text { Snow }\end{array}$ \\
\hline 20 & 3 & 1 & 10 & 6 & 5 & 7 & 5 & 4 & 7 & 6 \\
\hline 40 & 2 & 1 & 8 & 2 & 5 & 4 & 3 & 1 & 7 & 2 \\
\hline 60 & 1 & No Read & 6 & 2 & 4 & 3 & 1 & 1 & 4 & 3 \\
\hline 80 & 1 & No Read & 3 & 3 & 2 & 2 & 2 & 2 & 2 & 2 \\
\hline 90 & 1 & No Read & 2 & 3 & 1 & 1 & 2 & 1 & 2 & 2 \\
\hline $\begin{array}{l}\text { Total } \\
\text { Read } \\
\text { Count }\end{array}$ & 1.6 & NA & 5.8 & 3.2 & 3.4 & 3.4 & 2.6 & 1.8 & 4.4 & 3 \\
\hline
\end{tabular}

Table 7: Tag Read Time in Ambient Air vs. 4 inches Snow in backward-facing single antenna orientation.

\begin{tabular}{|l|c|c|}
\hline & Ambient & Snow \\
\hline Total Read Time & 1309 & 849 \\
$(\mathrm{msec})$ & & \\
\hline Total Num & 89 & 59 \\
\hline Reads & 14.7 & 14.4 \\
\hline Time(msec)/ & & \\
\hline Read & & \\
\hline
\end{tabular}


Table 8: Comparison of RSSI in Ambient Air vs. 2.5 inches of Ice in single-front-antenna orientation.

\begin{tabular}{|c|c|c|c|c|c|c|c|c|c|c|c|c|c|c|}
\hline \multirow{2}{*}{$\begin{array}{l}\text { Tag\# } \\
\text { Speed } \\
(\mathrm{km} / \mathrm{h})\end{array}$} & \multicolumn{2}{|c|}{9} & \multicolumn{2}{|c|}{18} & \multicolumn{2}{|c|}{24} & \multicolumn{2}{|l|}{ ExoP } & \multicolumn{2}{|l|}{ ConP } & \multicolumn{2}{|l|}{ BAP1 } & \multicolumn{2}{|l|}{ BAP2 } \\
\hline & $\begin{array}{l}\text { RSSI } \\
(\mathrm{dBm})\end{array}$ & $\begin{array}{l}\text { RSSI Ice } \\
\text { (dBm) }\end{array}$ & $\begin{array}{l}\text { RSSI } \\
(\mathrm{dBm})\end{array}$ & $\begin{array}{l}\text { RSSI Ice } \\
(\mathrm{dBm})\end{array}$ & $\begin{array}{l}\text { RSSI } \\
(\mathrm{dBm})\end{array}$ & $\begin{array}{l}\text { RSSI Ice } \\
(\mathrm{dBm})\end{array}$ & $\begin{array}{l}\text { RSSI } \\
(\mathrm{dBm})\end{array}$ & $\begin{array}{l}\text { RSSI Ice } \\
(\mathrm{dBm})\end{array}$ & $\begin{array}{l}\text { RSSI } \\
(\mathrm{dBm})\end{array}$ & $\begin{array}{l}\text { RSSI Ice } \\
(\mathrm{dBm})\end{array}$ & $\begin{array}{l}\text { RSSI } \\
(\mathrm{dBm})\end{array}$ & $\begin{array}{l}\text { RSSI Ice } \\
(\mathrm{dBm})\end{array}$ & $\begin{array}{l}\text { RSSI } \\
(\mathrm{dBm})\end{array}$ & $\begin{array}{l}\text { RSSI Ice } \\
(\mathrm{dBm})\end{array}$ \\
\hline 0 & -65 & No Read & -62 & -79 & -63 & No Read & -51 & -73 & -53 & No Read & No Read & No Read & -66 & -81 \\
\hline 10 & -67 & No Read & -63 & -77 & -70 & No Read & -67 & -79 & -52 & No Read & No Read & No Read & -81 & -80 \\
\hline 30 & -71 & No Read & -66 & -77 & -67 & No Read & -59 & -69 & -63 & No Read & No Read & No Read & No Read & -80 \\
\hline 40 & -72 & No Read & -66 & No Read & -63 & No Read & -64 & -68 & -52 & No Read & No Read & No Read & -82 & -80 \\
\hline 60 & -66 & No Read & -65 & No Read & -65 & No Read & -55 & -70 & -55 & No Read & No Read & No Read & -78 & -75 \\
\hline
\end{tabular}

Table 9: Tag Read Count in Ambient Air vs. 2.5 inches of Ice in single-front-antenna orientation.

\begin{tabular}{|c|c|c|c|c|c|c|c|c|c|c|c|c|c|c|}
\hline $\begin{array}{l}\text { Tag\# } \\
\text { Speed } \\
(\mathrm{km} / \mathrm{h})\end{array}$ & $\begin{array}{l}\text { Read } \\
\text { Count }\end{array}$ & $\begin{array}{l}\text { Read } \\
\text { Count } \\
\text { (Ice) }\end{array}$ & $\begin{array}{l}\text { Read } \\
\text { Count }\end{array}$ & $\begin{array}{l}\text { Read } \\
\text { Count } \\
\text { (Ice) }\end{array}$ & $\begin{array}{l}\text { Read } \\
\text { Count }\end{array}$ & $\begin{array}{l}\text { Read } \\
\text { Count } \\
\text { (Ice) }\end{array}$ & $\begin{array}{l}\text { Read } \\
\text { Count }\end{array}$ & $\begin{array}{l}\text { Read } \\
\text { Count } \\
\text { (Ice) }\end{array}$ & $\begin{array}{l}\text { Read } \\
\text { Count }\end{array}$ & $\begin{array}{l}\text { Read } \\
\text { Count } \\
\text { (Ice) }\end{array}$ & $\begin{array}{l}\text { Read } \\
\text { Count }\end{array}$ & $\begin{array}{l}\text { Read } \\
\text { Count } \\
\text { (Ice) }\end{array}$ & $\begin{array}{l}\text { Read } \\
\text { Count }\end{array}$ & $\begin{array}{l}\text { Read } \\
\text { Count } \\
\text { (Ice) }\end{array}$ \\
\hline 10 & 7 & No Read & 4 & 6 & 7 & No Read & 17 & 11 & 4 & No Read & No Read & No Read & 1 & 1 \\
\hline 30 & 3 & No Read & 2 & 1 & 2 & No Read & 6 & 5 & 1 & No Read & No Read & No Read & No Read & 1 \\
\hline 40 & 3 & No Read & 2 & No Read & 2 & No Read & 5 & 4 & 2 & No Read & No Read & No Read & 1 & 1 \\
\hline 60 & 2 & No Read & 1 & No Read & 2 & No Read & 4 & 3 & 1 & No Read & No Read & No Read & 1 & 1 \\
\hline
\end{tabular}


Table 10: Tag Read Time in Ambient Air vs. 2.5 inches Ice in single-front-antenna orientation.

\begin{tabular}{|l|c|c|}
\hline & $\begin{array}{l}\text { Ambient } \\
\text { Air }\end{array}$ & Ice \\
\hline $\begin{array}{l}\text { Total } \\
\text { Read Time } \\
\text { (msec) }\end{array}$ & 3290 & 1652 \\
\hline \begin{tabular}{ll|} 
Tag Read \\
Count
\end{tabular} & 128 & 48 \\
\hline $\begin{array}{l}\text { Time(msec) } \\
\text { Read }\end{array}$ & 25.7 & 34.4 \\
\hline
\end{tabular}

Table 11: Comparison of RSSI in Ambient Air vs. $2.5 \mathrm{cms}$ of Water in single-front-antenna orientation.




Table 12: Tag Read Count in Ambient Air vs. $2.5 \mathrm{cms}$ of Water in single-front-antenna orientation.

\begin{tabular}{|c|c|c|c|c|c|c|c|c|c|c|c|c|c|c|}
\hline \multirow{3}{*}{$\begin{array}{l}\text { Tag\# } \\
\text { Speed } \\
(\mathrm{km} / \mathrm{h})\end{array}$} & \multicolumn{2}{|c|}{9} & \multicolumn{2}{|c|}{18} & \multicolumn{2}{|c|}{24} & \multicolumn{2}{|l|}{ ExoP } & \multicolumn{2}{|l|}{ ConP } & \multicolumn{2}{|l|}{ BAP1 } & \multicolumn{2}{|l|}{ BAP2 } \\
\hline & Read & Read & Read & Read & Read & Read & Read & Read & Read & Read & Read & Read & Read & Read \\
\hline & (Air) & (Water) & (Air) & (Water) & (Air) & (Water) & (Air) & (Water) & (Air) & (Water) & (Air) & (Water) & (Air) & (Water) \\
\hline 10 & 7 & No Read & 4 & No Read & 7 & 12 & 17 & No Read & 4 & No Read & No Read & No Read & 1 & No Read \\
\hline 30 & 3 & No Read & 2 & No Read & 2 & 4 & 6 & No Read & 1 & No Read & No Read & No Read & No Read & 1 \\
\hline 40 & 3 & No Read & 2 & No Read & 2 & 3 & 5 & No Read & 2 & No Read & No Read & No Read & 1 & No Read \\
\hline 60 & 2 & No Read & 1 & No Read & 2 & 2 & 4 & No Read & 1 & No Read & No Read & No Read & 1 & No Read \\
\hline
\end{tabular}

Table 13: Tag Read Time in Ambient Air vs. 2.5 cms of Water in single-front-antenna configuration.

\begin{tabular}{|l|c|c|}
\hline & Ambient & Water \\
Air & 3290 & 209 \\
Read Time & & \\
$($ msec $)$ & 128 & 13 \\
\hline Tag Read & 128 \\
Count & 25.7 & 16 \\
\hline Time(msec) & & \\
\hline Per Read & \\
\hline
\end{tabular}


Table 14: Comparison of RSSI in Ambient Air vs. 4 inches of Underground covered with 0.5 inch of soil in single-front-antenna orientation.

\begin{tabular}{|c|c|c|c|c|c|c|c|c|c|c|c|c|c|c|}
\hline Tag\# & & & & 8 & 24 & & ExoP & & ConP & & BAP1 & & BAP2 & \\
\hline $\begin{array}{l}\text { Speed } \\
(\mathrm{km} / \mathrm{h})\end{array}$ & $\begin{array}{l}\text { RSSI } \\
(\mathrm{dBm})- \\
\text { Air }\end{array}$ & $\begin{array}{l}\text { RSSI } \\
(\mathrm{dBm})- \\
\text { Under- } \\
\text { ground }\end{array}$ & $\begin{array}{l}\text { RSSI } \\
(\mathrm{dBm})- \\
\text { Air }\end{array}$ & $\begin{array}{l}\text { RSSI } \\
(\mathrm{dBm})- \\
\text { Under- } \\
\text { ground }\end{array}$ & $\begin{array}{l}\text { RSSI } \\
(\mathrm{dBm}) \\
\text { Air }\end{array}$ & $\begin{array}{l}\text { RSSI } \\
(\mathrm{dBm})- \\
\text { Under- } \\
\text { ground }\end{array}$ & $\begin{array}{l}\text { RSSI } \\
(\mathrm{dBm}) \\
\text { Air }\end{array}$ & $\begin{array}{l}\text { RSSI } \\
(\mathrm{dBm}) \\
\text { Under- } \\
\text { ground }\end{array}$ & $\begin{array}{l}\text { RSSI } \\
(\mathrm{dBm}) \\
\text { Air }\end{array}$ & $\begin{array}{l}\text { RSSI } \\
(\mathrm{dBm})- \\
\text { Under- } \\
\text { ground }\end{array}$ & $\begin{array}{l}\text { RSSI } \\
(\mathrm{dBm})- \\
\text { Air }\end{array}$ & $\begin{array}{l}\text { RSSI } \\
(\mathrm{dBm})- \\
\text { Under- } \\
\text { ground }\end{array}$ & $\begin{array}{l}\text { RSSI } \\
\text { (dBm) - } \\
\text { Air }\end{array}$ & $\begin{array}{l}\text { RSSI } \\
(\mathrm{dBm}) \\
\text { Under- } \\
\text { ground }\end{array}$ \\
\hline 10 & -71 & -82 & -56 & No Read & -66 & No Read & -78 & -55 & -62 & -66 & -50 & No Read & -79 & -82 \\
\hline 20 & -62 & -82 & -57 & No Read & -62 & No Read & -79 & -80 & -53 & No Read & -56 & No Read & -81 & -82 \\
\hline 30 & -58 & No Read & -54 & No Read & -67 & No Read & -48 & -80 & -56 & No Read & -47 & No Read & -81 & -81 \\
\hline 40 & -62 & -82 & -57 & No Read & -66 & No Read & -71 & -78 & -58 & No Read & -53 & No Read & -82 & -80 \\
\hline 50 & -58 & -81 & -63 & No Read & -68 & No Read & -52 & -75 & -49 & No Read & -45 & No Read & -79 & -78 \\
\hline 60 & -62 & No Read & -55 & No Read & -69 & No Read & -51 & -79 & -57 & -56 & -45 & No Read & -82 & -79 \\
\hline 70 & -66 & No Read & -56 & No Read & -66 & No Read & -54 & -79 & -54 & No Read & -48 & No Read & -82 & -78 \\
\hline $\begin{array}{l}\text { Avg. of } \\
\text { Readings }\end{array}$ & -62.7 & -81.8 & -56.9 & NA & -66.3 & $\mathrm{NA}$ & -61.9 & -75.1 & -55.6 & NA & -49.1 & NA & -80.9 & -80 \\
\hline
\end{tabular}

Table 15: Tag Read Count in Ambient Air vs. 4 inches of underground covered with 0.5 inch of soil in single-front-antenna orientation.

\begin{tabular}{|c|c|c|c|c|c|c|c|c|c|c|c|c|c|c|}
\hline \multirow{2}{*}{$\frac{\mid \text { Tag\# }}{\mid \begin{array}{l}\text { Speed } \\
(\mathrm{km} / \mathrm{h})\end{array}}$} & \multicolumn{2}{|c|}{9} & \multicolumn{2}{|c|}{18} & \multicolumn{2}{|c|}{24} & \multicolumn{2}{|l|}{ ExoP } & \multicolumn{2}{|l|}{ ConP } & \multicolumn{2}{|l|}{ BAP1 } & \multicolumn{2}{|l|}{ BAP2 } \\
\hline & $\begin{array}{l}\text { Read } \\
\text { Count - } \\
\text { Air }\end{array}$ & $\begin{array}{l}\text { Read } \\
\text { Count - } \\
\text { Air }\end{array}$ & $\begin{array}{l}\text { Read } \\
\text { Count - } \\
\text { Under- } \\
\text { ground }\end{array}$ & $\begin{array}{l}\text { Tag } \\
\text { Read } \\
\text { Count - } \\
\text { Under- } \\
\text { ground }\end{array}$ & $\begin{array}{l}\text { Tag } \\
\text { Read } \\
\text { Count - } \\
\text { Air }\end{array}$ & $\begin{array}{l}\text { Tag } \\
\text { Read } \\
\text { Count - } \\
\text { Under- } \\
\text { ground }\end{array}$ & $\begin{array}{l}\text { Tag } \\
\text { Read } \\
\text { Count } \\
\text { Air }\end{array}$ & $\begin{array}{l}\text { Tag } \\
\text { Read } \\
\text { Count } \\
\text { Under- } \\
\text { ground }\end{array}$ & $\begin{array}{l}\text { Tag } \\
\text { Read } \\
\text { Count - } \\
\text { Air }\end{array}$ & $\begin{array}{l}\text { Tag } \\
\text { Read } \\
\text { Count - } \\
\text { Under- } \\
\text { ground }\end{array}$ & $\begin{array}{l}\text { Tag } \\
\text { Read } \\
\text { Count } \\
\text { Air }\end{array}$ & $\begin{array}{l}\text { Tag } \\
\text { Read } \\
\text { Count - } \\
\text { Under- } \\
\text { ground }\end{array}$ & $\begin{array}{l}\text { Tag } \\
\text { Read } \\
\text { Count - } \\
\text { Air }\end{array}$ & \begin{tabular}{|l} 
Tag \\
Read \\
Count \\
Under- \\
ground
\end{tabular} \\
\hline 10 & 16 & 1 & 12 & No Read & 13 & No Read & 26 & 2 & 6 & 1 & 8 & No Read & 1 & 1 \\
\hline 20 & 10 & 1 & 8 & No Read & 9 & No Read & 16 & 1 & 4 & No Read & 6 & No Read & 1 & 1 \\
\hline 30 & 5 & No Read & 5 & No Read & 5 & No Read & 9 & 1 & 3 & No Read & 3 & No Read & 1 & 1 \\
\hline 40 & 5 & 1 & 4 & No Read & 5 & No Read & 8 & 1 & 3 & No Read & 3 & No Read & 1 & 1 \\
\hline 50 & 5 & 1 & 4 & No Read & 3 & No Read & 7 & 1 & 2 & No Read & 2 & No Read & 1 & 1 \\
\hline 60 & 3 & No Read & 3 & No Read & 3 & No Read & 5 & 1 & 2 & 1 & 2 & No Read & 1 & 1 \\
\hline 70 & 3 & No Read & 2 & No Read & 2 & No Read & 4 & 1 & 1 & No Read & 2 & No Read & 1 & 1 \\
\hline $\begin{array}{l}\text { Avg. of } \\
\text { Readings }\end{array}$ & 6.7 & NA & 5.4 & NA & 5.7 & NA & 10.7 & 1.1 & 3 & NA & 3.7 & NA & 1 & -80 \\
\hline
\end{tabular}


Table 16: Tag Read Time in Ambient Air vs. Underground in single-front-antenna configuration.

\begin{tabular}{|l|c|c|}
\hline & $\begin{array}{l}\text { Ambient } \\
\text { Air }\end{array}$ & $\begin{array}{c}\text { Underground } \\
\text { With Soil }\end{array}$ \\
\hline Total & 3836 & 1497 \\
Read Time & & \\
\hline (msec) & & \\
\hline Tag Read & 254 & 21 \\
Count & & \\
\hline Time(msec) & 15.1 & 71.3 \\
Per Read & & \\
\hline
\end{tabular}




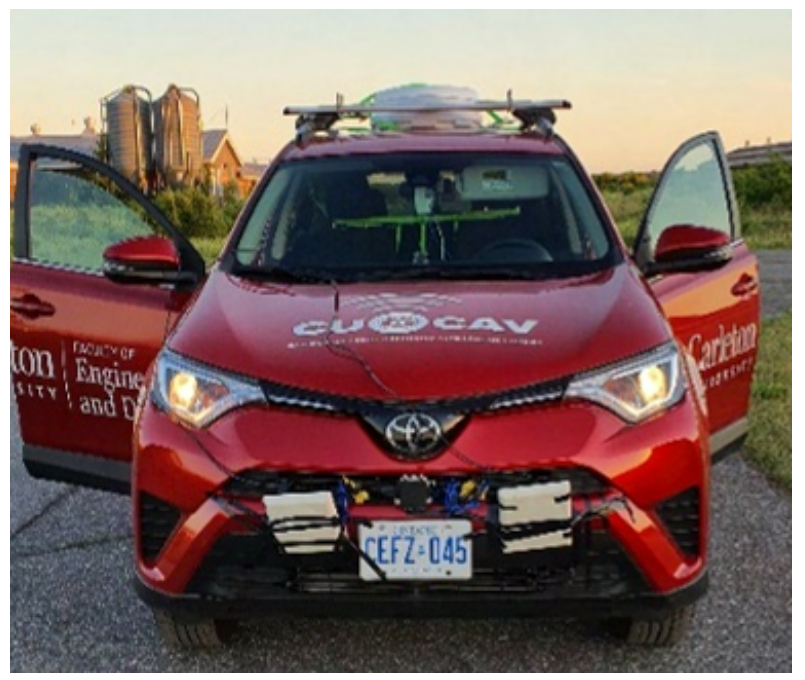

Figure 24: Dual-Antenna Configuration.

\section{Results With Passive and BAP Tags (Dual Antenna)}

Ice and water really diminished RSSI such that most of the tags were not read. Of those that were read, their RSSI was lower than in free air. This is when dual-antenna configuration was tried since literature suggests that one of the ways to increase the RF system's performance was to use multiple antennas [10]. To transmit and receive power, only one antenna was active at a time (since the two antennas were connected to the same reader), and the reader dynamically switched between the two. The other option in the reader's software was to activate the readers for equal time but it was unsuitable for our dynamic application. Dual-Antenna configuration dramatically improved the results. The main reason is that it increases the coverage area and transmits the power at increased angles (azimuth). The other possible reason could be that while one antenna powers the tag's IC, the other antenna reads it. Although, this would be more probable in case of two readers having one antenna each, where both are simultaneously active, so while one transmits the power, the other receives it. All experiments conducted with dual-antenna configuration were at $37.6 \mathrm{dBm}$. Dual Antenna configuration is shown in figure 24 . 


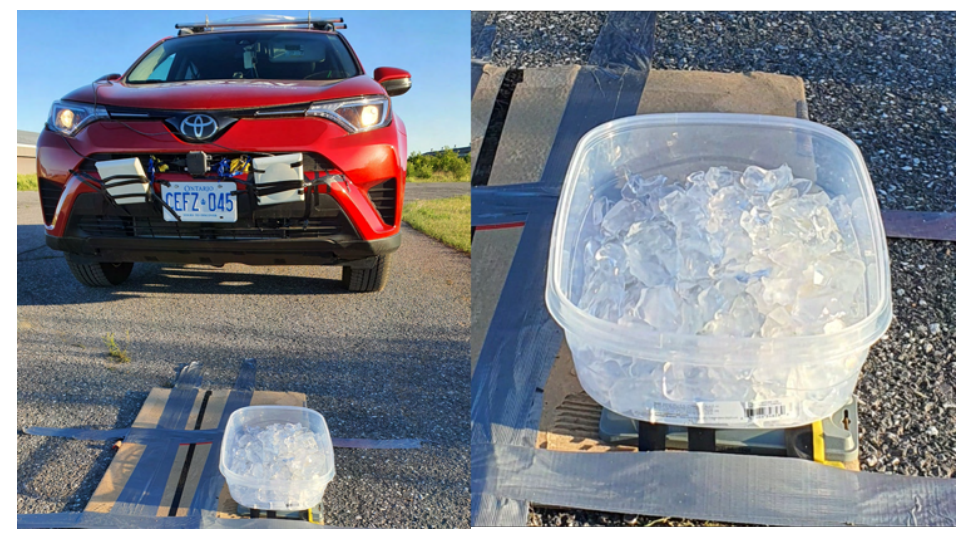

Figure 25: Setup shows 2 inches of Ice placed on tags in a dual-antenna configuration.

\subsection{Free-Air vs. Ice}

To compare the results between Air and Ice in dual-antenna configuration, the plastic container was topped with 2 inches of Ice and placed over the tags. It can be seen in Figure 25. Results are captured in tables 17,18 , and 19. Results demonstrated:

- 6 out of 7 tags were read. This is in stark contrast to the single antenna where only 2 out of 7 tags were fully read and 1 partially read.

- For RSSI, as expected the signal power greatly reduced in Ice as compared to Air - anywhere from 7 to $12 \mathrm{dBm}$. One of the tags was unread while one of the tags surprisingly showed equal power.

- Tag Read count decreased in the presence of Ice.

- In Ice, for about the same $1800 \mathrm{msec}$ of total read time, total tag read count was 40 in comparison to 66 of Air. Thus, Time/Tag Read count was $43.8 \mathrm{msec}$ or about $60 \%$ more in Ice as compared to $27.4 \mathrm{msec}$ in Air.

\subsection{Free-Air vs. Water and Salted Water Results}

To compare the results between Air and Water in dual-antenna configuration, the plastic container was topped with $2.5 \mathrm{cms}$ of Water and placed over the tags. It can be seen in Figure 26. Results are captured 




Figure 26: Setup shows 1 inch of Water placed on tags in a dual-antenna configuration.

in tables 20, 21, and 22. Results demonstrated:

- 5 out of 7 tags were read. This is in stark contrast to the single antenna where only 1 out of 7 tags was read in Water.

- For RSSI, other than the two unread tags, power significantly reduced in Water as compared to Air. The drop was around 12-13 dBm on average for most tags. For one tag the RSSI was comparable while for another one it was surprisingly higher.

- Tag Read count as expected decreased in the presence of Water.

- Tag Read Count in Water was almost half than in Air. Time (msec) per tag read in Water was $19.3 \mathrm{msec}$ or $42 \%$ less as compared to $27.4 \mathrm{msec}$ in Air. This was surprising as Water reduced RSSI and Tag Read Count the most in comparison to Air, Snow and Ice yet its time per tag read was the lowest.

Various cities and municipalities in Canada put salt on the road during Winter to counter the slippery and Icy conditions. Therefore, to find the effect of salt on the RFID, 4 grams of salt was mixed into the water and stirred - seen in figure 27. Since salt when added in Water, makes it a better 


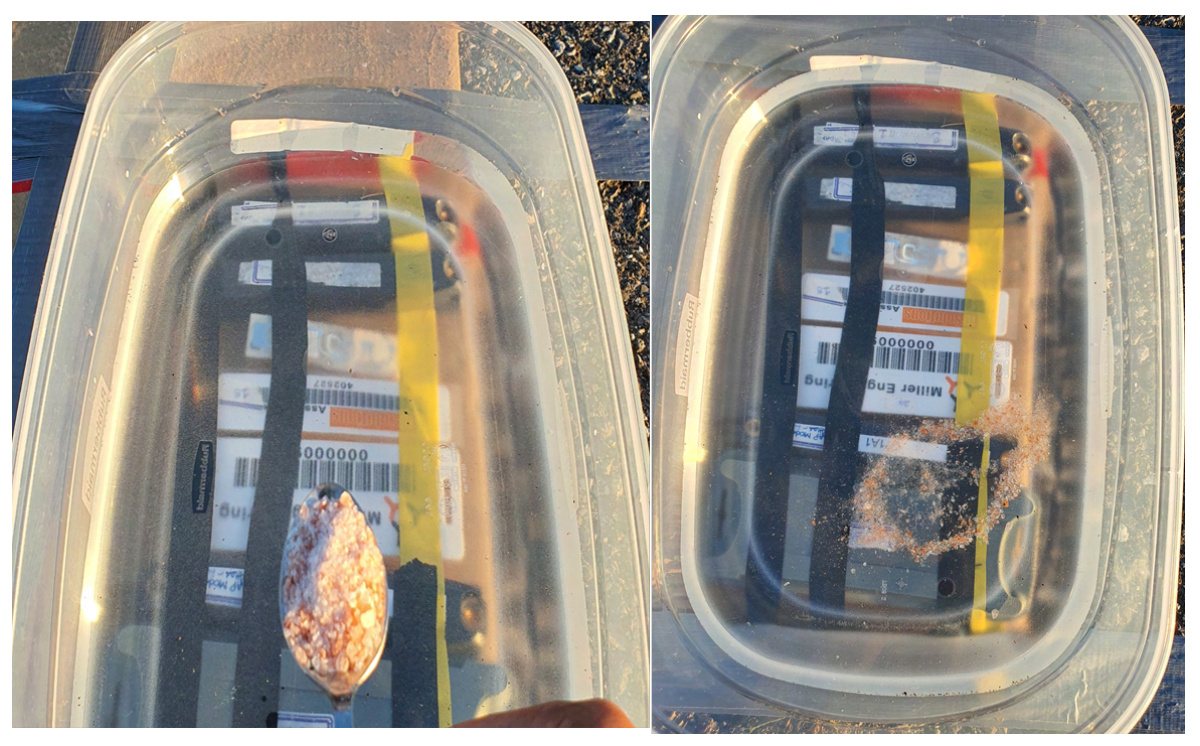

Figure 27: 4 grams of Salt was added in $2.5 \mathrm{cms}$ of Water to measure its effect in dual-antenna configuration.

conductor, the results were expected to be worse than Water without it. Results were captured in tables 23, 24 and 25, and demonstrated: As expected, there was significant impact of salt in Water. Out of 7 tags, 2 were unread while 4 were partially unread. This is because a conducting material absorbs more signal than a non-conductor, and reflects back less energy. As readability of the tags were impacted, so did the Tag Read Count. However, Time (msec) per tag read count was slightly better than in Water. This is perhaps due to a fewer data points.

\subsection{Free-Air vs. Underground Results}

To compare the results of signal power (RSSI) and Tag Read Count on tags when embedded underground with Dual Passive antenna, the tags were embedded underground in a 4-inch-deep unpaved earth and covered with half an inch of soil. The setup is shown in figure 23. Results are captured in tables 26,27 and 28. Results demonstrated:

- In Air, all the tags were read. Placing tags underground diminished the signal power such that 4 out of 7 tags were unread even when the experiments were conducted with higher $37.6 \mathrm{dBm}$. With 
Single Antenna, 5 out of 7 were unread.

- Tag Read Count comparison between Air and Embedded-Underground tags were not possible since most of the latter tags were unread.

- Time (msec) per tag read in Air was about $71.3 \mathrm{msec}$ while that of Embedded Underground was 95.2 msec. This however could be a bit skewed owing to fewer reads in this setup.

- Dual Passive Antenna greatly improved the results in other propagation mediums but in Underground where most of the tags were still unread. Perhaps 4 inch underground is too much for the tags. If the same could be tried with tags embedded underground 2 inches or less, it would be preferable.

\subsubsection{Results (Tables) of Dual Passive Antenna}

Table 17: Comparison of RSSI (dBm) with in Ambient Air vs. 2 inches of Ice in front-facing dual-antenna configuration.

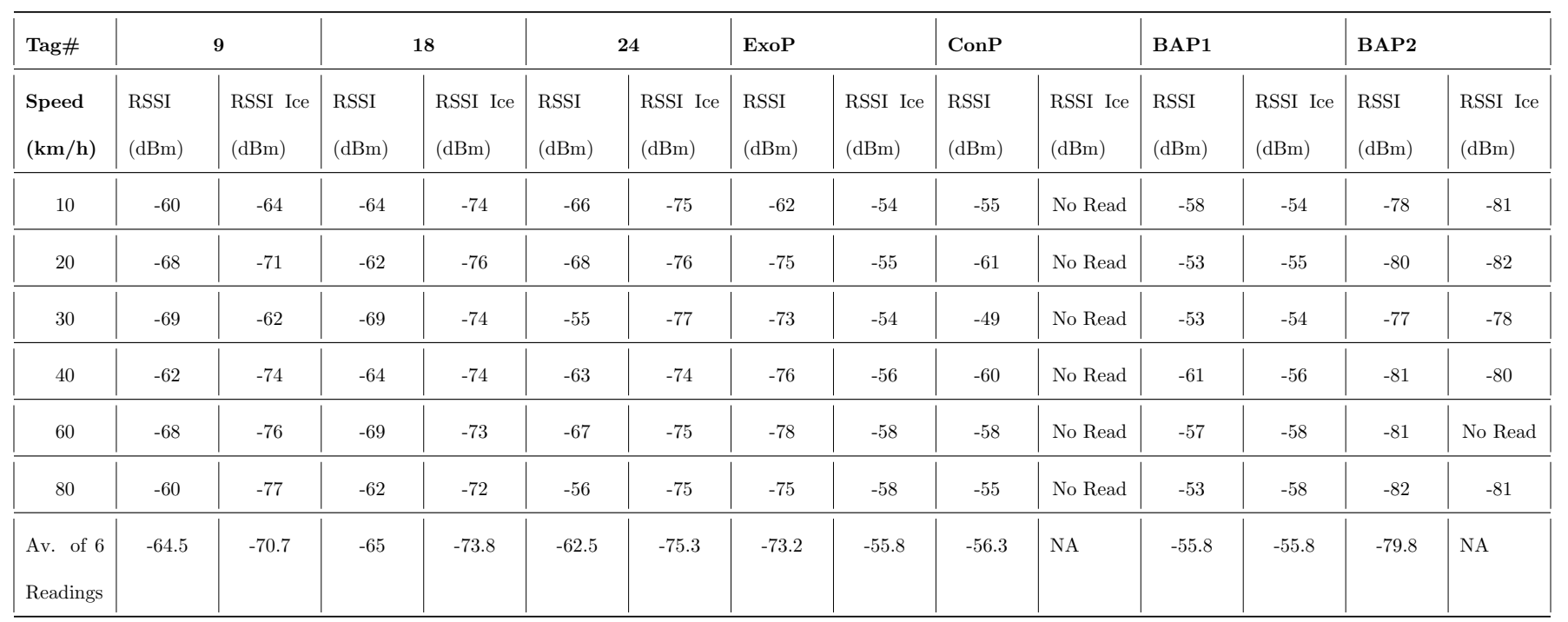


Table 18: Tag Read Count in Ambient Air vs. 2 inches of Ice in front-facing dual-antenna configuration.

\begin{tabular}{|c|c|c|c|c|c|c|c|c|c|c|c|c|c|c|}
\hline \multirow{3}{*}{$\begin{array}{l}\text { Tag\# } \\
\text { Speed } \\
(\mathrm{km} / \mathrm{h})\end{array}$} & \multicolumn{2}{|c|}{9} & \multicolumn{2}{|c|}{18} & \multicolumn{2}{|c|}{24} & \multicolumn{2}{|l|}{ ExoP } & \multicolumn{2}{|c|}{ ConP } & \multicolumn{2}{|c|}{ BAP1 } & \multicolumn{2}{|c|}{ BAP2 } \\
\hline & Read & Read & Read & Read & Read & Read & Read & Read & Read & Read & Read & Read & Read & Read \\
\hline & Rate & Rate Ice & Rate & Rate Ice & Rate & Rate Ice & Rate & Rate Ice & Rate & Rate Ice & Rate & Rate Ice & Rate & Rate Ice \\
\hline 10 & 11 & 3 & 1 & 1 & 1 & 1 & 2 & 1 & 1 & No Read & 1 & 1 & 1 & 1 \\
\hline 20 & 5 & 2 & 1 & 1 & 1 & 1 & 1 & 1 & 1 & No Read & 1 & 1 & 1 & 1 \\
\hline 30 & 4 & 2 & 1 & 1 & 1 & 1 & 1 & 1 & 1 & No Read & 1 & 1 & 1 & 1 \\
\hline 40 & 5 & 2 & 1 & 1 & 1 & 1 & 1 & 1 & 1 & No Read & 1 & 1 & 1 & 1 \\
\hline 60 & 2 & 1 & 1 & 1 & 1 & 1 & 1 & 1 & 1 & No Read & 1 & 1 & 1 & No Read \\
\hline 80 & 2 & 1 & 1 & 1 & 1 & 1 & 1 & 1 & 1 & No Read & 1 & 1 & 1 & 1 \\
\hline $\begin{array}{l}\text { Av. of } \\
\text { Readings }\end{array}$ & 4.8 & 1.8 & 1 & 1 & 1 & 1 & 1.2 & 1 & 1 & NA & 1 & 1 & 1 & $\mathrm{NA}$ \\
\hline
\end{tabular}

Table 19: Tag Read Time in Ambient Air vs. 2 inches of Ice in dual antenna configuration.

\begin{tabular}{|l|c|c|}
\hline & Free Air & Ice \\
\hline Total Read & 1809 & 1750 \\
Time (msec) & & \\
\hline Tag Read & 66 & 40 \\
Count & & \\
\hline Time(msec) & 27.4 & 43.8 \\
Per Read & & \\
\hline
\end{tabular}


Table 20: Comparison of RSSI ( $\mathrm{dBm})$ in Free Air vs. $2.5 \mathrm{cms}$ Water in front-facing dual-antenna configuration.

\begin{tabular}{|c|c|c|c|c|c|c|c|c|c|c|c|c|c|c|}
\hline Tag\# & \multicolumn{2}{|c|}{9} & \multicolumn{2}{|c|}{18} & \multicolumn{2}{|c|}{24} & \multicolumn{2}{|l|}{ ExoP } & \multicolumn{2}{|l|}{ ConP } & \multicolumn{2}{|l|}{ BAP1 } & \multicolumn{2}{|l|}{ BAP2 } \\
\hline $\begin{array}{l}\text { Speed } \\
(\mathrm{km} / \mathrm{h})\end{array}$ & $\begin{array}{l}\text { RSSI } \\
(\mathrm{dBm})\end{array}$ & $\begin{array}{l}\text { RSSI } \\
\text { Water } \\
(\mathrm{dBm})\end{array}$ & $\begin{array}{l}\text { RSSI } \\
(\mathrm{dBm})\end{array}$ & $\begin{array}{l}\text { RSSI } \\
\text { Water } \\
(\mathrm{dBm})\end{array}$ & $\begin{array}{l}\text { RSSI } \\
(\mathrm{dBm})\end{array}$ & $\begin{array}{l}\text { RSSI } \\
\text { Water } \\
(\mathrm{dBm})\end{array}$ & $\begin{array}{l}\text { RSSI } \\
(\mathrm{dBm})\end{array}$ & $\begin{array}{l}\text { RSSI } \\
\text { Water } \\
(\mathrm{dBm})\end{array}$ & $\begin{array}{l}\text { RSSI } \\
(\mathrm{dBm})\end{array}$ & $\begin{array}{l}\text { RSSI } \\
\text { Water } \\
(\mathrm{dBm})\end{array}$ & $\begin{array}{l}\text { RSSI } \\
(\mathrm{dBm})\end{array}$ & $\begin{array}{l}\text { RSSI } \\
\text { Water } \\
(\mathrm{dBm})\end{array}$ & $\begin{array}{l}\text { RSSI } \\
(\mathrm{dBm})\end{array}$ & $\begin{array}{l}\text { RSSI } \\
\text { Water } \\
(\mathrm{dBm})\end{array}$ \\
\hline 10 & -60 & -70 & -64 & -74 & -66 & -79 & -62 & -75 & -55 & No Read & -58 & No Read & -78 & -81 \\
\hline 20 & -68 & -75 & -62 & -74 & -68 & -74 & -75 & -74 & -61 & No Read & -53 & No Read & -80 & -68 \\
\hline 30 & -69 & -79 & -69 & -73 & -55 & -76 & -73 & -75 & -49 & No Read & -53 & No Read & -77 & -79 \\
\hline 40 & -62 & -79 & -64 & -72 & -63 & -75 & -76 & -75 & -60 & No Read & -61 & No Read & -81 & -79 \\
\hline 60 & -68 & -81 & -69 & -74 & -67 & -70 & -78 & -70 & -58 & No Read & -57 & No Read & -81 & -68 \\
\hline 80 & -60 & -80 & -62 & -75 & -56 & -74 & -75 & -73 & -55 & No Read & -53 & No Read & -82 & -83 \\
\hline $\begin{array}{l}\text { Av. of } \\
\text { Readings }\end{array}$ & -64.5 & -77.3 & -65 & -73.7 & -62.5 & -74.7 & -73.2 & -73.7 & -56.3 & NA & -55.8 & NA & -79.8 & -76.3 \\
\hline
\end{tabular}

Table 21: Tag Read Count in Ambient Air vs. 2.5 cms Water in front-facing dual-antenna configuration.

\begin{tabular}{|c|c|c|c|c|c|c|c|c|c|c|c|c|c|c|}
\hline \multirow{4}{*}{$\begin{array}{l}\text { Tag\# } \\
\text { Speed } \\
(\mathrm{km} / \mathrm{h})\end{array}$} & \multicolumn{2}{|c|}{9} & \multicolumn{2}{|c|}{18} & \multicolumn{2}{|c|}{24} & \multicolumn{2}{|l|}{ ExoP } & \multicolumn{2}{|c|}{ ConP } & \multicolumn{2}{|c|}{ BAP1 } & \multicolumn{2}{|c|}{ BAP2 } \\
\hline & Read & Read & Read & Read & Read & Read & Read & Read & Read & Read & Read & Read & Read & Read \\
\hline & Rate & Rate & Rate & Rate & Rate & Rate & Rate & Rate & Rate & Rate & Rate & Rate & Rate & Rate \\
\hline & & Water & & Water & & Water & & Water & & Water & & Water & & Water \\
\hline 10 & 11 & 2 & 1 & 1 & 1 & 1 & 2 & 1 & 1 & No Read & 1 & No Read & 1 & 1 \\
\hline 20 & 5 & 1 & 1 & 1 & 1 & 1 & 1 & 1 & 1 & No Read & 1 & No Read & 1 & 1 \\
\hline 30 & 4 & 1 & 1 & 1 & 1 & 1 & 1 & 1 & 1 & No Read & 1 & No Read & 1 & 1 \\
\hline 40 & 5 & 1 & 1 & 1 & 1 & 1 & 1 & 1 & 1 & No Read & 1 & No Read & 1 & 1 \\
\hline 60 & 2 & 1 & 1 & 1 & 1 & 1 & 1 & 1 & 1 & No Read & 1 & No Read & 1 & 1 \\
\hline 80 & 2 & 1 & 1 & 1 & 1 & 1 & 1 & 1 & 1 & No Read & 1 & No Read & 1 & 1 \\
\hline $\begin{array}{l}\text { Av. of } \\
\text { Readings }\end{array}$ & 4.8 & 1.2 & 1 & 1 & 1 & 1 & 1.2 & 1 & 1 & $\mathrm{NA}$ & 1 & $\mathrm{NA}$ & 1 & 1 \\
\hline
\end{tabular}


Table 22: Tag Read Time in Ambient Air vs. $2.5 \mathrm{cms}$ of Water in front-facing dual antenna configuration.

\begin{tabular}{|l|c|c|}
\hline & Free Air & Water \\
\hline $\begin{array}{l}\text { Total Read } \\
\text { Time (msec) }\end{array}$ & 1809 & 599 \\
\hline \begin{tabular}{lr|c|} 
Tag Read \\
Count
\end{tabular} & 66 & 31 \\
\hline $\begin{array}{l}\text { Time(msec)/ } \\
\text { Read }\end{array}$ & 27.4 & 19.3 \\
\hline
\end{tabular}

Table 23: Comparison of RSSI (dBm) in Ambient Air vs. $2.5 \mathrm{cms}$ of Water having 4 grams of salt in front-facing dual-antenna configuration.

\begin{tabular}{|c|c|c|c|c|c|c|c|c|c|c|c|c|c|c|}
\hline \multirow{2}{*}{$\begin{array}{l}\text { Tag\# } \\
\text { Speed } \\
(\mathrm{km} / \mathrm{h})\end{array}$} & \multicolumn{2}{|c|}{9} & \multicolumn{2}{|c|}{18} & \multicolumn{2}{|c|}{24} & \multicolumn{2}{|l|}{ ExoP } & \multicolumn{2}{|l|}{ ConP } & \multicolumn{2}{|l|}{ BAP1 } & \multicolumn{2}{|l|}{ BAP2 } \\
\hline & RSSI & RSSI & RSSI & RSSI & RSSI & RSSI & RSSI & RSSI & RSSI & RSSI & RSSI & RSSI & RSSI & RSSI \\
\hline 10 & -60 & -80 & -64 & -74 & -66 & -76 & -62 & -74 & -55 & No Read & -58 & No Read & -78 & -78 \\
\hline 30 & -69 & -82 & -69 & -74 & -55 & -71 & -73 & -74 & -49 & No Read & -53 & No Read & -77 & -72 \\
\hline 40 & -62 & -82 & -64 & -78 & -63 & -75 & -76 & No Read & -60 & No Read & -61 & No Read & -81 & -73 \\
\hline 60 & -68 & No Read & -69 & -74 & -67 & -75 & -78 & -74 & -58 & No Read & -57 & No Read & -81 & -79 \\
\hline
\end{tabular}


Table 24: Tag Read Rate in Ambient Air vs. $2.5 \mathrm{cms}$ of Water having 4 grams of salt in front-facing dual-antenna configuration.

\begin{tabular}{|c|c|c|c|c|c|c|c|c|c|c|c|c|c|c|}
\hline \multirow{2}{*}{\begin{tabular}{|l|} 
Tag\# \\
Speed \\
$(\mathrm{km} / \mathrm{h})$
\end{tabular}} & \multicolumn{2}{|c|}{9} & \multicolumn{2}{|c|}{18} & \multicolumn{2}{|c|}{24} & \multicolumn{2}{|l|}{ ExoP } & \multicolumn{2}{|l|}{ ConP } & \multicolumn{2}{|c|}{ BAP1 } & \multicolumn{2}{|c|}{ BAP2 } \\
\hline & Rate & Rate & Rate & Rate & Rate & Rate & Rate & Rate & Rate & Rate & Rate & Rate & Rate & Rate \\
\hline & & Water & & Water & & Water & & Water & & Water & & Water & & Water \\
\hline 10 & 11 & 1 & 1 & 1 & 1 & 1 & 2 & 1 & 1 & No Read & 1 & No Read & 1 & 1 \\
\hline 30 & 4 & 1 & 1 & 1 & 1 & 1 & 1 & 1 & 1 & No Read & 1 & No Read & 1 & 1 \\
\hline 40 & 5 & 1 & 1 & 1 & 1 & 1 & 1 & No Read & 1 & No Read & 1 & No Read & 1 & 1 \\
\hline 60 & 2 & No Read & 1 & 1 & 1 & 1 & 1 & 1 & 1 & No Read & 1 & No Read & 1 & 1 \\
\hline 80 & 2 & No Read & 1 & No Read & 1 & No Read & 1 & 1 & 1 & No Read & 1 & No Read & 1 & 1 \\
\hline
\end{tabular}

Table 25: Tag Read Time in Ambient Air vs. $2.5 \mathrm{cms}$ of Water with 4 grams of salt in front-facing dual antenna configuration.

\begin{tabular}{|l|c|c|}
\hline & Ambient & Water \\
Total & 1809 & 409 \\
Read Time & & \\
$($ msec $)$ & & \\
\hline Tag Read & 66 & 25 \\
Count & & \\
\hline Time(msec) & 27.4 & 16.4 \\
Per Read & & \\
\hline
\end{tabular}


Table 26: Comparison of RSSI in Ambient Air vs. 4 inches of underground covered with 0.5 inch of soil in dual-front-antenna orientation.

\begin{tabular}{|c|c|c|c|c|c|c|c|c|c|c|c|c|c|c|}
\hline \multirow{2}{*}{$\begin{array}{l}\text { Tag\# } \\
\text { Speed } \\
(\mathrm{km} / \mathrm{h})\end{array}$} & \multicolumn{2}{|c|}{9} & \multicolumn{2}{|c|}{18} & \multicolumn{2}{|c|}{24} & \multicolumn{2}{|l|}{ ExoP } & \multicolumn{2}{|l|}{ ConP } & \multicolumn{2}{|l|}{ BAP1 } & \multicolumn{2}{|l|}{ BAP2 } \\
\hline & $\begin{array}{l}\text { RSSI } \\
(\mathrm{dBm}) \\
\text { Air }\end{array}$ & $\begin{array}{l}\text { RSSI } \\
(\mathrm{dBm}) \\
\text { Under- } \\
\text { ground }\end{array}$ & $\begin{array}{l}\text { RSSI } \\
(\mathrm{dBm}) \\
\text { Air }\end{array}$ & $\begin{array}{l}\text { RSSI } \\
(\mathrm{dBm}) \\
\text { Under- } \\
\text { ground }\end{array}$ & $\begin{array}{l}\text { RSSI } \\
(\mathrm{dBm}) \\
\text { Air }\end{array}$ & $\begin{array}{l}\text { RSSI } \\
(\mathrm{dBm}) \\
\text { Under- } \\
\text { ground }\end{array}$ & $\begin{array}{l}\text { RSSI } \\
(\mathrm{dBm}) \\
\text { Air }\end{array}$ & $\begin{array}{l}\text { RSSI } \\
(\mathrm{dBm}) \\
\text { Under- } \\
\text { ground }\end{array}$ & $\begin{array}{l}\text { RSSI } \\
(\mathrm{dBm}) \\
\text { Air }\end{array}$ & $\begin{array}{l}\text { RSSI } \\
(\mathrm{dBm}) \\
\text { Under- } \\
\text { ground }\end{array}$ & $\begin{array}{l}\text { RSSI } \\
(\mathrm{dBm}) \\
\text { Air }\end{array}$ & $\begin{array}{l}\text { RSSI } \\
(\mathrm{dBm}) \\
\text { Under- } \\
\text { ground }\end{array}$ & $\begin{array}{l}\text { RSSI } \\
(\mathrm{dBm}) \\
\text { Air }\end{array}$ & $\begin{array}{l}\text { RSSI } \\
(\mathrm{dBm}) \\
\text { Under- } \\
\text { ground }\end{array}$ \\
\hline 20 & -82 & -82 & -69 & No Read & -69 & No Read & -54 & -81 & -63 & No Read & -63 & No Read & -82 & No Read \\
\hline 30 & -81 & -80 & -68 & No Read & -69 & No Read & -74 & No Read & -62 & No Read & -61 & No Read & -82 & No Read \\
\hline 40 & -79 & -80 & -68 & No Read & -68 & No Read & -79 & No Read & -58 & No Read & -63 & No Read & -80 & No Read \\
\hline 70 & -82 & No Read & -68 & No Read & -68 & -81 & -75 & -74 & -55 & -58 & -60 & No Read & -82 & -74 \\
\hline $\begin{array}{l}\text { Avg. of } \\
\text { Readings }\end{array}$ & -80.1 & $\mathrm{NA}$ & -68.6 & NA & -68.7 & $\mathrm{NA}$ & -72.4 & NA & -60.3 & NA & -62.4 & NA & -77.7 & NA \\
\hline
\end{tabular}

Table 27: Tag Read Count in Ambient Air vs. 4 inches of underground covered with 0.5 inch of soil in dual-front-antenna orientation.

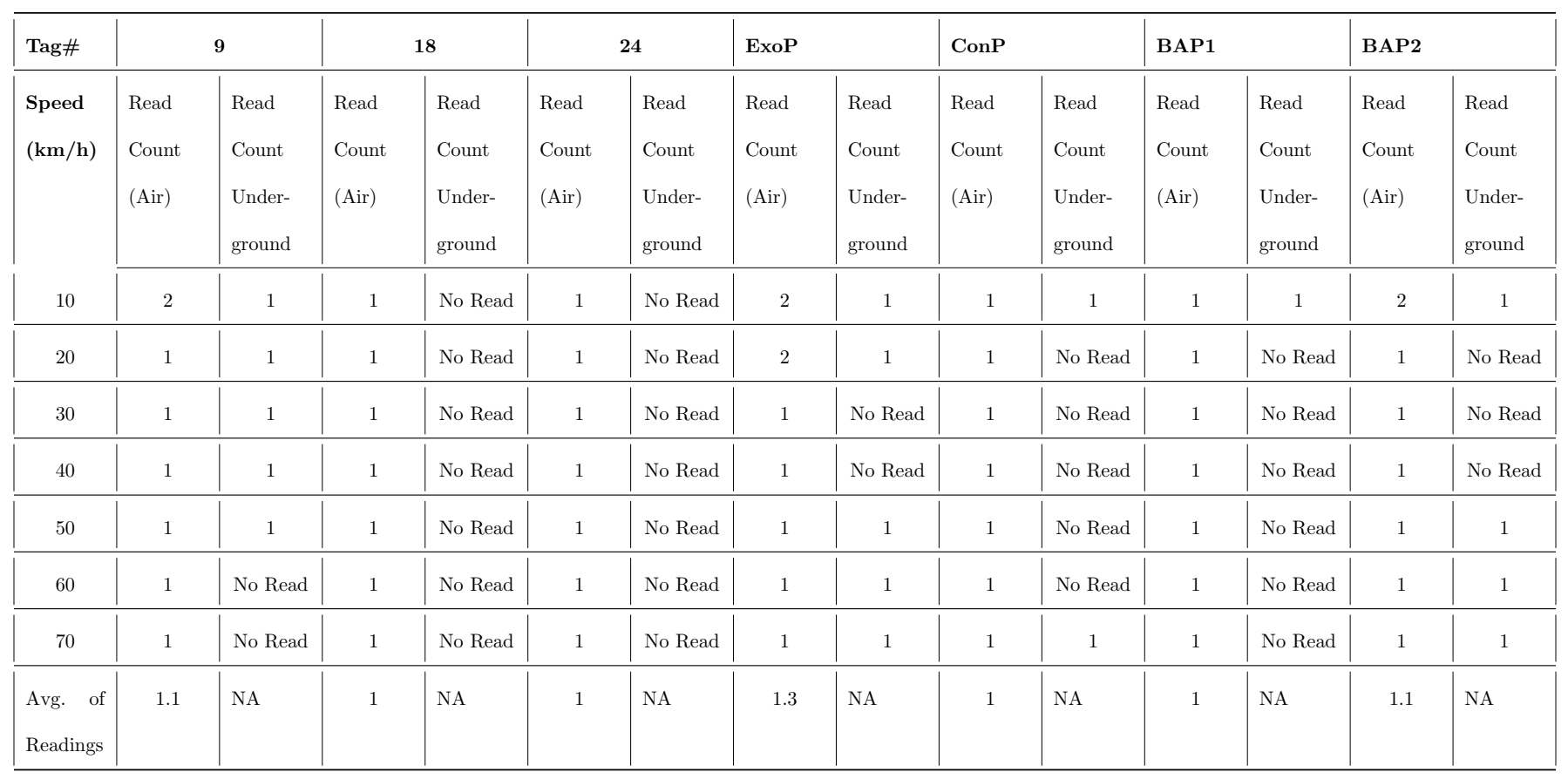


Table 28: Tag Read Time in Ambient Air vs. 4 inches of underground covered with 0.5 inch of soil in dual-front-antenna orientation.

\begin{tabular}{|l|c|c|}
\hline & $\begin{array}{c}\text { Ambient } \\
\text { Air }\end{array}$ & $\begin{array}{c}\text { Underground } \\
\text { With Soil }\end{array}$ \\
\hline $\begin{array}{l}\text { Total Read } \\
\text { Time (msec) }\end{array}$ & 1497 & 1619 \\
\hline Tag Read & 21 & 17 \\
Count & 71.3 & 95.2 \\
\hline Time(msec) & & \\
Per Read & & \\
\hline
\end{tabular}




\section{Summary of Passive RFID Tag Results}

- Tag power and readability response is the highest in ambient air, followed by snow, ice, water, salted water and finally embedded underground.

- Readings were successfully collected at various AV speeds - up to $90 \mathrm{~km} / \mathrm{h}$. Higher speeds could not be tried due to track constraints. Passive tags however were read up to $200 \mathrm{~km} / \mathrm{h}$ in one of the studies conducted in Germany [27].

- Front antenna orientation is better than downward due to the increased Tag Read Count. This is likely because tags are exposed to the RF energy much earlier than the downward antenna which is confined to a smaller area.

- Tag read count decreases with the increase in speed, but RSSI was not impacted due to speed. This is likely due to the Dynamic Effect or Automatic Gain Control (AGC) of the reader which automatically adjusts the gain.

- Time per tag read for single antenna in ambient Air is about 8-14 msec while for two antennas connected to the same reader is $25 \mathrm{msec}$, since the reader switches between the two tags. This increases for mediums other than ambient Air such as in Snow and Ice. For Water however it decreased - possibly due to a fewer data point.

- BAP tags did not considerably increase the performance in comparison to their passive counterparts.

- Most tags were unread in mediums other than Air such as Ice and Water in single antenna configuration. For the tags that were read, at minimum $10 \mathrm{dBm}$ drop was observed. Tag Read Count also significantly suffered and reduced by $30 \%$ to $70 \%$ for the tags that were read. Results were not impressive at all. The summary table with Single Passive Antenna in various propagation mediums is shown in 29 .

- Literature suggested that one of the ways to improve results of Single Antenna was to trial multiple antennas. This is when Dual Antenna was trialed. Dual Antenna connected to the same reader 
drastically improved the results mainly due to increased coverage area. Tags were read in most mediums but Underground where half the tags were not read. For the tags that were read, at minimum 4 dBm drop was observed. Tag Read Count also decreased from 30\% to 50\%. Results were not great but provided a good start. In future, more antennas connected to multiple readers are recommended for experimentation. The summary table with Dual Passive Antenna in various propagation mediums is shown in 30 .

Table 29: Shows summary of Passive RFID Tags results in various propagation mediums with Single Passive Antenna

\begin{tabular}{|c|c|c|c|c|c|}
\hline $\begin{array}{l}\text { Propagation } \\
\text { Medium }\end{array}$ & $\begin{array}{l}\text { Average } \\
\text { RSSI } \\
(\mathrm{dBm})\end{array}$ & $\begin{array}{l}\text { Variance } \\
\text { Against } \\
\text { Air (dBm) }\end{array}$ & $\begin{array}{l}\text { Tag Read } \\
\text { Count }\end{array}$ & $\begin{array}{l}\text { Time/Tag } \\
\text { Read (mil- } \\
\text { lisecond) }\end{array}$ & Comments \\
\hline Air & -48 & & 18 & 15 & Backward Antenna \\
\hline Snow (4 inch) & -66 & -17 & 12 & 15 & Backward Antenna \\
\hline Air & -66 & & 3 & 26 & Front Antenna \\
\hline Ice (2.5 inch) & -76 & -10 & 3 & 34 & $\begin{array}{l}\text { Front Antenna. } 3 \text { of } 6 \text { tags un- } \\
\text { read, few partial reads }\end{array}$ \\
\hline $\begin{array}{l}\text { Underground } \\
(4 \text { inch }+0.5 \\
\text { inch of soil })\end{array}$ & -79 & -13 & 1 & 71 & $\begin{array}{l}\text { Front Antenna. } 4 \text { of } 7 \text { tags un- } \\
\text { read }\end{array}$ \\
\hline Water (1 inch) & No Read & No Read & No Read & No Read & $\begin{array}{l}\text { Front Antenna. Most tags un- } \\
\text { read }\end{array}$ \\
\hline
\end{tabular}


Table 30: Shows summary of Passive RFID Tags results in various propagation mediums with Dual Passive Antenna

\begin{tabular}{|c|c|c|c|c|c|}
\hline $\begin{array}{l}\text { Propagation } \\
\text { Medium }\end{array}$ & $\begin{array}{l}\text { Average } \\
\text { RSSI } \\
(\mathrm{dBm})\end{array}$ & $\begin{array}{l}\text { Variance } \\
\text { Against } \\
\text { Air } \\
(\mathrm{dBm})\end{array}$ & $\begin{array}{l}\text { Average } \\
\text { Tag } \\
\text { Read } \\
\text { Count }\end{array}$ & $\begin{array}{l}\text { Time/Tag } \\
\text { Read (mil- } \\
\text { lisecond) }\end{array}$ & Comments \\
\hline Air & -65.3 & & 1.6 & 27.4 & \\
\hline Ice (2 inch) & -69.2 & 6 & 1.1 & 43.8 & 1 of 7 unread tag \\
\hline Water (1 inch) & -75.1 & 0 & 1 & 19.3 & 2 of unread tags \\
\hline $\begin{array}{l}\text { Salted Water (1 } \\
\text { inch) }\end{array}$ & -76.8 & -2 & 0.83 & 16.4 & $\begin{array}{l}2 \text { of unread tags, few } \\
\text { partial unreads }\end{array}$ \\
\hline $\begin{array}{l}\text { Underground }(4 \\
\text { inch }+0.5 \text { inch of } \\
\text { soil) }\end{array}$ & -80 & -5 & 0.7 & 95.2 & 4 of 7 unread tags \\
\hline
\end{tabular}




\section{Results With Active Tags}

After Passive and BAP tags, Active tags were tried under the similar conditions to compare their performance against their Passive and BAP counterparts. Active refers to the tags having battery for both powering the IC of the tag and transmission (or beaconing) of the signal to the reader. Active RFID operates at different frequency bandwidth than the Passive at $433 \mathrm{MHz}$ and $2.4 \mathrm{GHz}$. Higher the frequency means higher the data carrying capacity, more penetration power but also more prone to interference. Read range for Active tags is also higher owing to its battery and higher frequency. The boost that the signal receives from the battery also allows to overcome the hindrance generated by the environments such as water and metal. These tags also typically have higher memory and hence the storage capacity. Another benefit of Active technology is that the tags can store the GPS co-ordinates as typically they are used to track in real-time of high value assets [10]. Tags are typically of two types: beacons and transponders. Beacons typically broadcast the information after a set interval from 100 msec to 10 seconds. Time interval is usually adjustable. The other type is a transponder which responds to an interrogating signal.

For the application of AV, there are some serious downsides to the Active technology. The biggest ones being its cost and form factor (size). Wherein the Passive tags cost a few cents, the Active tags can cost up to $\$ 5-50$ dollar each. And this makes their case for AV weak since a lot of them are required for navigation. However, just like LIDAR, the bulk production and convergence to this technology might significantly bring the price down. The other downsize is that of its much bigger size and more weight versus the Passive counterparts. This is because of battery and powering the IC. Another major downside is that the battery runs out after a while and if the tags are embedded within the infrastructure or let say underground, they have to be replaced periodically which is not very feasible. Beacons runs out of battery quicker than the transponders since they beam the power periodically while transponders only respond when interrogated. The battery may last a few years.

As observed with the Passive and BAP tags, there are a few companies that develop the tag IC and there is often over-promise from the marketing departing of the companies versus what the 

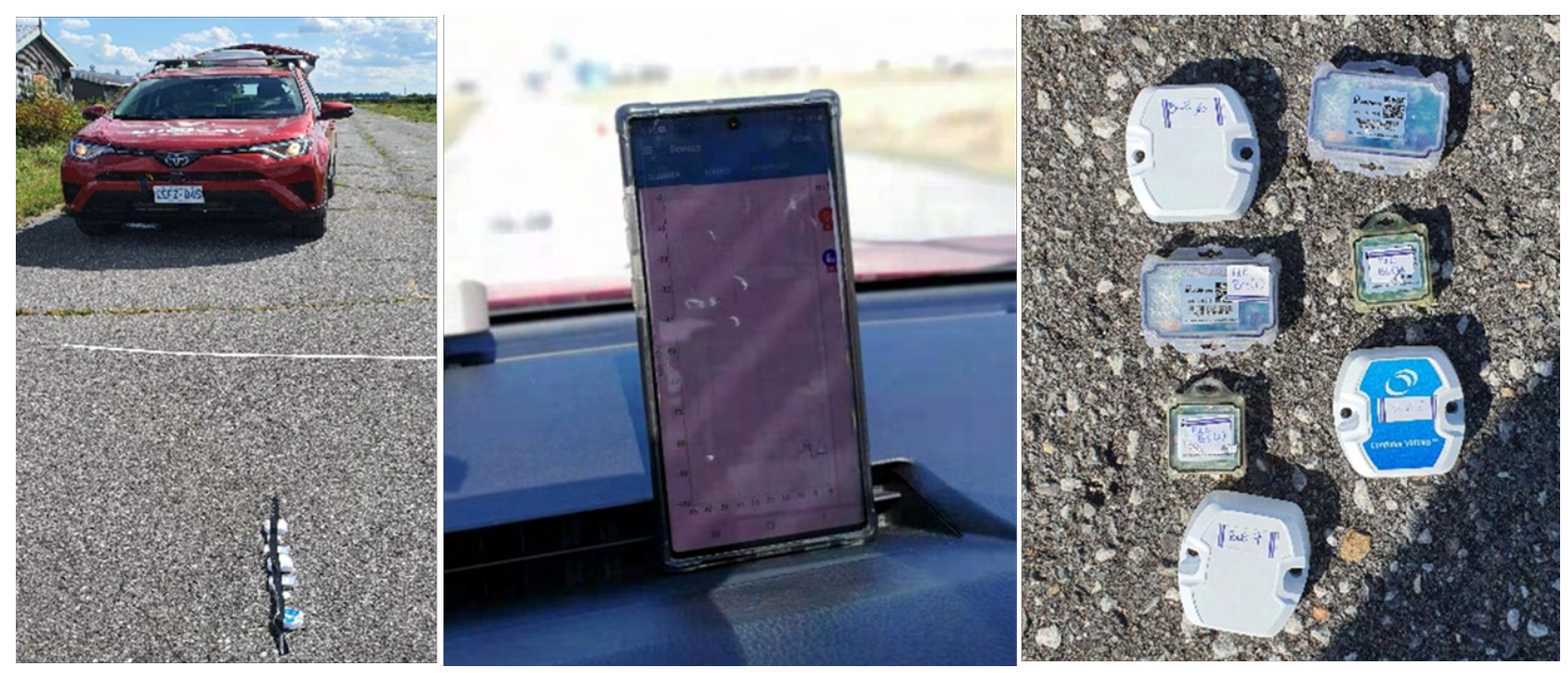

Figure 28: Active RFID setup shows Active tags placed on the ground and cellphone as reader in the vehicle.

performance of the device, the software and availability in general. The experiments were conducted using Confidex Viking tags [28] after the trail of a few other Bluetooth tags. Specifications are provided in the equipment table. The tags are Bluetooth Low Energy (BLE) for beaconing RFID because it is power-efficient. Figure 28 shows the typical setup of Active RFID. Samsung Note 10+ cell phone's Bluetooth chip was used as the reader. As for the software, the tags were activated by NFC using Confidex's proprietary Runestone application. The readings were collected using the NRF application as tags' chip was designed by NRF. The setup is shown in figure 28 where the Active tags are placed on the asphalt road and reader in the form of cell phone is placed in the moving vehicle.

In free-air, in figure 29, the results show that as the speed goes up, total Tag Read Count goes down. However, in contrast to Passive and BAP tags, with the increase in speed, the RSSI (dBm) slightly went down. This further confirmed the understanding that the increase of RSSI with speed in Passive and BAP tags was due to the reader's Dynamic Effect and Automatic Gain. 


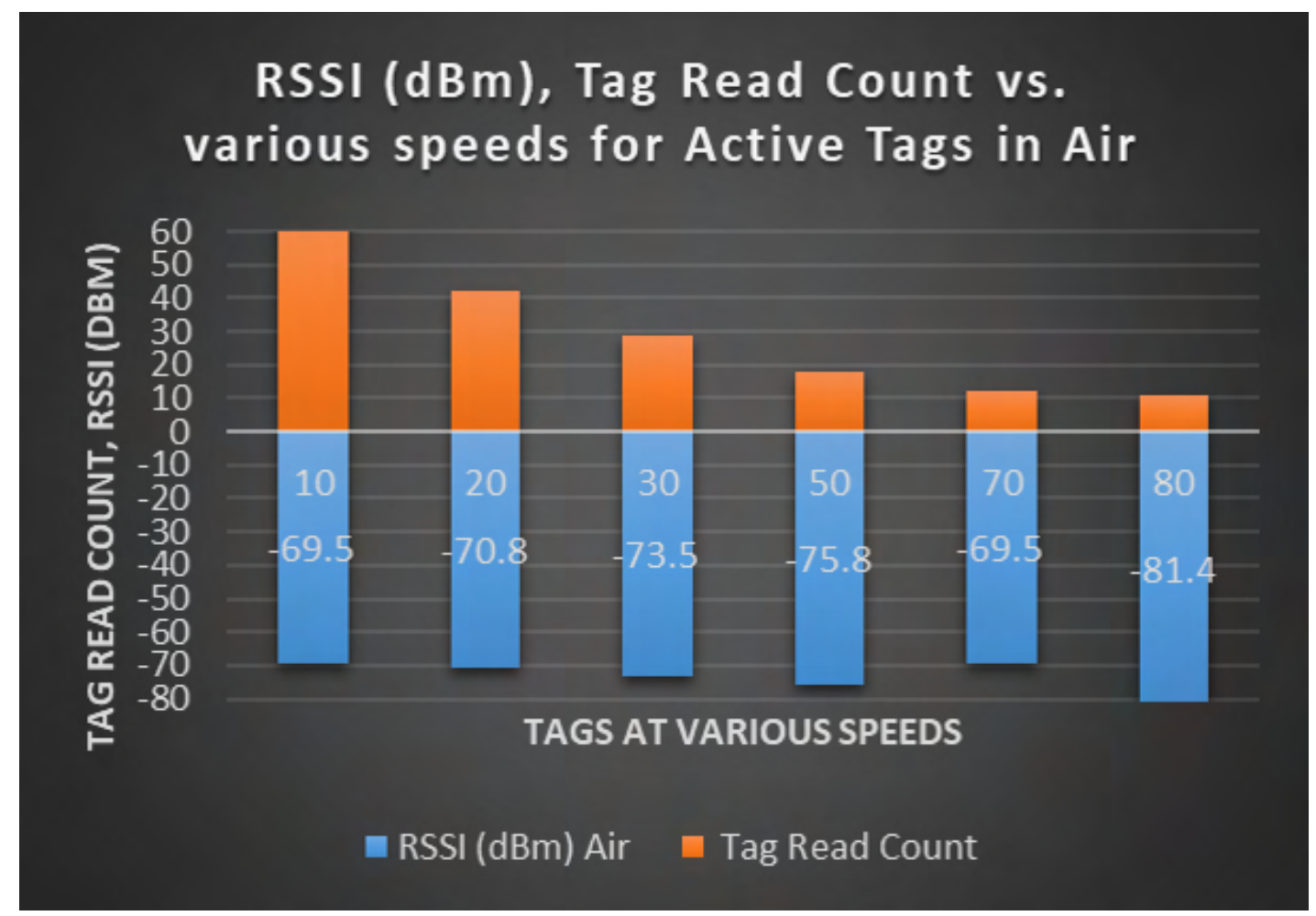

Figure 29: Active RFID Tags' Tag Read Count and RSSI (dBm) over various speeds in free air.

\subsection{Results in Free-Air vs. Ice}

To compare the RSSI and Tag Read Count between Free-Air and Ice using Active tags, readings were first taken by placing tags on the asphalt road for the former environment and in a plastic container filled with 2 inch of ice and placed over the tags. Previous experiments showed that since plastic container is an insulator, there was no noticeable difference in RSSI. The setup is shown in figure 30. Results are shown in table 31 and demonstrated:

- As expected, RSSI and Tag Read Count were highest in free-Air than in Ice.

- For RSSI, the average was about $6 \mathrm{dBm}$ lesser than in free-Air. The difference was particularly significant at higher speeds where a few tags were not read at all.

- Tag Read Count was about 30\% less in Ice than Free-Air on average.

- One observation was that 2 inches of Ice was perhaps too much of Ice to simulate its effect. The 


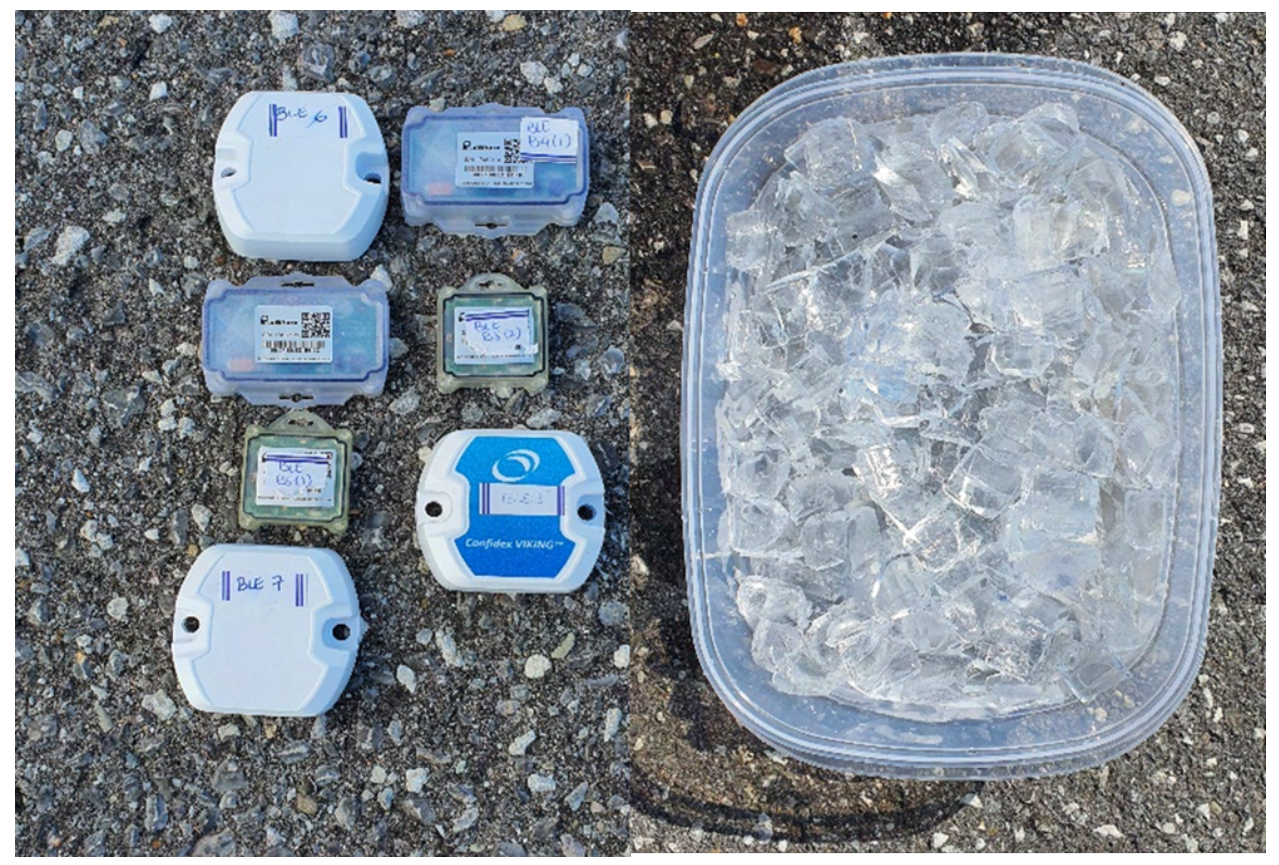

Figure 30: Shows Active tags in free-Air on the left and 2 inches of Ice on the right.

same could have been done with 1 inch only.

\subsection{Results in Free-Air vs. Water and Salted Water}

Free-Air results were collected by placing the tags on the asphalt road. To compare the RSSI and Tag Read Count between the Free-Air and Water, $2.5 \mathrm{cms}$ of Water was poured into the container and placed on the tags. The setup is shown in figure 31. Results are shown in Tables 32 and 33, and demonstrated:

- For RSSI, the average of 2 out of 3 tags were about $3 \mathrm{dBm}$ lesser in Water. The $3 \mathrm{rd}$ tag was about $6 \mathrm{dBm}$ lesser.

- Tag Read Count in Free-Air and Water was comparable.

- RSSI and Tag Read Count further decreased in Salted Water as expected. Not only the RF signal does not like Water as a medium but adding salt makes it even more conductive. Therefore, RSSI in Salted Water reduced 6-8 $\mathrm{dBm}$ on average, which was relatively a lot higher than the plain Water. 


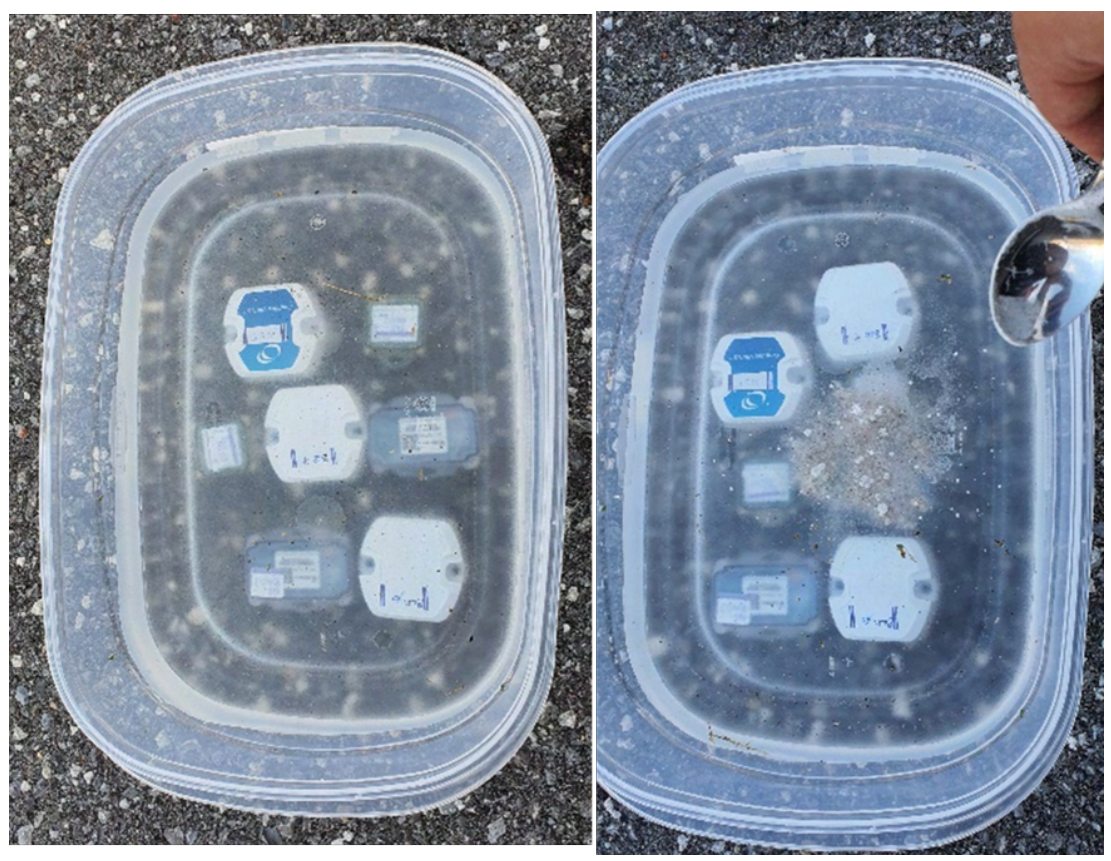

Figure 31: Shows tags with $2.5 \mathrm{cms}$ of Water on left and $2.5 \mathrm{cms}$ of Salted Water on the right with 4 grams of Salt.

- There was a noticeable difference in Tag Read Count in Salted Water where the Tag read count reduced by $33 \%$ - slightly more than Ice.

\subsection{Results in Free-Air vs. Embedded Underground}

This time Free-Air results were collected by placing the tags on the unpaved road as it was unknown how the RF signal and RSSI performed/reflected off the unpaved road. Another reason was to get its Free-Air reading as close as possible to the Underground setting. To compare the RSSI and Tag Read Count between the Free-Air and Underground, soil was excavated 4-inch deep, and tags were placed in it. Tags were then covered with 0.5 inch of soil rendering the effective depth to be 3.5 inches. This scenario was trialed to simulate the results if the tags were to be embedded within the road/underground for AV navigation.

The setup is shown in figure 32. Results are shown in table 34 and demonstrated: 


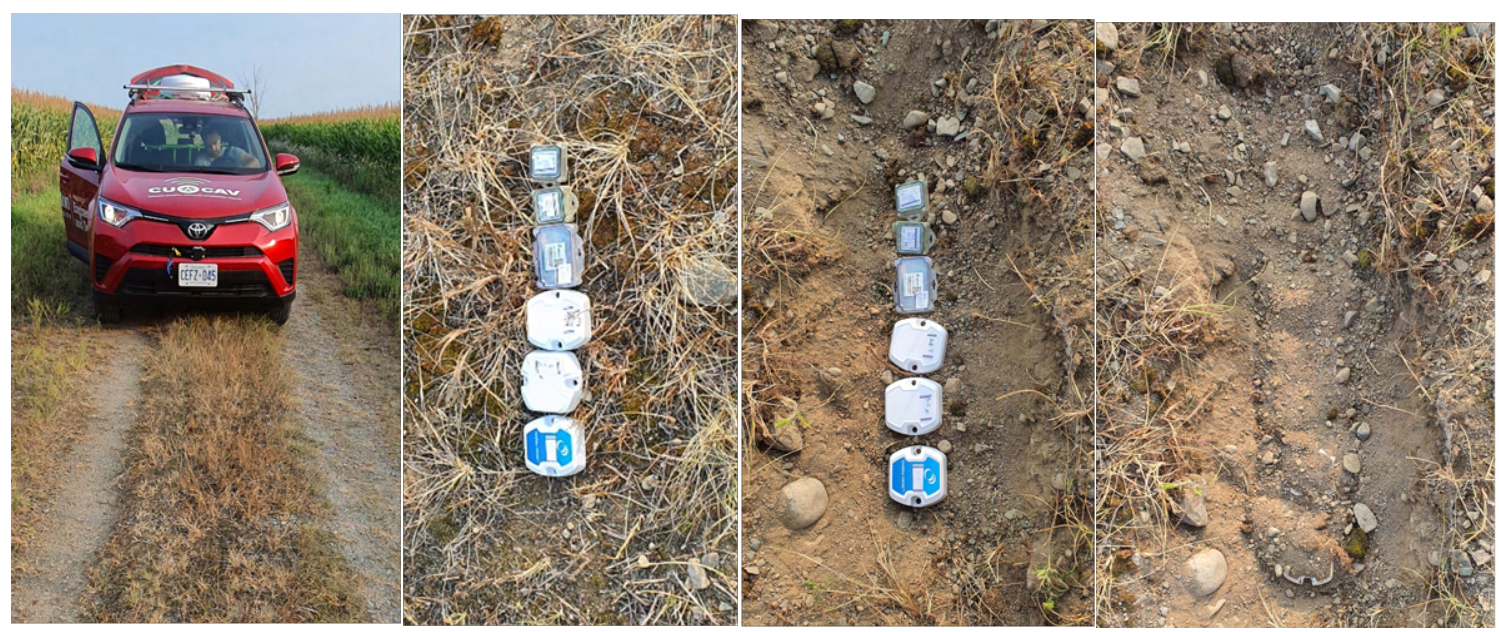

Figure 32: Shows setup for Active tags embedded in 4-inch Underground Soil.

- When embedded Underground, RSSI for Underground was the worst as compared to free-Air, Water, and Ice.

- Tag Read Count was lowest even in Free-Air versus other mediums when results were collected on the unpaved road. Results were comparable when the tags were embedded Underground.

- This shows that both RSSI and Tag Read Count were the lowest in Underground settings versus the rest. 
Table 31: Comparison of RSSI (dBm) and Tag Read Count in Free-Air and 2 inches of Ice using Active Tags.

\begin{tabular}{|c|c|c|c|c|c|c|c|c|}
\hline Tag\# & BLE 5 & BLE 5 & BLE 6 & BLE 6 & BLE 7 & BLE 7 & & \\
\hline $\begin{array}{l}\text { Speed } \\
(\mathrm{km} / \mathrm{h})\end{array}$ & $\begin{array}{l}\text { RSSI } \\
(\mathrm{dBm}) \text { Air }\end{array}$ & $\begin{array}{l}\text { RSSI } \\
(\mathrm{dBm}) \text { Ice }\end{array}$ & $\begin{array}{l}\text { RSSI } \\
(\mathrm{dBm}) \text { Air }\end{array}$ & $\begin{array}{l}\text { RSSI } \\
(\mathrm{dBm}) \text { Ice }\end{array}$ & $\begin{array}{l}\text { RSSI } \\
(\mathrm{dBm}) \text { Air }\end{array}$ & $\begin{array}{l}\text { RSSI } \\
(\mathrm{dBm}) \text { Ice }\end{array}$ & $\begin{array}{l}\text { Total } \\
\text { Count Air }\end{array}$ & $\begin{array}{l}\text { Total } \\
\text { Count Ice }\end{array}$ \\
\hline 10 & -75.7 & -77.1 & -69.5 & -79.4 & -70.4 & -71.7 & 68.0 & 60.0 \\
\hline 20 & -75.2 & -81.1 & -70.8 & -79.7 & -72.2 & -72.2 & 42.0 & 30.0 \\
\hline 30 & -75.7 & -85.8 & -73.5 & -83.9 & -72.9 & -75.2 & 29.0 & 16.0 \\
\hline 50 & -79.4 & -87.0 & -75.8 & -83.2 & -78.4 & -81.6 & 18.0 & 10.0 \\
\hline 70 & -75.2 & NA & -69.5 & -86.5 & -70.4 & -89.5 & 12.0 & 7.0 \\
\hline 80 & -83.6 & -89.5 & -81.4 & NA & -84.1 & -81.3 & 11.0 & 5.0 \\
\hline $\begin{array}{l}\text { Avg. of } \\
\text { Readings }\end{array}$ & -77.5 & $\mathrm{NA}$ & -73.4 & NA & -74.7 & -78.6 & 30.0 & 21.3 \\
\hline
\end{tabular}


Table 32: Comparison of RSSI (dBm) and Tag Read Count in Free-Air and $2.5 \mathrm{cms}$ of Water using Active Tags.

\begin{tabular}{|c|c|c|c|c|c|c|c|c|}
\hline Tag\# & BLE 5 & BLE 5 & BLE 6 & BLE 6 & BLE 7 & BLE 7 & & \\
\hline $\begin{array}{l}\text { Speed } \\
(\mathrm{km} / \mathrm{h})\end{array}$ & $\begin{array}{l}\text { RSSI } \\
(\mathrm{dBm}) \text { Air }\end{array}$ & $\begin{array}{l}\text { RSSI } \\
(\mathrm{dBm}) \\
\text { Water }\end{array}$ & $\begin{array}{l}\text { RSSI } \\
(\mathrm{dBm}) \text { Air }\end{array}$ & $\begin{array}{l}\text { RSSI } \\
(\mathrm{dBm}) \\
\text { Water }\end{array}$ & $\begin{array}{l}\text { RSSI } \\
(\mathrm{dBm}) \text { Air }\end{array}$ & $\begin{array}{l}\text { RSSI } \\
(\mathrm{dBm}) \\
\text { Water }\end{array}$ & $\begin{array}{l}\text { Total } \\
\text { Count Air }\end{array}$ & $\begin{array}{l}\text { Total } \\
\text { Count } \\
\text { Water }\end{array}$ \\
\hline 10 & -75.7 & -76.5 & -69.5 & -73.5 & -70.4 & -71.1 & 68.0 & 65.0 \\
\hline 20 & -75.2 & -80.8 & -70.8 & -75.9 & -72.2 & -73.6 & 42.0 & 36.0 \\
\hline 30 & -75.7 & -81.0 & -73.5 & -75.0 & -72.9 & -77.3 & 29.0 & 28.0 \\
\hline 50 & -79.4 & -81.8 & -75.8 & -82.4 & -78.4 & -79.9 & 18.0 & 14.0 \\
\hline 70 & -75.2 & -79.0 & -69.5 & -82.2 & -70.4 & -79.8 & 12.0 & 17.0 \\
\hline 80 & -83.6 & -83.7 & -81.4 & -84.6 & -84.1 & -79.7 & 11.0 & 8.0 \\
\hline $\begin{array}{l}\text { Avg. of } \\
\text { Readings }\end{array}$ & -77.5 & -80.5 & -73.4 & -78.9 & -74.7 & -76.9 & 30.0 & 28.0 \\
\hline
\end{tabular}


Table 33: Comparison of RSSI (dBm) and Tag Read Count in Free-Air and $2.5 \mathrm{cms}$ of Water with 4 grams of salt using Active Tags.

\begin{tabular}{|c|c|c|c|c|c|c|c|c|}
\hline Tag\# & BLE 5 & BLE 5 & BLE 6 & BLE 6 & BLE 7 & BLE 7 & & \\
\hline $\begin{array}{l}\text { Speed } \\
(\mathrm{km} / \mathrm{h})\end{array}$ & $\begin{array}{l}\text { RSSI } \\
(\mathrm{dBm}) \text { Air }\end{array}$ & $\begin{array}{l}\text { RSSI } \\
(\mathrm{dBm}) \\
\text { Salted } \\
\text { Water }\end{array}$ & $\begin{array}{l}\text { RSSI } \\
(\mathrm{dBm}) \text { Air }\end{array}$ & $\begin{array}{l}\text { RSSI } \\
(\mathrm{dBm}) \\
\text { Salted } \\
\text { Water }\end{array}$ & $\begin{array}{l}\text { RSSI } \\
(\mathrm{dBm}) \text { Air }\end{array}$ & $\begin{array}{l}\text { RSSI } \\
(\mathrm{dBm}) \\
\text { Salted } \\
\text { Water }\end{array}$ & $\begin{array}{l}\text { Total } \\
\text { Count Air }\end{array}$ & $\begin{array}{l}\text { Total } \\
\text { Count } \\
\text { Salted } \\
\text { Water }\end{array}$ \\
\hline 10 & -75.7 & -83.0 & -69.5 & -84.7 & -70.4 & -80.0 & 68.0 & 32.0 \\
\hline 20 & -75.2 & -81.9 & -70.8 & -82.3 & -72.2 & -81.2 & 42.0 & 27.0 \\
\hline 30 & -75.7 & -81.2 & -73.5 & -81.7 & -72.9 & -80.5 & 29.0 & 19.0 \\
\hline 50 & -79.4 & -82.1 & -75.8 & -80.7 & -78.4 & -82.2 & 18.0 & 12.0 \\
\hline 70 & -75.2 & -83.7 & -69.5 & -83.9 & -70.4 & -84.6 & 12.0 & 14.0 \\
\hline 80 & -83.6 & -87.8 & -81.4 & -84.0 & -84.1 & -84.7 & 11.0 & 13.0 \\
\hline $\begin{array}{l}\text { Avg. of } \\
\text { Readings }\end{array}$ & -77.5 & -83.3 & -73.4 & -82.9 & -74.7 & -82.2 & 30.0 & 19.5 \\
\hline
\end{tabular}


Table 34: Comparison of RSSI (dBm) and Tag Read Count in Free-Air and 4 inch of Underground with 0.5 inch of soil (rendering effective depth at 3.5 inch) using Active Tags.

\begin{tabular}{|c|c|c|c|c|c|c|c|c|}
\hline Tag\# & BLE 5 & BLE 5 & BLE 6 & BLE 6 & BLE 7 & BLE 7 & & \\
\hline $\begin{array}{l}\text { Speed } \\
(\mathrm{km} / \mathrm{h})\end{array}$ & $\begin{array}{l}\text { RSSI } \\
(\mathrm{dBm}) \text { Air }\end{array}$ & $\begin{array}{l}\text { RSSI } \\
(\mathrm{dBm}) \text { Un- } \\
\text { derground }\end{array}$ & $\begin{array}{l}\text { RSSI } \\
(\mathrm{dBm}) \text { Air }\end{array}$ & $\begin{array}{l}\text { RSSI } \\
(\mathrm{dBm}) \text { Un- } \\
\text { derground }\end{array}$ & $\begin{array}{l}\text { RSSI } \\
(\mathrm{dBm}) \text { Air }\end{array}$ & $\begin{array}{l}\text { RSSI } \\
(\mathrm{dBm}) \text { Un- } \\
\text { derground }\end{array}$ & $\begin{array}{l}\text { Total } \\
\text { Count Air } \\
\text { (Unpaved) }\end{array}$ & $\begin{array}{l}\text { Total } \\
\text { Count Un- } \\
\text { derground }\end{array}$ \\
\hline 10 & -76.8 & -75.3 & -75.2 & -71.8 & -80.2 & -77.0 & 36 & 37 \\
\hline 20 & -81.8 & NA & -78.3 & -88.7 & -81.6 & -88.8 & 27 & 16 \\
\hline 30 & NA & -76.5 & NA & -75.3 & -91.0 & -77.2 & 7 & 11 \\
\hline 50 & -69.0 & NA & NA & NA & -75.0 & NA & 2 & 0 \\
\hline 70 & -84.6 & -89 & -85.3 & -82.5 & -88.5 & -85.5 & 10 & 3 \\
\hline 80 & -69.0 & NA & -79.0 & -85.3 & -71.0 & NA & 4 & 4 \\
\hline $\begin{array}{l}\text { Avg. of } \\
\text { Readings }\end{array}$ & NA & NA & NA & NA & -81.2 & NA & 14 & 12 \\
\hline
\end{tabular}




\subsection{Summary of Active RFID Tags Results}

- RSSI and Tag Read Count is highest with Active RFID tags in comparison to their Passive counterparts.

- Readings were taken up to $90 \mathrm{~km} / \mathrm{h}$. One study in Germany however was able to take readings up to $200 \mathrm{~km} / \mathrm{h}$ with tags [27].

- Active tags were successfully read in all propagation mediums including Underground.

- RSSI dropped by $4 \mathrm{dBm}$ to $8 \mathrm{dBm}$ in different propagation mediums such as Ice and Water.

- Tag Read Count dropped by $7 \%$ to $50 \%$ in mediums other than Air.

- Results were much better than Passive RFID. This however comes at the cost of battery replacement and high cost of the Active tags. In future, Piezoelectric technology and bulk production can help with the challenges, respectively.

- Summary of Active RFID in various propagation mediums can be seen in table 35 . 
Table 35: Shows summary of Active RFID Tags results in various propagation mediums.

\begin{tabular}{|l|l|l|l|l|}
\hline Propagation & Average & Variance & Tag Read & Comment \\
\hline Air & RSSI & Against & Count & \\
\hline (dBm) & -75 & Air (dBm) & & \\
\hline Water (1 inch) & -79 & -4 & 28 & \\
\hline Ice (2 inch) & -82 & -7 & 21 & A couple partial unreads. \\
\hline Salted Water (1 & -83 & -8 & 20 & \\
\hline inch, 4 grams of & & -6 & 12 & unreads 3 unread tag and partial \\
\hline salt) & & & & \\
\hline Underground (4 & & & & \\
\hline inch plus 0.5 inch & & & & \\
\hline
\end{tabular}




\section{Conclusion and Future Work}

In this thesis, experiments were conducted to find the feasibility of using Active and Passive RadioFrequency Identity (RFID) Tags for Autonomous Vehicle (AV) navigation and communication to augment existing AV sensors and enhance public safety. This is because the tags can help with current AV limitations such as camera occlusions, traffic-sign tempering problems, spotty GPS signals interrupting localization necessary for AV navigation, and near real-time communication for example construction zones and weather warning.

RFID readings were successfully obtained over various speeds up to $90 \mathrm{~km} / \mathrm{h}$ and in various propagation mediums such as ice, water, Snow, and underground. Speeds higher than $90 \mathrm{~km} / \mathrm{h}$ could not be tried due to track constraints. One study, however, was able to read the Passive tags up to 200 km/h. RSSI, Tag Read Count, and Time Per Tag read were found over various speed ranges and propagation mediums. It is typically the highest in Air than in other mediums.

Active RFID is better than Passive RFID but costly and needs a battery replacement. Mass industry adoption and Piezoelectric technology are likely to help with it, respectively. In Passive RFID, a greater number of antenna and readers increase the coverage area and enhance the results. Current technology is feasible in controlled indoor and outdoor environments but as more equipment is developed with keeping AV use-case in mind, it can show promise against the current above-mentioned AV limitations.

In the future, this research can be enhanced by the following:

- For Passive RFID tags, by conducting experiments with more than one reader with two or more Passive antennas.

- For Active RFID tags, by finding tags whose beaming interval is less than 100 milliseconds.

- By conducting experiments with speeds higher than $90 \mathrm{~km} / \mathrm{h}$.

- In this research, the data was collected by moving the vehicle over the tags. This can be furthered 
by placing the tags on the infrastructure such as intersection lights, traffic signs, and by placing the tags away from the vehicle path and finding the results if the vehicle does not go through directly over the tags.

- Evaluating the number of tags needed and the distance between them for communication once the most suitable tags are determined between Active and Passive tags.

- Find the position accuracy results for GPS localization. 


\section{References}

[1] M. E. McGrath, Autonomous Vehicles Opportunities, Strategies, and Disruptions. 2nd Ed. Independent, 2020, ISBN: 9781706683599 .

[2] T. Jones, Autonomous Vehicles: The Emerging Landscape. Future Agenda Limited. 1st Ed. Independent, 2019.

[3] (). "Infrastructure enhancements for cav navigation," [Online]. Available: https ://apps . ict . illinois.edu/projects/getfile.asp?id=9282. Accessed: Sep. 05, 2021.

[4] D. M. Dobkin, The RF in RFID: Passive UHF RFID in Practice. USA: Newnes, 2007, ISBn: 0750682094 .

[5] (). "What is an inertial measurement unit?" [Online]. Available: https ://www . vectornav . com/ resources/inertial-navigation-articles/what-is-an-inertial-measurement-unit-imu. (accessed: September 19, 2021).

[6] (). "Proprioceptive inertial measurement units (imu) for self-driving cars," [Online]. Available: https : //www . aitrends . com/ai-insider/proprioceptive-inertial-measurement-unitsimu-self-driving-cars/. Accessed: Aug. 25, 2021.

[7] S. Sukkarieh, E. Nebot, and H. Durrant-Whyte, "A high integrity imu/gps navigation loop for autonomous land vehicle applications," IEEE Transactions on Robotics and Automation, vol. 15, no. 3 , pp. $572-578,1999$. DOI: $10.1109 / 70.768189$.

[8] A. Motroni, A. Buffi, and P. Nepa, "A survey on indoor vehicle localization through rfid technology," IEEE Access, vol. 9, pp. 17921-17 942, 2021. DOI: 10.1109/ACCESS. 2021.3052316.

[9] P. Nikitin and K. Rao, "Performance limitations of passive uhf rfid systems," in 2006 IEEE Antennas and Propagation Society International Symposium, 2006, pp. 1011-1014. DOI: 10.1109/ APS . 2006.1710704.

[10] S. Smiley, The insider's guide to working with RFID Book (1ST. ed.) Birmingham, AL, USA: independent, 2020. 
[11] (). "Battery assisted passive (bap) tags - do you know your reader receiver sensitivity?" [Online]. Available: https : //voyantic.com/blog/posts/battery-assisted-passive-bap-tags-doyou-know-your-reader-receiver-sensitivity. Accessed: Aug. 25, 2021.

[12] (). "Understanding gen2 readers' receive sensitivity requirements," [Online]. Available: https : //webcache . googleusercontent . com/search?q=cache : EROHMeB1Fmw : https : //www . fuwit . com/Download/prDownload. aspx\%5C\%3Foid\%5C\%3D176+\&cd=1\&hl=en\&ct=clnk\&gl=ca. Accessed: Sep. 05, 2021.

[13] S. R. Walvekar and R. J. Burkholder, "Feko" ${ }^{T M}$ modeling study of passive uhf rfid tags embedded in pavement," in 2018 International Applied Computational Electromagnetics Society Symposium (ACES), 2018, pp. 1-2. DOI: 10.23919/ROPACES.2018.8364180.

[14] M. Khosyi'in, S. A. D. Prasetyowati, Z. Nawawi, and B. Y. Suprapto, "Review and design of gps-rfid localization for autonomous vehicle navigation," ser. EEET 2019, Penang, Malaysia: Association for Computing Machinery, 2019, pp. 42-46, ISBN: 9781450372145. DOI: 10.1145/3362752. 3362766. [Online]. Available: https://doi.org/10.1145/3362752.3362766.

[15] D. et. al, "Concrete embedded rfid for way-point positioning.," International Conference on Indoor Positioning and Indoor Navigation, pp. 1-10, 2010.

[16] O. Franek, P. Kyritsi, and G. F. Pedersen, "Rfid on the road-some considerations about passive tag antennas," in Proceedings of the 5th European Conference on Antennas and Propagation (EUCAP), 2011, pp. 1203-1207.

[17] D. II, J. Mwakalonge, and J. Perkins, "An investigation of factors influencing performance of radio frequency identification (rfid): Applications in transportation," Journal of Transport Literature, vol. 10, pp. 25-29, Dec. 2016. DOI: 10.1590/2238-1031.jtl.v10n4a5.

[18] Z. Wang and R. Edwards, "An enhanced road vehicle positioning method using roadside furniture with radio frequency identity tags and the epc gen2 standard," in 2020 14th European Conference on Antennas and Propagation (EuCAP), 2020, pp. 1-4. DOI: 10.23919/EuCAP48036. 2020. 9136078. 
[19] H. Chu, G. Wu, J. Chen, and Y. Zhao, "Study and simulation of semi-active rfid tags using piezoelectric power supply for mobile process temperature sensing," in 2011 IEEE International Conference on Cyber Technology in Automation, Control, and Intelligent Systems, 2011, pp. 38-42. DOI: $10.1109 /$ CYBER. 2011.6011760.

[20] M. Takeuchi, S. Matsuzawa, K. Tairaku, and C. Takatsu, "P6f-2 piezoelectric generator as power supply for rfid-tags and applications," in 2007 IEEE Ultrasonics Symposium Proceedings, 2007, pp. 2558-2561. DOI: 10.1109/ULTSYM. 2007.644.

[21] M. I. Ahson Syed., RFID Handbook: Applications, Technology, Security, and Privacy. USA: Boca Raton : CRC Press, 2008, ISBN: 1-315-21932-8.

[22] (). "Welcome to area x.o drive the future," [Online]. Available: https://areaxo.com/. (accessed: September 19, 2021).

[23] (). "Thingmagic m6e embedded rfid reader module developer kit," [Online]. Available: https : //wWw . atlasrfidstore . com/thingmagic-m6e-embedded-rfid-reader-module-developerkit/. Accessed: Aug. 5, 2021.

[24] (). "Thingmagic m6e embedded rfid reader module," [Online]. Available: https ://www . atlasrfidstore. com/thingmagic-m6e-embedded-rfid-reader-module/. Accessed: Aug. 5, 2021.

[25] (). "Mti mt-242025/trh/a (rhcp) outdoor rfid antenna (865-956 mhz)," [Online]. Available: https: //www . atlasrfidstore.com/mti-mt-242025-trh-a-rhcp-outdoor-rfid-antenna-865-956mhz/. Accessed: Aug. 5, 2021.

[26] (). "Vulcan rfid ${ }^{\top M}$ power mapper," [Online]. Available: https : / / www . atlasrfidstore . com / vulcan-rfid-power-mapper/. Accessed: Aug. 5, 2021.

[27] (). "How fast can a uhf rfid reader detect tags?" [Online]. Available: https://www.rs-online . com/designspark/how-fast-can-a-uhf-rfid-reader-detect-tags. (accessed: September 19, 2021). 
[28] (). "Confidex viking ${ }^{\top M}$ bluetooth beacon development kit with android device," [Online]. Available: https://www . atlasrfidstore.com/confidex-viking-bluetooth-beacon-development-kitwith-android-device/. Accessed: Aug. 5, 2021. 